\title{
Physiopathologie des maladies humaines
}

\author{
Giovanni BRIGANTI*
}

Département de Physiopathologie, École Supérieure de la Santé

17 février 2019

\section{Table des matières}

1 Physiopathologie cardiovasculaire 3

1.1 Anatomie cardiovasculaire . . . . . . . . . . . . 3

1.2 Physiologie cardiovasculaire . . . . . . . . . . . 4

1.3 Exploration fonctionnelle de l'activité cardiaque . . . . . . . 6

1.4 Histologie cardiovasculaire . . . . . . . . . . . 7

1.5 Électrophysiologie de la contraction myocardique . . . . . . . 12

1.6 Physiologie de la pression artérielle . . . . . . . . . . . 16

2 Physiopathologie respiratoire $\quad 22$

2.1 Anatomie et histologie respiratoire . . . . . . . . . 22

2.2 Physiologie respiratoire $\ldots \ldots \ldots \ldots \ldots$

3 Physiopathologie digestive $\quad 38$

3.1 Introduction et histologie digestive générale . . . . . . . 38

3.2 Cavité orale, pharynx et oesophage . . . . . . . . . . 40

*giovanni.briganti@hotmail.com 
3.3 Estomac . . . . . . . . . . . . . . . . . . . . 42

3.4 Intestin grêle et côlon . . . . . . . . . . . . . . 46

3.5 Foie et vésicule biliaire . . . . . . . . . . . . . . 51

3.6 Pancréas . . . . . . . . . . . . . . . . 58

4 Physiopathologie urinaire $\quad 62$

4.1 Anatomie et physiologie urinaire . . . . . . . . . . . 62

4.2 Néphrosclérose . . . . . . . . . . . . . . . . . . . . 67

4.3 Insuffisance rénale aigue $\ldots \ldots \ldots \ldots$. . . . . . . 67

4.4 Insuffisance rénale chronique $\ldots \ldots \ldots \ldots$

5 Physiopathologie neurologique $\quad 69$

5.1 Neuroanatomie et neurophysiologie . . . . . . . . . . . . 69

5.2 Neuropathies . . . . . . . . . . . . . . . . . 80

5.3 Myasthénie . . . . . . . . . . . . . . . 85

5.4 Botulisme . . . . . . . . . . . . . . 87

5.5 Dystrophie musculaire de Duchenne . . . . . . . . . 88

5.6 Accidents vasculaires cérébraux . . . . . . . . . 88

5.7 Maladie de Parkinson . . . . . . . . . . . . . . 91

5.8 Maladie d'Alzheimer . . . . . . . . . . . . . . . . . 94

5.9 Epilepsie . . . . . . . . . . . . . . . . . 97

6 Physiopathologie endocrinienne 104

6.1 Définitions . . . . . . . . . . . . . . . . . . . . 104

6.2 Physiopathologie de l'axe hypothalamo-hypophysaire . . . . . 105

6.3 Physiopathologie thyroïdienne . . . . . . . . . . . 107

6.4 Physiopathologie surrénalienne . . . . . . . . . . . 108 


\section{Physiopathologie cardiovasculaire}

\subsection{Anatomie cardiovasculaire}

Le cœur est un organe cavitaire situé dans le thorax, spécifiquement dans la région du médiastin moyen.

Le cœur est divisé en 2 compartiments. Le cœur droit véhicule du sang désoxygéné (envoie le sang vers les poumons pour reoxygénation) et le cœur gauche véhicule du sang oxygéné (envoie le sang vers le reste du corps). Chaque compartiment est divisé en 2 chambres : une qui recueille le sang, l'atrium et une qui le chasse, le ventricule. L'atrium gauche est séparé par la valve mitrale ( 2 cuspides) du ventricule gauche. Le ventricule gauche est séparé par la valve aortique (3 cuspides) de l'aorte. L'atrium droit est séparé par la valve tricuspide (3 cuspides) du ventricule droit. Le ventricule droit est séparé par la valve pulmonaire (3 cuspides) du tronc pulmonaire. Le sang désoxygéné est amené à l'atrium droit par la veine cave supérieure, la veine cave inférieure et le sinus coronaire.

La veine cave supérieure (qui ramène le sang désoxygéné des régions sus diaphragmatiques) draine le sang de la tête et du cou (par les veines jugulaires interne - externe - antérieure ainsi que les veines vertébrales) ainsi que les membres supérieurs (par les veines subclavières). Les veines jugulaires interne et subclavière se réunissent pour former les veines brachiocéphaliques droite et gauche. Les deux veines brachiocéphaliques se réunissent pour former la veine cave supérieure.

La veine cave supérieure reçoit également le système veineux azygos qui draine le sang veineux de la paroi du tronc.

La veine cave inférieure (ramène le sang vicié des régions sous diaphragmatiques) : elle nait de la réunion des veines iliaques communes droite et 


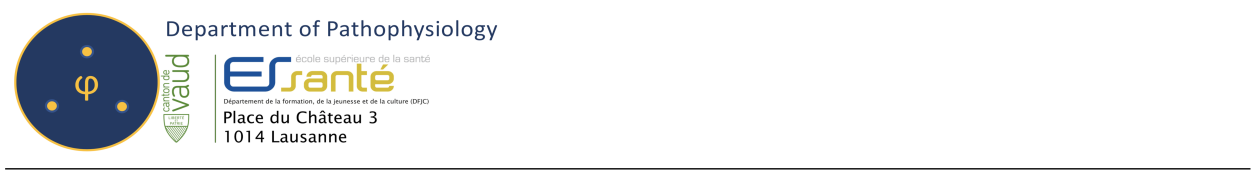

gauche qui naissent de la réunion des veines iliaques externe (pour le membre inférieur) et interne (pour le petit bassin). La veine iliaque externe est un prolongement de la veine fémorale à distance du ligament inguinal. La veine cave inférieure reçoit de nombreux affluents : veines lombaires, veines rénales, veines phréniques inférieures, veine gonadique et surrénale droite (la veine gonadique gauche se jette dans la veine rénale gauche), veines hépatiques (pour le foie qui reçoit la veine porte).

Le sinus coronaire ramène sang désoxygéné du cœur.

Le sang vicié est donc amené à l'atrium droit.

La vascularisation du cœur se fait par l'artère coronaire droite, l'artère coronaire gauche et les veines coronaires. L'innervation cardiaque se fait par le nœud sinu-atrial, situé dans l'atrium droit postéro-supérieurement : celui-ci est connecté au nœud atrioventriculaire antéro-inférieurement dans le ventricule droit. Le nœud atrioventriculaire se prolonge par le faisceau de His, constitué d'une branche droite et deux branches gauches, une antérieure et une postérieure. De plus, le cœur bénéficie d'une innervation orthosympathique (branches T1 à T5), et d'une innervation parasympathique (nerf X vague).

\subsection{Physiologie cardiovasculaire}

Le cycle du cœur droit est organisé en plusieurs phases.

Premièrement, l'atrium droit se remplit : il s'agit de la diastole atriale, correspondant à la systole ventriculaire.

Deuxièmement, la valve tricuspide s'ouvre, laissant passer d'abord passivement le sang de l'atrium droit au ventricule droit, puis l'atrium droit se contracte pour pousser ce qui reste : il s'agit de la systole atriale, correspondant à la diastole ventriculaire. 


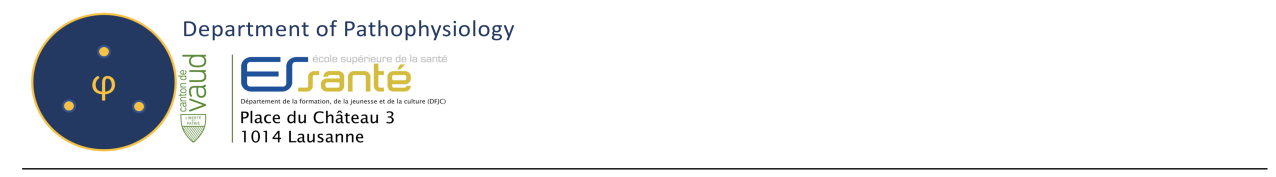

Troisièmement, le sang désoxygéné passe de l'atrium droit au ventricule droit à travers la valve tricuspide qui s'ouvre. Le ventricule droit se remplit : il s'agit de la diastole ventriculaire.

Quatrièmement, une fois le ventricule droit rempli, la valve tricuspide se referme.

Cinquièmement, pendant la systole ventriculaire, le ventricule commence à se contracter pour augmenter sa pression sans que la valve pulmonaire s'ouvre (terme physiologique : contraction iso-volumétrique), quand la pression ventriculaire dépasse la pression dans le tronc pulmonaire, la valve pulmonaire s'ouvre laissant passer le sang désoxygéné du ventricule droit au tronc pulmonaire et donc aux poumons.

Sixièmement, la valve pulmonaire se ferme.

Septièmement, e tronc pulmonaire se divise en une artère pulmonaire gauche et une artère pulmonaire droite qui vont vers les poumons. Au niveau des alvéoles, le sang se décharge de $\mathrm{CO} 2$ et capte $\mathrm{O} 2$. Le sang est ainsi oxygéné. Le sang oxygéné est amené à l'atrium gauche par 4 veines pulmonaires (deux droites et deux gauches).

Le cycle du cœur gauche se divise aussi en plusieurs phases : Premièrement, l'atrium gauche se remplit : il s'agit de la diastole atriale, correspondant à la systole ventriculaire.

Deuxièmement, la valve mitrale s'ouvre, laissant passer d'abord passivement le sang de l'atrium gauche au ventricule gauche (remplissage passif), puis l'atrium gauche se contracte pour pousser ce qui reste : systole atriale (remplissage actif), correspondant à la diastole ventriculaire.

Troisièmement, le sang oxygéné passe de l'atrium gauche au ventricule gauche à travers la valve mitrale qui s'ouvre. Le ventricule gauche se remplit : il s'agit de la diastole ventriculaire. 


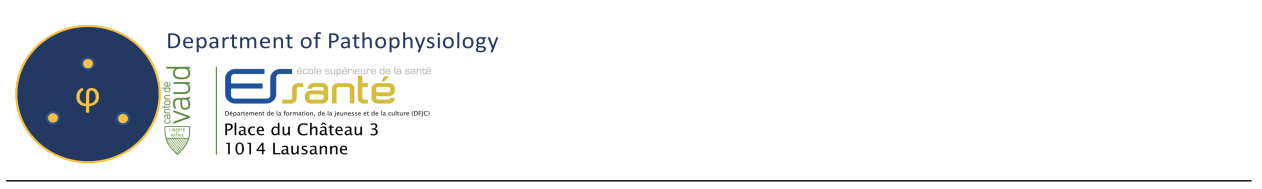

Quatrièmement, une fois le ventricule gauche rempli, la valve mitrale se referme.

Cinquièmement et pendant la systole ventriculaire, le ventricule commence à se contracter pour augmenter sa pression sans que la valve aortique s'ouvre (contraction iso-volumétrique), quand la pression ventriculaire dépasse la pression dans l'aorte, la valve aortique s'ouvre laissant passer le sang oxygéné du ventricule gauche à l'aorte et donc à tous les organes du corps.

Sixièmement, la valve aortique se ferme.

Maladie valvulaire Les maladies valvulaires comprennent la sténose aortique, l'insuffisance aortique, l'insuffisance mitrale et la sténose mitrale. Lors d'une sténose, la valve est rétrécie et empêche le passage normal du sang d'une cavité à l'autre. Ainsi, lors de la sténose aortique, le sang sort difficilement du ventricule gauche.

Lors d'une insuffisance, il y a une régurgitation du sang vers l'endroit d'origine. Ainsi, lors de l'insuffisance mitrale, le sang revient vers l'atrium lors de la systole atriale, empêchant le ventricule de bien se remplir.

Les maladies valvulaires sont généralement traitée avec un remplacement par prothèse.

\subsection{Exploration fonctionnelle de l'activité cardiaque}

L'électrocardiogramme est l'outil de choix pour explorer l'activité électrique du cœur.

Un électrocardiogramme normal est composé de différents éléments.

L'onde $\mathrm{P}$ correspond à la dépolarisation atriale précédant la systole atriale (et donc diastole ventriculaire). L'intervalle PR représente l'intervalle entre 


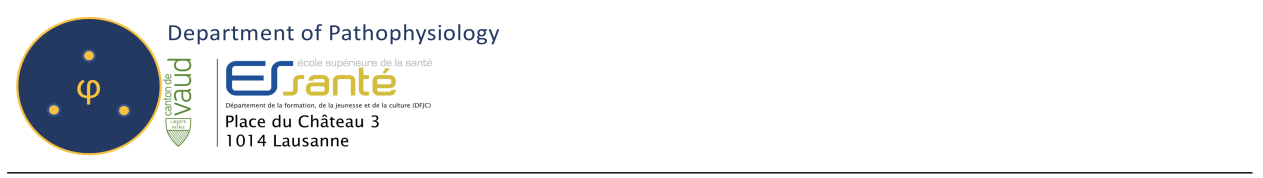

l'onde $\mathrm{P}$ et le début du QRS. Le complexe QRS correspond à la dépolarisation ventriculaire (onde $\mathrm{Q}$ : dépolarisation du septum; onde $\mathrm{R}$ : dépolarisation ventriculaire; onde $\mathrm{S}$ déflection après l'onde $\mathrm{R}$; durée normale ¡100 msec pour tout le complexe) précédant la systole ventriculaire (et la diastole atriale).

L'intervalle QT représente le temps entre le début du QRS et la fin de l'onde T. Le segment ST représente la phase plateau du potentiel d'action. L'onde $\mathrm{T}$ représente la repolarisation ventriculaire. Le point $\mathrm{J}$ à la fin de l'onde $\mathrm{S}$ est le point isoélectrique (doit être au niveau de base).

\subsection{Histologie cardiovasculaire}

L'unité de base du cœur est le cardiomyocyte. Il s'agit d'une cellule musculaire striée cardiaque séparée par ses voisines de jonctions intracellulaires pour assurer une contraction simultanée. Les cellules de Purkinje sont des cardiomyocytes différenciés qui peuvent transmettre l'information nerveuse (sont situées au niveau du faisceau de His).

Maladie cardiaque ischémique Les maladies cardiovasculaires présentent est une des premières causes de mortalité (NB mortalité $=$ nombre de décès dans une population dans un intervalle de temps donné; morbidité $=$ nombre de personnes malades dans une population dans un intervalle de temps donné) dans les pays développés.

La maladie cardiaque ischémique cause la nécrose (mort cellulaire) des cardiomyocytes. Ceci conduit à une insuffisance cardiaque.

La base physiopathologique de l'ischémie cardiaque est l'occlusion coronaire, causée par des plaques athéromateuses, formée de matériel graisseux. Le thrombus se forme suite à une réaction combinée des macrophages et des 


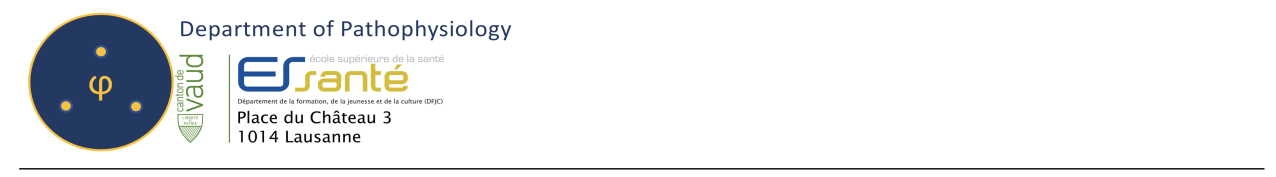

cascades de coagulation sur un dépôt de graisse dans les couches des artères. Les principaux facteurs de risque de la maladie cardiaque ischémique sont : le niveau de cholestérol, le tabac, le manque d'exercice physique, l'obésité, l'hypertension, le diabète.

Épidémiologie cardiovasculaire La maladie cardiaque ischémique est la première cause de décès dans le monde.

Le tabagisme est un véritable problème de santé publique et ne diminue pas; les femmes fument autant que les hommes.

La consommation de fruits et légumes progresse, mais la consommation des graisses est stable. L'exercice physique est trop peu performé par les individus, et l'obésité est trop prépondérante. La prévalence du diabète augmente. Toutes ces réalités ont comme conséquence immédiate l'augmentation des coûts pour les soins de santé.

Un facteur de risque est un élément clinique ou biologique dont la présence ou l'augmentation majorent statistiquement la morbidité-mortalité. La prévention se définit comme l'abaissement (dans la mesure du possible) des facteurs de risque pour diminuer la survenue de l'événement.

Le tabac est le principal facteur de risque cardiovasculaire : l'arrêt du tabagisme diminue la mortalité d'environ 50\%. Le tabac intervient aussi pour la plupart des cancers, puisqu'il contient différents types de produits cancérigènes et irritants. La dyslipidémie est impliquée dans la formation des plaques d'athérome : les taux sanguins impliqués sont ceux du cholestérol (LDL) et triglycérides.

L'obésité, le manque d'exercice physique, la sédentarité sont aussi des facteurs de risque cardiovasculaire. 


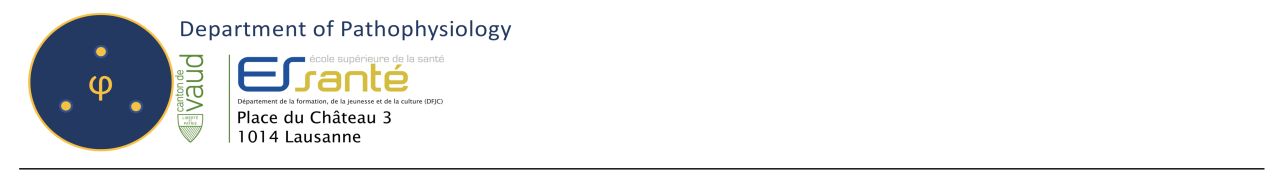

Angina pectoris Il s'agit de la manifestation de l'ischémie cardiaque. Le patient se plaint le plus souvent de douleurs thoraciques rétro-sternales à l'effort (mais aussi dyspnée, nausée), pouvant irradier.

L'angine peut être stable (présente depuis longtemps) ou instable (apparition récente). L'angine instable se traduit le plus souvent par un infarctus myocardique. Finalement, l'angine de Printzmetal correspond à un spasme coronaire.

Le traitement de l'angor passe par la réduction des facteurs de risque, et un traitement médical basé sur des nitrates (vasodilatation des coronaires), aspirine (contre la formation des caillots bouchant les coronaires) et bétabloquants. L'angine instable nécessite un traitement en urgence.

Si le traitement médical n'induit pas la réduction des symptômes, alors on traite le patient par angioplastie coronaire. Le principe : rentrer par voie endovasculaire (radiale ou fémorale) dans les coronaires en insérant un ballonnet pour les dilater, puis un stent pour les élargir. Ceci a pour but d'augmenter le flux sanguin du myocarde et restaurer la circulation.

Syndrome coronarien aigu (SCA) Le syndrome coronarien aigu est l'état d'ischémie aigue du myocarde suite à une obstruction des coronaires. Les facteurs de risque sont identiques à ceux de l'angor stable.

Les patients atteints de SCA se présentent avec une douleur thoracique rétrosternale aigue depuis plus que 20 minutes, dyspnée, nausée, pâleur, palpitations, sueur. Le diagnostic avec un dosage des troponines et un ECG. Il existe selon les résultats de l'ECG deux types de SCA : avec ou sans élévation du segment ST. Les troponines augmentent généralement après $3 \mathrm{~h}$ du début de la souffrance myocardique (d'où l'intérêt de les mesurer 3 heures après à nouveau si clinique pertinente et résultats négatifs une première fois), et 


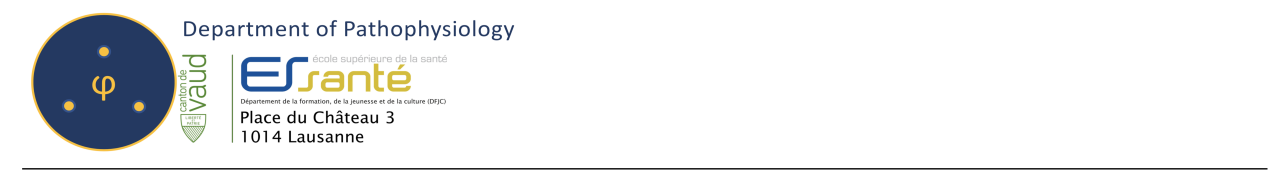

leur augmentation est due à la nécrose des cardiomyocytes.

Le traitement du SCA avec élévation du ST se fait en urgence soit par angioplastie (si disponible endéans les $2 \mathrm{~h}$ ) soit par thrombolyse (puis récupération par angioplastie si cette dernière n'est pas disponible en $2 \mathrm{~h}$ ).

Une alternative chirurgicale existe pour le traitement de l'infarctus myocardique : le bypass coronaire : un lambeau de l'artère mammaire interne est le plus souvent utilisé pour constituer un pont entre l'aorte et l'artère coronaire en aval de l'occlusion.

Le traitement du SCA sans élévation du ST se fait par bétabloquants, antithrombotiques (héparines) et réévaluation continue.

L'infarctus myocardique peut se compliquer de péricardite, arythmies, maladie thromboembolique.

Péricardite La péricardite est l'inflammation des deux feuillets du péricarde. Elles peuvent être accompagnées par un épanchement liquidien (contenant le plus souvent des polymorphonucléaires, lymphocytes ou fibrine).

L'étiologie de la péricardite peut être infectieuse : les péricardites virales sont souvent bénignes, les bactériennes sont généralement plus graves et causant des tamponnades (tamponnade étant une insuffisance circulatoire due à une compression des cavités cardiaques); la tuberculose est une maladie systémique pouvant causer des péricardites (surtout chez les patients séropositifs) ; finalement, les parasites et les champignons peuvent également causer cette pathologie. Une forme de péricardite chronique et obstructive est aussi décrite.

La radiographie de thorax et l'échographie sont les examens standards pour la détection de cette pathologie ainsi que la biologie sanguine montrant une élévation des enzymes cardiaques. 


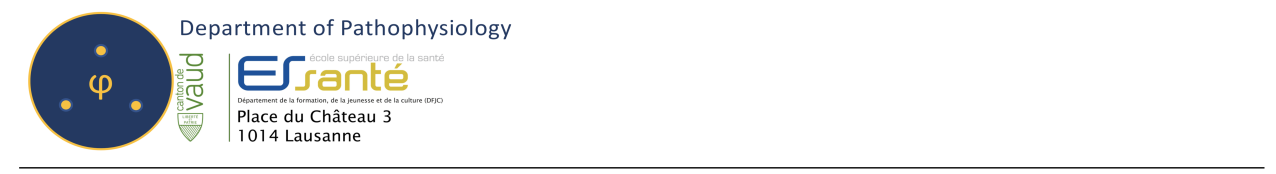

Le traitement est basé sur les antiinflammatoires non stéroïdiens (AINS) ainsi que le traitement étiologique.

Endocardite L'endocardite est l'infection de l'endocarde et d'au moins une valve cardiaque causée par un micro-organisme.

Les facteurs favorisants de cette pathologie sont la toxicomanie intraveineuse, les prothèses valvulaires. L'étiologie bactérienne inclut essentiellement Streptococcus Viridans et Staphylococcus Aureus. Le patient se présente le plus souvent avec une toux, dyspnée, souffle, un purpura pétéchial (faux panaris d'Osler), une protéinurie, hématurie ou encore embole septique.

Les portes d'entrées principales incluent l'oropharynx (dents essentiellement), tube digestif, et la peau.

Le diagnostic se pose par hémoculture, échocardiographie, bilan inflammatoire et immunitaire.

Les critères de Duke pour le diagnostic de l'endocardite sont définis comme suit : deux critères majeurs représentés par deux hémocultures de suite positives, une démonstration d'atteinte cardiaque par échocardiographie; des critères mineurs incluent une prédisposition, une fièvre, un phénomène immunologique, ou encore un argument microbiologique. La présence des deux critères majeurs suffit au diagnostic; ou encore un critère majeur et trois mineurs; ou encore cinq critères mineurs.

La prise en charge se doit d'être immédiate au vu du taux élevé de mortalité : une antibiothérapie intraveineuse de longue durée sera débutée (amoxicilline + gentamycine) et un débridement chirurgical avec reconstruction ou remplacement valvulaire si nécessaire.

Les complications de l'endocardites incluent une insuffisance cardiaque, une maladie thromboembolique, une fistulisation, un embole septique, une myo- 


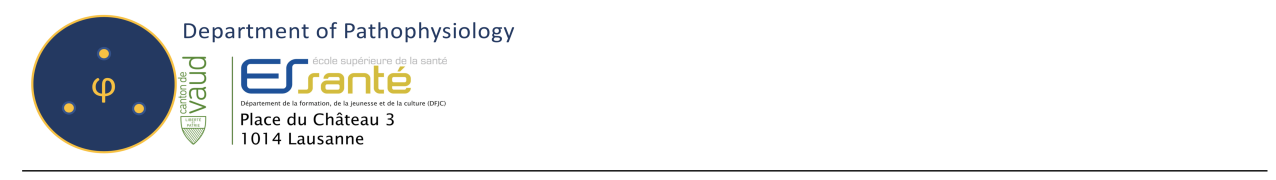

cardite, et des troubles de la conduction.

\section{5 Électrophysiologie de la contraction myocardique}

Pour générer une impulsion électrique, les cellules du nœud sinusal sont pourvues de canaux If.

Ces canaux laissent rentrer automatiquement des ions Sodium dans la cellule, qui se dépolarise à des intervalles réguliers. Une fois l'impulsion transmise d'abord à l'atrium même puis au nœud atrioventriculaire et au faisceau de His, elle atteint le cardiomyocyte.

Il existe cinq phases de conduction cardiaque dans le myocyte. La phase 0 correspond à l'arrivée du potentiel d'action nerveux : le Na+ rentre dans le myocyte; ceci cause une dépolarisation (le potentiel intramembranaire augmente), avec les canaux $\mathrm{Na}+$ voltage dépendant ouverts; cette rentrée est stimulée par les récepteurs béta-adrénergiques du système sympathique.

La phase 1 correspond à la sortie du K+ du myocyte : il s'agit d'une petite repolarisation, le potentiel descend et les canaux $\mathrm{Na}+$ sont inactivés.

La phase 2 correspond à l'entrée de Ca2+ par les canaux de type L (long) dans le myocyte à la suite de la propagation du potentiel. Quand le Ca2+ passe d'une concentration de $0.1 \mathrm{mM}$ à $1 \mathrm{mM}$, la contraction se déclenche via relargage important de $\mathrm{Ca} 2+$ contenu à l'intérieur du réticulum endoplasmique. Quand le Ca2+ est présent en suffisance, la Myosine Light Chain Kinase (MLCK) associe l'actine et la myosine du cytosquelette pour démarrer la contraction.

La phase 3 correspond à la sortie du Ca2+ (et la repolarisation, onde $\mathrm{T}$ ). La phase 4 correspond au retour au repos. Dans la cellule nodale, la phase 4 correspond aux courants dépolarisants de $\mathrm{Na}+$ et $\mathrm{Ca} 2+$ via les canaux If et $\mathrm{Ca} 2+$ de type transitoire $(\mathrm{T})$. La phase 0 nodale se présente comme 


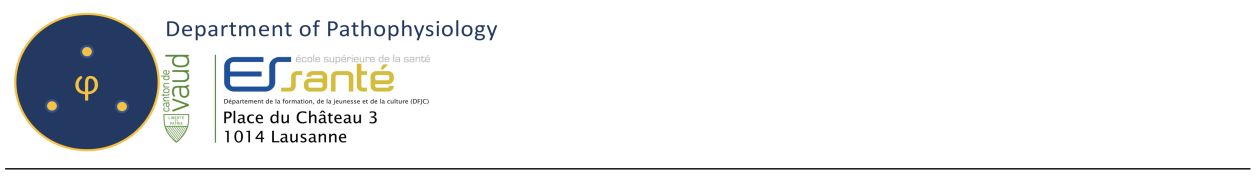

le pic de dépolarisation, et la phase 3 comme la phase de repolarisation. Le contrôle orthosympathique de l'excitabilité se fait via l'adrénaline et la noradrénaline.

Ces molécules se posent sur les récepteurs Béta 1 adrénergiques, ce qui provoque une ouverture des canaux $\mathrm{Ca} 2+$; ceci se traduit par un effet chronotrope positif (fréquence cardiaque augmente) et dromotrope positif (cœur se relâche plus vite).

Le contrôle parasympathique de l'excitabilité se fait via l'acétylcholine, se fixant sur les récepteurs muscariniques M2 provoquant la sortie du potassium via les canaux $\mathrm{K}+$, ce qui prolonge la repolarisation : il s'agit d'un effet chronotrope négatif.

La relaxation se fait via la diminution de la concentration plasmatique de $\mathrm{Ca} 2+$ : ceci est fait en réinjectant le $\mathrm{Ca} 2+$ à l'intérieur du réticulum endoplasmique via les pompes SERCA (consommant de l'ATP), via des pompes ATP intracellulaire - extracellulaire.

L'actine et la myosine se dissocient grâce à la Myosine Light Chain Phosphatase (MLCP) et la relaxation commence.

Troubles du rythme cardiaque Les troubles du rythme cardiaque sont fréquents dans la population générale. Il s'agit de pathologies diverses dans lesquelles la régularité ou la fréquence du rythme est compromise.

Bradycardie Lors d'une bradycardie, le rythme cardiaque est inférieur à 60 battements par minute (bpm).

La cause la plus fréquente de bradycardie est la bradycardie de l'athlète; le rythme cardiaque de l'athlète est diminué puisque celui-ci est habitué à l'effort physique intense.

Une cause pathologique de la bradycardie est l'hypothyroïdie. 


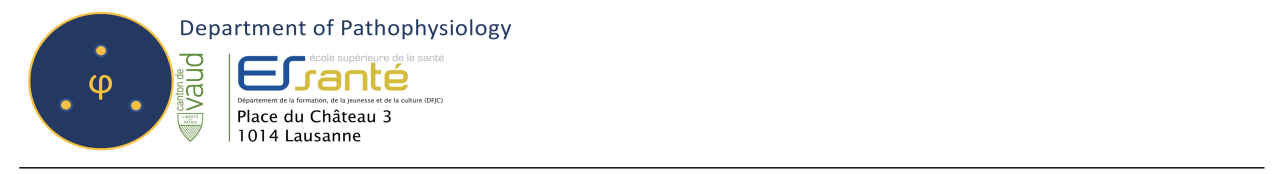

Tachycardie Lors d'une tachycardie, le rythme cardiaque est supérieur à $100 \mathrm{bpm}$.

La tachycardie la plus fréquente est la tachycardie à l'effort physique : le corps nécessite plus de sang plus vite, il produit de l'adrénaline qui stimule les récepteurs adrénergiques cardiaques $\$ 2$ ce qui cause un effet chronotrope positif.

Une cause pathologique fréquente de tachycardie est l'intoxication éthylique.

Bloc sino-atrial Lors d'un bloc sino-atrial, l'impulsion électrique du nœud sinusal est bloquée avant de rentrer dans le muscle atrial.

L'ECG montrera une absence d'onde P. En absence d'une impulsion atriale, le nœud atrioventriculaire prend le relai, donc le rythme cardiaque sera diminué.

Bloc atrioventriculaire Lors d'un bloc atrioventriculaire, la communication est interrompue entre le nœud atrioventriculaire et le faisceau de His.

Il existe trois types de bloc atrioventriculaire. Le bloc de premier degré est incomplet, il résulte d'un allongement de l'intervalle PR. Il existe deux blocs de deuxième degré. Le bloc de deuxième degré de type Mobitz I (aussi connu comme rythme de Wenckebach) consiste à un allongement progressif de l'intervalle PR jusqu'à disparition d'un battement.

Le bloc de deuxième degré de type Mobitz II présente une absence de battement régulièrement sans allongement de l'intervalle PR.

Enfin, le bloc de troisème degré montre une déconnexion complète entre le battement de l'atrium et celui du ventricule. 


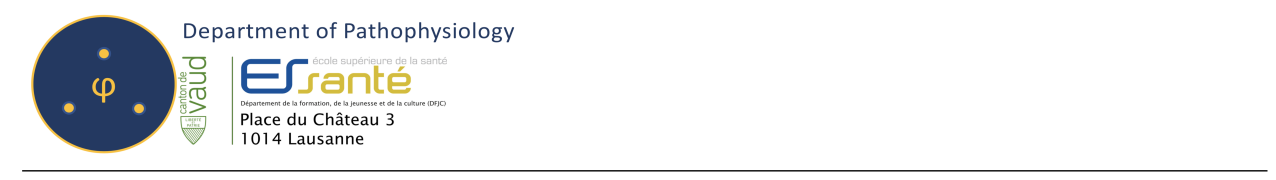

Battement prématuré Lors d'un battement prématuré, l'impulsion $\mathrm{P}$ arrive plus tôt que prévu.

Suite à ce battement prématuré, il existe un temps compensatoire plus long avant le prochain battement, tel que l'intervalle entre le premier battement normal, le battement prématuré et le battement post-compensation est égale à la somme de deux intervalles normaux.

Fibrillation atriale Lors de la fibrillation atriale, l'atrium se contracte de façon anarchique : de multiples impulsions ont lieu dans des localisations différentes. Il sera donc impossible d'observer une onde P.

La fibrillation atriale est traitée par cardioversion par choc cardiaque externe ou médicamenteux.

Une complication fréquente de la fibrillation atriale est la formation d'un thrombus (caillot). Suite au mouvement anarchique, le flux du sang est perturbé et un caillot est formé : ce caillot peut partir vers les carotides et causer un accident vasculaire cérébral par exemple.

Flutter atrial Lors d'un flutter atrial, un signal électrique parcourt un cercle toujours dans la même direction autour de l'atrium, ceci cause des fréquences atriales très élevées (250-350 bpm).

Parmi toutes ces impulsions, seulement une portion pourra générer un battement ventriculaire $(2: 1,2$ battements atriaux pour 1 battement ventriculaire, $3: 1$, etc.).

Fibrillation ventriculaire Quand l'impulsion normale cardiaque passe au ventricule, elle s'arrête après avoir excité le muscle puisque ce dernier sera en période réfractaire.

Par contre, si le circuit est assez long, si l'impulsion assez lente, ou si la 
période réfractaire diminue (médicaments), lorsque l'impulsion atteint le départ à nouveau, celui-ci ne sera plus en période réfractaire et une nouvelle impulsion sera possible; ce phénomène est connu comme phénomène de réentrée.

Lors d'une fibrillation ventriculaire, le ventricule est sujet à un phénomène de réentrée.

La fibrillation ventriculaire est l'arythmie la plus dangereuse : si non corrigée endéans les 3 minutes elle peut causer un arrêt cardiaque. Elle se traite par choc électrique externe.

\subsection{Physiologie de la pression artérielle}

Biophysique de la pression artérielle Soient deux verres : un rempli d'eau, un vide. S'ils rentrent en communication, l'eau va passer du verre rempli d'eau vers le verre vide.

L'eau exerce une pression : cette pression est plus élevée dans le verre rempli. La pression est le moteur du mouvement de l'eau dans ce cas : le verre continuera à se vider jusque quand les deux verres seront remplis à moitié; c'est l'égalisation des pressions.

Au même titre, lors de la systole atriale, l'atrium gauche est rempli de sang tandis que le ventricule est vide : naturellement, le sang va aller de l'atrium au ventricule. Le moteur n'est pas la pression à un endroit donné, mais la différence des pressions entre un endroit et l'autre.

Déterminants de la pression artérielle Le sang présent dans les vaisseaux exerce une force sur ceux-ci : il s'agit de la pression. La pression respecte la formule suivante, qui est une application aux fluides de la Loi d'Ohm $(\Delta$ V $=$ R.I $)$ : 


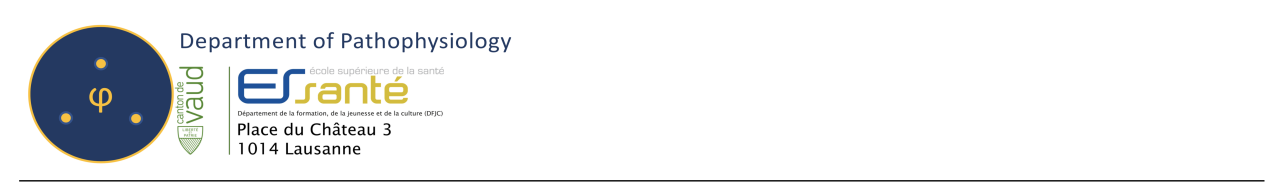

$$
\Delta P=R Q
$$

où $\Delta \mathrm{P}$ est la différence de pression, $\mathrm{R}$ est la résistance du vaisseau et Q est le débit. Cette formule indique que le sang se déplacera sous l'effet d'une différence de pression entre un endroit et l'autre de la circulation sanguine. Le sang se déplacera de l'endroit où la pression est la plus élevée vers l'endroit où la pression est la plus faible. Le sang étant un liquide visqueux, on peut exprimer la résistance grâce à la loi de Poiseuille (loi de l'écoulement visqueux) :

$$
Q=\Delta P \frac{\pi r^{4}}{8 \eta l}=\Delta P \frac{1}{R}
$$

où r est le rayon du vaisseau, $\eta$ la viscosité et 1 la longueur. La résistance d'un vaisseau est dépendante de son rayon : au plus le vaisseau est serré, au plus la résistance augmente.

Sténose carotidienne Lors de la sténose carotidienne, l'artère carotide propulsant le sang vers la tête est rétrécie par des plaques athéromateuses. La résistance du vaisseau augmente, et le sang passera plus difficilement.

\section{Mesure de la tension artérielle en pratique courante La pres-} sion dans les artères est appelée tension artérielle (TA) et est mesurée de manière courante en clinique avec un tensiomètre.

Elle est exprimée en millimètres de mercure $(\mathrm{mmHg}=$ pression hydrostatique exercée par une colonne de mercure d'un millimètre de haut et d'une surface d'un cm2. La tension artérielle se divise en systolique (pression dans les vaisseaux lorsque le ventricule est en systole) et diastolique (pression lorsque le ventricule est en diastole). 


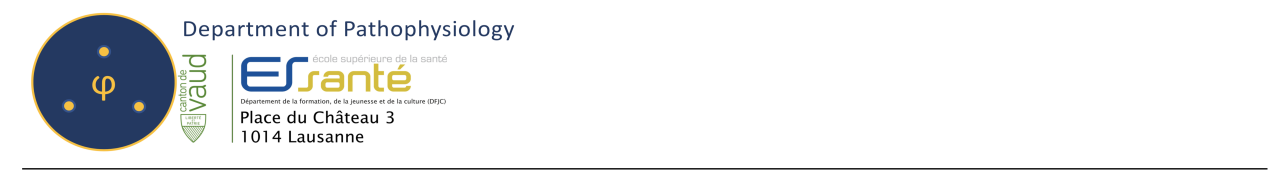

La valeur normale recommandée pour la tension artérielle est de 120/80 (120 $\mathrm{mmHg}$ de pression systolique et $80 \mathrm{mmHg}$ de diastolique). La pression artérielle varie au cours du cycle cardiaque : elle augmente lors de la contraction du ventricule, lors de la phase isovolumétrique. La pression artérielle est plus élevée que la pression veineuse.

Effet Windkessel Au moment de la systole ventriculaire, le ventricule gauche chasse du sang dans l'aorte.

Si aucun mécanisme ne rentrait en jeu, l'aorte se rétrécirait après avoir transmis le sang aux artères principales par manque de pression. Dans ce cas de figure, le sang circulerait pendant un petit instant avant de s'arrêter. Heureusement, l'effet Windkessel s'applique et ce grâce aux propriétés élastiques de la paroi artérielle.

La paroi recueille de l'énergie suite au passage du sang en se gonflant et la libère après son passage en se dégonflant pour entretenir une pression minimum et un flux continu.

Compliance vasculaire La compliance vasculaire est la quantité de sang que peut contenir une portion donnée du réseau circulatoire pour chaque augmentation d'un $\mathrm{mmHg}$ de pression (ce paramètre répond à la question : combien de sang peut contenir un vaisseau donné si la pression augmente ou diminue?).

Les veines sont plus compliantes que les artères : elles contiennent la majorité du sang dans le corps car elles peuvent plus facilement se dilater.

En pratique : quand un volume de sang s'ajoute dans un vaisseau, initialement, la pression augmente. Ensuite, la compliance entre en jeu et l'élasticité du vaisseau permet à la pression de diminuer. Ainsi, si un volume est retiré d'un vaisseau donné avec une baisse concomitante de pression, la compliance 


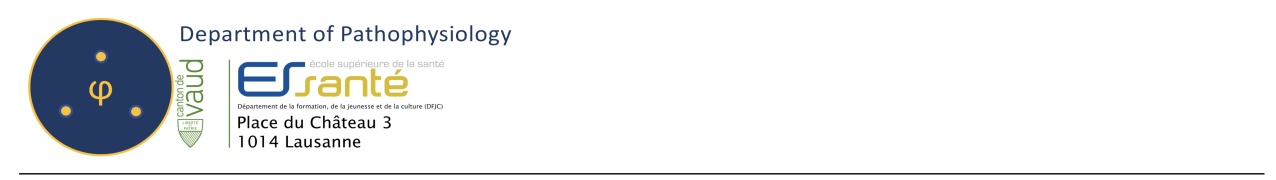

permettra au vaisseau d'augmenter la pression pour la maintenir stable.

Loi de Starling En moyenne, le débit cardiaque (volume de sang sortant par intervalle de temps) est de $5 \mathrm{~L} / \mathrm{min}$.

La loi de Starling sert à comprendre les interactions entre les différentes pressions dans les vaisseaux.

Le devoir premier du sang est de délivrer de l'oxygène aux tissus et de les décharger de dioxyde de carbone. Pour ce faire, le fluide contenu dans les capillaires doit être capable de sortir et d'y entrer. La pression nette de filtration (NFP) est le paramètre déterminant si le fluide sort du vaisseau ou y rentre.

La formule pour déterminer la NFP est la suivante :

$$
N F P=P_{c}-P_{i f}-\Pi_{p}-\Pi_{i f}
$$

$P_{c}$ est la pression hydrostatique du capillaire c'est-à-dire la force exercée par le sang sur les vaisseaux : cette force pousse le fluide à sortir du vaisseau. Pif est la pression interstitielle en dehors du capillaire, c'est-à-dire la force exercée par les fluides dans les tissus sur le capillaire : cette force tend à faire rentrer les fluides dans le vaisseau. $\Pi_{p}$ est la pression oncotique du plasma, c'est-à-dire la force utilisée par l'albumine (principale protéine du sang) pour retenir le sang dans le vaisseau. $\Pi_{i f}$ est la pression oncotique interstitielle, c'est-à-dire la force utilisée par les composantes organiques du tissu pour retenir du fluide.

Kwashiorkor La kwashiorkor est une maladie des pays en voie de développement. Il s'agit d'un manque aggravé de protéines.

Sans protéines, les taux d'albumine sanguins diminuent fortement, ce qui 


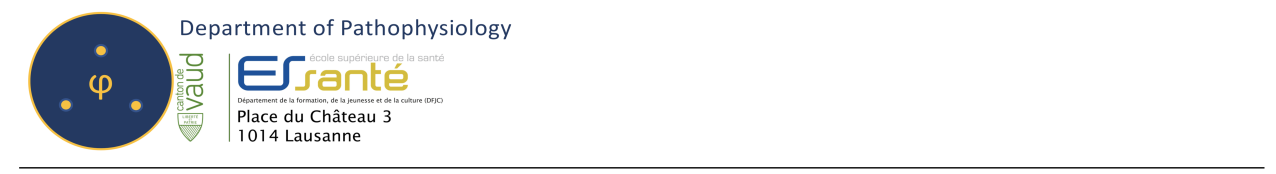

réduit la pression oncotique du plasma; le fluide sort du vaisseau ce qui cause un œdème, une accumulation de fluide dans le corps.

Précharge La précharge correspond à la pression dans le ventricule avant la systole ventriculaire.

Une augmentation de la précharge génère une augmentation du débit cardiaque, puisqu'elle optimise la longueur de fibres musculaires du myocarde en les faisant distendre. Une distension de la fibre myocardique à longueur optimale provoque une augmentation de la force de contraction et donc du débit.

La précharge est augmentée par l'augmentation de la quantité de sang dans le ventricule; ceci est obtenu par l'augmentation du retour veineux, c'està-dire la quantité de sang arrivant dans l'atrium droit. Après un certain palier, l'augmentation de précharge ne génère plus une augmentation du débit cardiaque et on obtient un plateau.

Postcharge La postcharge correspond à la pression dans l'aorte.

Il s'agit d'une pression constituant un obstacle à la sortie du sang à partir du cœur. En exerçant une postcharge, le cœur va fournir un travail plus important pour éjecter le même débit, en augmentant le volume télésystolique (à la fin de la systole) et le volume télédiastolique (à la fin de la diastole). Ce processus est défini comme l'adaptation hétérométrique en réponse à une augmentation de la postcharge.

Hypertension artérielle L'hypertension artérielle est une augmentation de la tension artérielle normale.

Elle se définit comme une pression artérielle systolique supérieure à 140 mmHg ou une pression artérielle diastolique supérieure à 90 mmHg. 


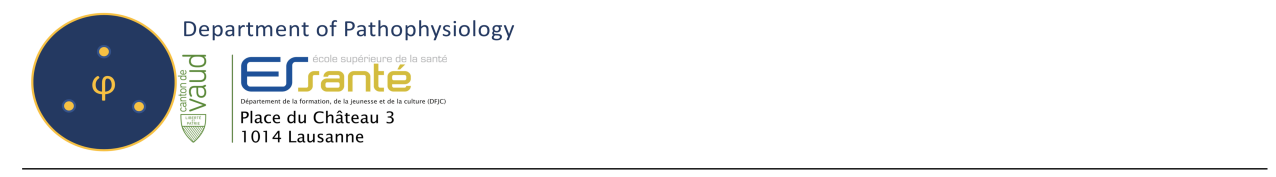

Il s'agit d'une maladie dont les facteurs principaux de risque sont le tabac, l'alcool et l'obésité. L'hypertension artérielle est un facteur de risque majeur de survenue de maladie ischémique tant cardiaque que cérébrale.

Au niveau cardiaque, l'hypertension artérielle augmente la postcharge à la sortie du ventricule gauche.

Suivant le schéma d'adaptation hétérométrique, les cardiomyocytes sont soumis à un travail plus important qui va in fine les hypertrophier (augmentation du volume de la cellule). L'hypertrophie myocardique une conséquence à long terme qui va affecter le débit cardiaque : en effet, la compliance du ventricule diminuera puisqu'il sera épaissi par du muscle, donc il pourra accueillir moins de sang. Le sang s'accumule en amont du ventricule, qui est surchargé ; l'atrium sera donc rempli de sang et la pression locale augmente. In fine, l'hypertension causera une insuffisance cardiaque, une insuffisance rénale, des rétinopathies hypertensives.

L'hypertension peut aussi provoquer des accidents vasculaires cérébraux, des anévrysmes et dissections aortiques.

Insuffisance cardiaque gauche L'insuffisance cardiaque gauche est une conséquence chronique de l'hypertension artérielle et de l'ischémie cardiaque.

A cause d'une baisse de fonction du ventricule gauche, du sang s'accumule en amont (ventricule gauche et atrium gauche), la pression augmente dans les cavités du cœur ainsi que les structures vasculaires en amont, par exemple, les veines pulmonaires.

La pression hydrostatique plasmatique devient tellement élevée que du liquide sort des vaisseaux pulmonaires pour se déposer dans les tissus du poumon; il s'agit d'un œedème pulmonaire. Parallèlement, le ventricule gauche 


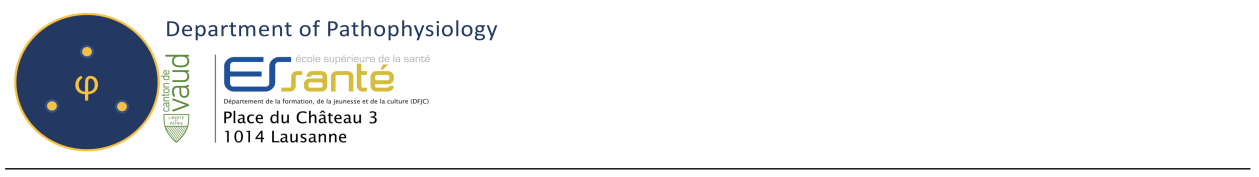

ne parvient pas à chasser du sang dans l'aorte et les organes sont peu perfusés; pour maintenir une pression stable, les vaisseaux périphériques se rétrécissent.

Suite à la baisse de pression systémique, le débit sanguin rénal diminue (puisque moins de sang arrive aux artères rénales) et par des mécanismes de compensation, notamment le système rénine-angiotensine-aldostérone, l'eau et le sel sont retenus par le rein, ce qui augmente d'avantage le volume sanguin circulant, aggravant le cercle vicieux.

C'est pour ces raisons qu'une insuffisance cardiaque est difficile à traiter, et la première étape consiste à décongestionner le cœur gauche en diminuant le volume du sang circulant : ceci est possible via une restriction hydrique et des diurétiques. Par la suite, des agents inotropes comme la dobutamine peuvent être considérés pour augmenter le débit cardiaque.

\section{Physiopathologie respiratoire}

\subsection{Anatomie et histologie respiratoire}

Le système respiratoire est un système formé de plusieurs composantes dont la fonction est la respiration. Deux voies aériennes sont retrouvées, une supérieure et une inférieure.

Le nez constitue l'extrémité supérieur des voies aériennes supérieure. Il est situé dans le crâne et est composé d'une partie osseuse, les os nasaux, et d'une partie cartilagineuse. Les os nasaux entourent la cavité piriforme ou fosse nasale, qui est séparée en deux parties par le septum nasal.

Le septum nasal est formé inférieurement par le vomer, et supérieurement par la lame perpendiculaire de l'os ethmoïde. De part et d'autre du septum on retrouve 3 cornets nasaux bilatéralement; plus spécifiquement, chaque 


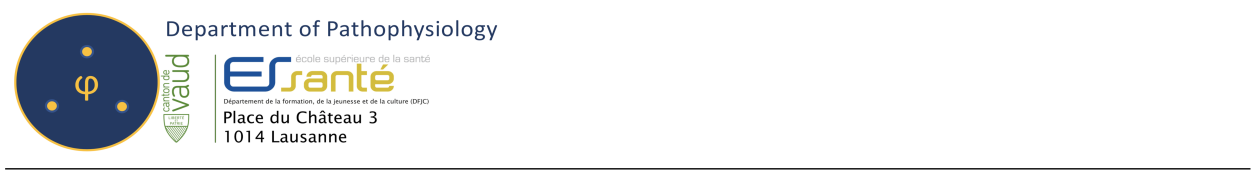

côté dispose d'un cornet nasal inférieur, d'un moyen et d'un supérieur.

Des méats (orifices de communication) sont présents qui permettent aux sinus (cavités aériennes pouvant se remplir de mucus) de se déverser dans la fosse nasale. Le méat inférieur est situé inférieurement au cornet inférieur ; le méat moyen est situé entre le cornet inférieur et moyen; le méat supérieur est situé entre le cornet moyen et supérieur. L'épithélium nasal est composé de cellules ciliées, avec quelque composante nerveuse des terminaisons du nerfs crânien I olfactif (pour l'odorat); les stimuli olfactifs remontent directement vers le cerveau au départ du nez.

Le pharynx est un tube de $13 \mathrm{~cm}$ débutant postérieurement au nez et se prolongeant dans l'œsophage. La fosse nasale est située antérieurement au nasopharynx, portion supérieure du pharynx.

L'oropharynx est situé postérieurement à la bouche et constitue la portion moyenne du pharynx. Il est séparé du nasopharynx par les choanes, deux orifices de passage de l'air postérieurs à la fosse nasale.

L'hypopharynx ou laryngopharynx est situé postérieurement au larynx et constitue la portion inférieure du pharynx. Le larynx est un passage composé de plusieurs parties cartilagineuses; il contient les cordes vocales qui génèrent les différents sons de la voix. Le cartilage thyroïde est le cartilage constituant la pomme d'Adam et compose la paroi antérieure du larynx. Il est supérieur au cartilage cricoïde et inférieur à l'épiglotte, qui ferme le larynx lorsque le bolus de nourriture passe vers l'œesophage pendant la déglutition pour éviter l'inhalation de corps étrangers.

Les cartilages aryténoïdes tendent les cordes vocales et sont situés de part et d'autre des sommets postérieurs du cartilage cricoïde. Le larynx est l'extrémité inférieure des voies aériennes supérieures.

Le larynx se prolonge inférieurement par la trachée, qui fait partie avec le 


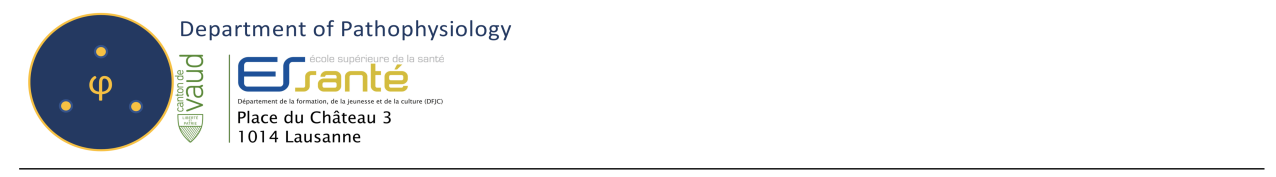

reste des voies respiratoires des voies aériennes inférieures. Il s'agit d'un tube de $11,5 \mathrm{~cm}$ de long et de $2 \mathrm{~cm}$ de large permettant à l'air de passer vers les poumons.

La trachée est entourée de 16 à 20 anneaux cartilagineux ne se fermant pas complètement au niveau postérieur, au contact avec l'œsophage (la trachée se détache en effet antérieurement à l'œesophage pendant la période embryonnaire). L'épithélium est pseudostratifié cilié comme celui du nez, et contient également des cellules à mucus permettant d'en sécréter. La trachée se termine par la carina, point de séparation en bronches souches (ou primaires) droite et gauche. Les bronches pénètrent dans les poumons et se divisent successivement en bronches secondaires, bronchioles, bronches tertiaires et alvéoles. Les divisions en alvéoles servent pour augmenter grandement la surface d'échange. L'épithélium alvéolaire est de type cuboïde simple.

La cage thoracique est formée du sternum, les clavicules, les scapula, des 12 paires de côtes. Les côtes 1 à 7 sont appelées vraies côtes puisqu'elles sont rattachées à la colonne vertébrale thoracique et au sternum directement via le cartilage costal. Les côtes 8 à 10 sont appelées fausses côtes puisque leur cartilage costal se rattache à celui de la côte 7 pour atteindre le sternum. Enfin, les côtes 11 et 12 ne sont ni directement ni indirectement rattachées au sternum, ce qui les rend flottantes.

Finalement, la cage thoracique est séparée de la cavité abdominale par le muscle diaphragme.

Les poumons sont des organes en forme de cône situés dans la cage thoracique de part et d'autre du cœur; ils sont divisés en lobes. Le poumon droit présente trois lobes : un lobe supérieur, un moyen, un inférieur; la scissure oblique (longue scissure) sépare le lobe supérieur et le lobe moyen du lobe inférieur, et la scissure moyenne (ou scissure horizontale) sépare le 


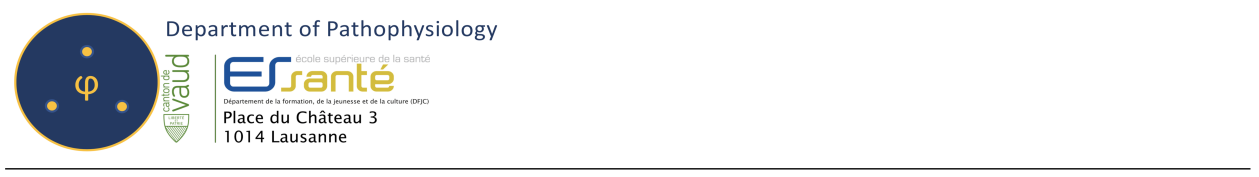

lobe supérieur du lobe moyen. Le poumon gauche présente uniquement la scissure moyenne puisque ce dernier ne présente pas de lobe moyen. Les deux poumons présentent sur leur face médiale des empreintes.

Le poumon droit présente les empreintes des veines pulmonaires, de l'artère pulmonaire, de la bronche souche droite se divisant en bronche lobaire supérieure et moyenne; ces empreintes constituent le hile pulmonaire droit, situé antérieurement à l'empreinte de la veine azygos. Inférieurement au hile pulmonaire bilatéralement, le ligament pulmonaire signale le repli de la plèvre, qui entoure le hile.

Le poumon gauche présente un hile semblable au poumon droit, antérieurement à l'empreinte de la crosse de l'aorte. Antérieurement au hile, on retrouve la grande empreinte cardiaque, qui réduit le volume du poumon gauche. Antéro-inférieurement à l'empreinte cardiaque on retrouve la lingula, excroissance terminale inférieure du poumon gauche (à la place du lobe moyen). Les poumons sont entourés de plèvre pariétale (couche la rattachant à la cage thoracique) et plèvre viscérale (couche recouvrant le poumon même).

\subsection{Physiologie respiratoire}

Principes physico-chimiques La pression est la force exercée par le choc des molécules sur une paroi. La pression partielle d'un gaz se définit comme la fraction de pression totale exercée par le gaz; la pression partielle de l'O2 est fixée à 20,95\% (159 mmHg) et celle du CO2 est de 0.03\% (0 mmHg). La loi de Dalton sert à calculer la pression totale à un endroit donnée :

$$
P_{t o t}=P_{g a z(1)}+P_{g a z(2)}+\ldots+P_{g a z(n)}
$$




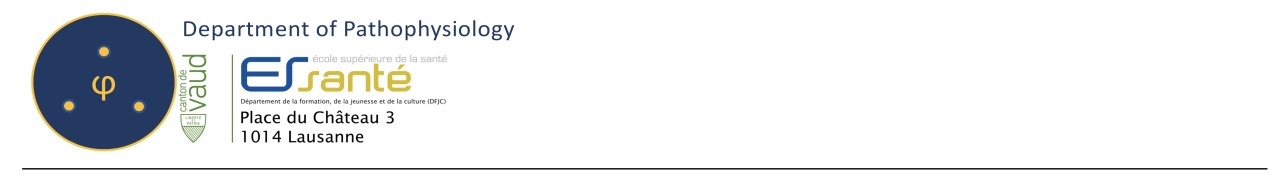

La pression atmosphérique se détermine avec la loi de Dalton et est fixée à $760 \mathrm{mmHg}=1 \mathrm{~atm}=1013$ mbar. La solubilité d'un gaz dépend de la loi d'Henry : la pression du gaz est proportionnelle à sa concentration et inversement proportionnelle à sa solubilité (s).

$$
P_{g a z}=\frac{[g a z]}{s}
$$

La solubilité de l'oxygène est égale à 0.024 , celle du $\mathrm{CO} 2$ est égale à 0.57 ; dans le sang on retrouvera donc $20 \mathrm{ml}$ d'O2 par $100 \mathrm{ml}$ de sang. La diffusion d'un gaz dépend de la loi de Fick : la diffusion d'un gaz est directement proportionnelle à la pression du gaz, la section (dimension de l'alvéole) et la solubilité et est inversement proportionnelle à la distance (dans ce cas, l'épaisseur de la membrane alvéolo-capillaire) et le poids moléculaire.

$$
D=\frac{P . A . s}{d \sqrt{P M}}
$$

La membrane alvéolo-capillaire est la membrane de diffusion des gaz de la respiration. Il s'agit d'un diaphragme composé de l'addition de l'épithélium cuboïde alvéolaire, la membrane basale et l'endothélium capillaire. Au plus la paroi est fine, au plus la diffusion se fait facilement.

Fibrose pulmonaire Lors d'une fibrose pulmonaire idiopathique, les cellules mésenchymateuse envahissent l'espace interstitiel alvéolaire, causant un excès de production de collagène et une distorsion de l'architecture normale des alvéoles.

Des fibroblastes seront retrouvés en groupes (foci). Un infiltrat inflammatoire précède généralement cette manifestation pathologique et y persiste. Une prédisposition génétique existe (altération de protéines du surfactant, 


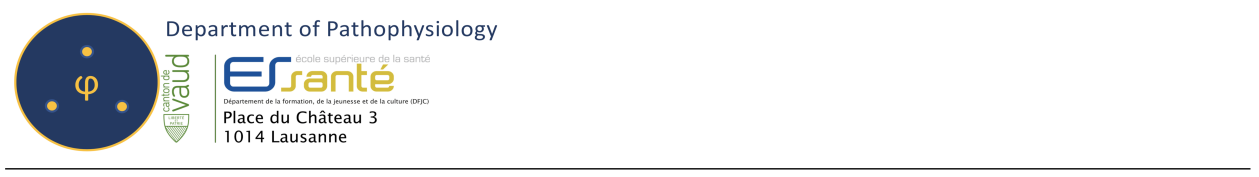

gènes de la télomérase).

La fibrose débute avec des phases alternées d'inflammation alvéolaire et ré-épithélialisation, résultant en un épaississement de la barrière alvéolocapillaire. Le patient présentera des difficultés respiratoires au vu de la diminution du tissu fonctionnel et de la diffusion de l'oxygène.

D'autres types de fibroses existent, comme la silicose (dû à l'inhalation de particules de $\mathrm{SiO} 2$ ).

Conditionnement de l'air dans les voies aériennes supérieures, escalator mucociliaire, filtration et taux de déposition Le but des voies aériennes supérieures est celui de réchauffer et humidifier l'air ; ce but est majoritairement accompli au niveau des cornets nasaux.

L'air pénètre dans le nez et au niveau des cornets s'effectue la filtration des particules, le réchauffement à 37 degrés et la saturation par vapeur d'eau à 100\% de l'air : ce processus se définit comme le conditionnement de l'air. Il s'agit d'un processus entrainant des pertes : au repos et à 25 degrés, on perd 1L d'eau par jour.

L'épithélium nasal, trachéal et bronchique est pseudostratifié cilié : chaque cellule possède environ 200 cils qui battent 20 fois/seconde pour faire avancer le mucus pour l'expulsion.

Chaque subdivision des voies aériennes, supérieures ou inférieures, arrête des particules d'un certain diamètres : les cornets nasaux arrêtent les molécules dont le diamètre est supérieur de $200 \mathrm{~m}$ tandis que les molécules d'un $\mu \mathrm{m}$ arrivent dans l'alvéole.

Le taux de déposition des molécules diminue donc au fur et à mesure que les particules progressent dans les voies aériennes. 
Effet du tabac sur les voies aériennes Le tabagisme chronique cause une irritation constante de la trachée, ce qui induit une conversion de l'épithélium pseudostratifié cilié en un épithélium stratifié squameux.

Sans escalator mucociliaire, le mucus ne peut pas être évacué, causant le développement de microorganismes et infections répétés. L'irritation chronique des voies aériennes cause une inflammation déclenchant les réflexes de toux du fumeur.

Pneumonie La pneumonie est une infection du parenchyme pulmonaire.

Elle est due le plus souvent à Streptococcus pneumoniae (pneumonie typique) ou Mycoplasma pneumoniae (pneumonie atypique). La pneumonie typique se présente avec un frisson solennel, de la température, de la toux le plus souvent productive. Le diagnostic se fait classiquement par radiographie de thorax.

Le traitement se fait par antibiotique si le tableau clinique est évocateur d'une étiologie bactérienne.

Tuberculose La tuberculose pulmonaire est la manifestation la plus fréquente de la tuberculose, due à une infection à Mycobacterium tuberculosis (aussi appelé Bacille de Koch).

Seul les tuberculeux pulmonaires actifs sont contagieux, la bactérie se transmet par voie aérienne suite à expulsion de microorganismes dans la toux via gouttelettes.

Le complexe T primaire ou (complexe de GHON) est formé par un foyer pulmonaire et une atteinte des ganglions autour de le hile pulmonaire (ganglions hilaires).

Les macrophages alvéolaires sont incapables d'anéantir le microorganismes 
et une inflammation chronique se met en place, avec le développement d'un granulome tuberculeux (centres d'inflammation avec collection de cellules inflammatoires et apparition de cellules multinuclées) pour confiner l'infection.

La bronchopneumonie tuberculeuse suit l'infection primaire et se présente à la tomodensitométrie comme un ensemble de cavernes tuberculeuses (cavités creuses suite aux dommages pulmonaires).

Finalement, la tuberculose miliaire est la manifestation finale de la tuberculose, avec une dissémination par voie sanguine qui atteint le reste du corps (os, méninges, rétine, rein, etc.).

Le patient tuberculeux se présentera avec toux et expectorations, sueurs nocturnes, perte de poids, fatigue, difficultés respiratoires.

Le dépistage de la tuberculose se fait par intradermoréaction à la tuberculine. Le diagnostic se fait par examen direct des expectorations (si présentes) ou lavage bronchoalvéolaire (si absentes). La PCR est le test le plus sensible pour détecter la bactérie. La culture est nécessaire mais prend environ 8 semaines. Le traitement se fait par antibiothérapie prolongée (Pyrazinamide, Isoniazide, Rifampicine, Ethambutol) mais des effets secondaires sont souvent présents.

Mécanique respiratoire La compliance pulmonaire statique se définit comme la capacité du poumon à accueillir de l'air en rapport avec la différence de pression entre l'intérieur du poumon et celle de l'air ambiant. Elle se définit par la formule suivante :

$$
\text { Compliance }=\frac{\Delta V}{\Delta P}
$$




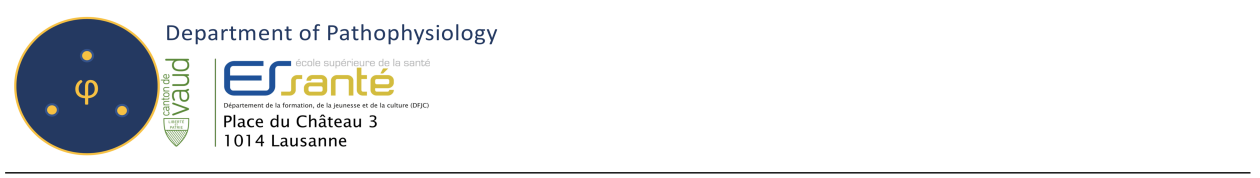

La compliance pulmonaire statique est contrée par la force des muscles de la paroi (cage thoracique) qui veulent l'étendre.

La compliance est haute à bas volume (si peu d'air dans le poumon, celui-ci se gonfle plus facilement) et basse à haut volume (si beaucoup d'air dans poumon, celui-ci se gonfle moins facilement.

La compliance pulmonaire est meilleure à l'expiration. Une fois le poumon dégonflé, une difficulté se présente pour expirer davantage : il s'agit de la force exercée par les muscles de la paroi qui veulent gonfler à nouveau le poumon. La relation entre la pression de la paroi thoracique et la pression pulmonaire est retrouvée classiquement par le diagramme de Rahn.

La résultante des deux forces est la pression du système respiratoire.

La pression transpulmonaire $\left(\Delta P_{t p}\right)$ est définie comme la différence des pressions de l'air entre les alvéoles et la plèvre :

$$
\Delta P_{t p}=P(\text { alveoles })-P(\text { plevre })
$$

Si $\Delta P_{t p}$ ¿ $0, \mathrm{P}($ alveoles $)$ ¿ $\mathrm{P}$ (plevre) et le poumon se gonfle.

Si $\Delta P_{t p}$ ¡ $0, \mathrm{P}$ (alveoles) i $\mathrm{P}$ (plevre) et le poumon se dégonfle.

La pression des alvéoles est équivalente à la pression de l'air ambiant, la pression de la plèvre reflète l'état de gonflement du poumon.

Quand le poumon est dégonflé, la pression de l'air ambiant est supérieure à celle de la plèvre, ce qui permet au poumon de gonfler. Quand le poumon est gonflé, la pression de la plèvre est supérieure à celle de l'air ambiant, ce qui permet au poumon de se dégonfler.

Le recul élastique du poumon se définit comme la tendance du poumon à revenir à son état de départ. Elle est influencée par les propriétés élastiques du tissu pulmonaire.

La capacité résiduelle fonctionnelle $(\mathrm{CRF})$ se définit comme le volume pul- 


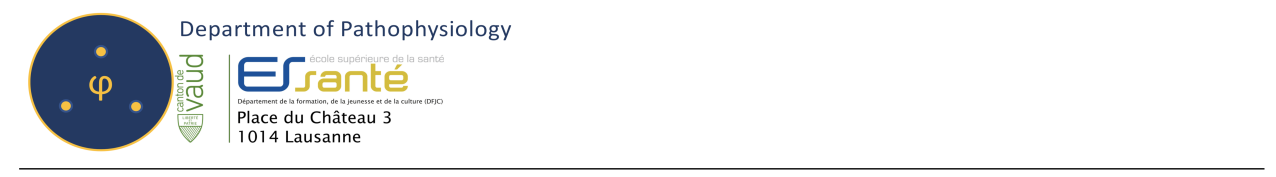

monaire à la fin d'une expiration non forcée ; à ce moment, la pression transpulmonaire est égale à 0 .

Pneumothorax Lors d'un pneumothorax, de l'air envahit l'espace entre la plèvre et le tissu pulmonaire, causant le dégonflement du poumon. La pression de recul élastique sera annulée et le poumon ne peut pas se regonfler.

Emphysème pulmonaire Lors de l'emphysème pulmonaire, les septa (cloisons) des alvéoles sont détruits suite à un déséquilibre entre la trypsine, protéine détruisant les tissus, et l' $\alpha 1$ antitrypsine, protéine contrastant la trypsine et inactivée par les dégâts oxydants causés par le tabagisme chronique. A cause du manque de surface, les échanges gazeux vont être moins efficaces.

De l'air restera séquestrée dans les alvéoles à la fin de l'expiration. La séquestration de l'air cause une hyperexpansion de la cage thoracique qui diminue les propriétés mécaniques des muscles de la respiration.

Les patients emphysémateux chroniques auront tendance à expirer avec leur bouche en soufflant doucement, pour que l'expiration génère le moins de pression possible sur les bronches et évite donc l'écrasement de ces derniers (limitation de la compression dynamique des voies aériennes).

Cycle respiratoire et volumes respiratoires $\mathrm{Au}$ repos, le volume pulmonaire est équivalent à la capacité résiduelle fonctionnelle $(\mathrm{CRF})$ et la pression pleurale est négative pour permettre au poumon de garder son volume de base.

Suite à l'inspiration (d'environ $5 \mathrm{~L} / \mathrm{min}$ au repos), l'expansion de la paroi thoracique causée par les mouvements du muscle diaphragme (en anse de 


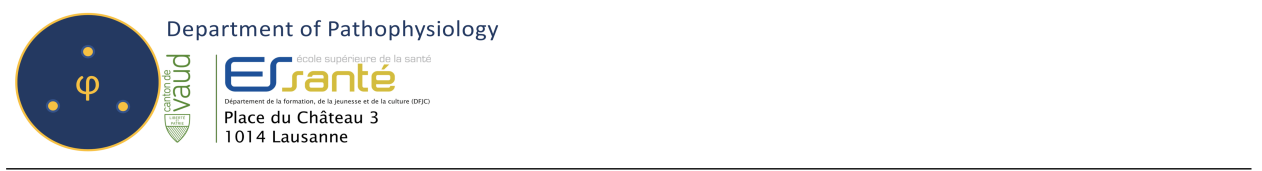

seau) tire sur la surface pulmonaire avec une force grandissante. Au cours de l'expiration, le phénomène inverse est appliqué.

Le système nerveux orthosympathique augmente la fréquence respiratoire et dilate les bronches, tandis que le système parasympathique diminue la fréquence respiratoire et réduit le diamètre des bronches.

Volumes statiques La spirométrie permet de mesurer la quantité d'air qui rentre et sort des voies respiratoires supérieures.

Le volume courant (VC) est égal à $300 \mathrm{ml}$ et est le volume qui rentre et sort au repos ( 1 minute $=5 \mathrm{~L}$ puisqu'on respire 12 à 15 fois $)$.

La capacité pulmonaire totale (CPT) est le volume contenu dans les poumons lors d'une inspiration maximale. Le volume résiduel (VR) est le volume contenu dans les poumons lors d'une expiration maximale. La capacité vitale $(\mathrm{CV})$ est la différence entre la CPT et le VR.

Le volume de réserve expiratoire (VRE) est la différence entre la CRF et le VR. Le volume de réserve inspiratoire (VRI) se définit comme le volume maximal pouvant être inspiré par un individu au repos. La capacité inspiratoire (CI) se définit comme la somme entre le VRI et le VC.

Le volume expiratoire maximale en 1 seconde (VEMS) est le volume expiré avec une effort expiratoire maximale après inspiration maximale. Le rapport entre le VEMS et la CV définit l'indice de Tiffeneau. Un index de Tiffeneau normal est estimé à $80 \%$.

$$
\text { IndexTiffeneau }=\frac{V E M S}{C V}
$$

Compression dynamique des voies aériennes En début d'expiration, si l'individu souffle très fort, le débit expiratoire augmente.

À moitié route expiratoire entre $\mathrm{CPT}$ et $\mathrm{VR}$, le débit expiratoire reste le 


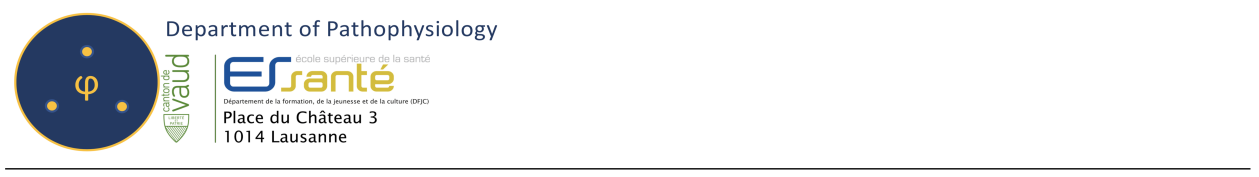

même. Ce phénomène est dû à la compression dynamique des voies aériennes : au plus l'individu souffle, au plus la pression exercée par les muscles de la paroi ferme la bronche par laquelle l'air sort, ce qui régularise le volume. La pression est maximale dans l'alvéole, et cette dernière diminue suite à la remontée de l'air pendant l'expiration. On définit le point d'égale pression comme le point au niveau des voies aériennes où la pression exercée par les muscles pour expirer est égale à celle présente dans les voies aériennes ; en amont du point d'égale pression et vers la sortie des voies aériennes, la bronche sera comprimé, ce qui va limiter le débit expiratoire maximum.

Asthme En début d'expiration, si l'individu souffle très fort, le débit expiratoire augmente.

À moitié route expiratoire entre $\mathrm{CPT}$ et $\mathrm{VR}$, le débit expiratoire reste le même. Ce phénomène est dû à la compression dynamique des voies aériennes : au plus l'individu souffle, au plus la pression exercée par les muscles de la paroi ferme la bronche par laquelle l'air sort, ce qui régularise le volume. La pression est maximale dans l'alvéole, et cette dernière diminue suite à la remontée de l'air pendant l'expiration. On définit le point d'égale pression comme le point au niveau des voies aériennes où la pression exercée par les muscles pour expirer est égale à celle présente dans les voies aériennes ; en amont du point d'égale pression et vers la sortie des voies aériennes, la bronche sera comprimé, ce qui va limiter le débit expiratoire maximum.

Bronchopneumopathie chronique obstructive La bronchopneumopathie chronique obstructive est une maladie caractérisée par une limitation persistante et progressive des voies aériennes associée avec une réponse inflammatoire chronique augmentées dans les voies aériennes et le poumon causée par des particules nocives. 


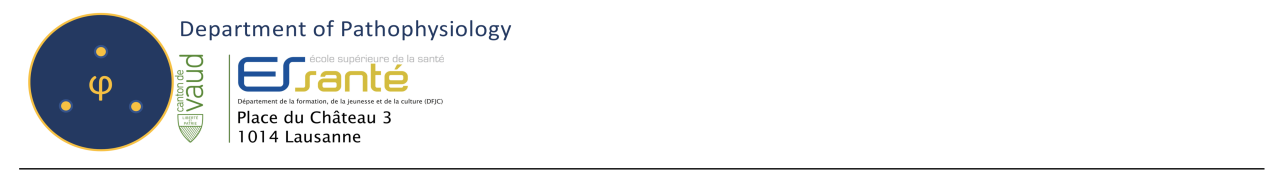

La limitation chronique des voies aériennes est caractérisée par deux composantes, la bronchiolite chronique et l'emphysème : les voies aériennes se ferment suite à la réduction du diamètre bronchique et la perte de recul élastique du poumon.

Les facteurs influençant le développement de la maladie sont le tabac, le milieu socio-économique, l'âge, l'exposition aux particules nocives (tabac, marijuana, fumées, pollution chimique), la présence de l'asthme, une bronchite chronique, et les infections.

Le tabac et les particules nocives causent une inflammation chronique par stress oxydatif et protéinases, conduisant à un emphysème pulmonaire par destruction de l'élastine. Les composantes inflammatoires présentes sont les lymphocytes T CD8 (cytotoxiques), les polymorphonucléaires, et les monocytes.

Le VEMS et l'indice de Tiffeneau sont diminués suite à la fibrose et l'inflammation. L'anomalie des échanges des gaz entraine une hypoxie et une hypercapnie. Une toux productive est générée par une hypersécrétion muqueuse due à une augmentation des cellules caliciformes. Le muscle lisse bronchique devient hypertrophie suite à l'inflammation ce qui cause une hypertension artérielle pulmonaire et une vasoconstriction hypoxique.

Des infections virales ou bactériennes sont plus fréquentes. Le diagnostic se fait par spirométrie. Deux types chroniques de patients BPCO existent, le blue boater (patient fumeur obèse, hypoxique, composante bronchite chronique prédominante) et le pink puffer (patient mince, âgé, composante emphysémateuse prédominante).

Le traitement se base sur l'arrêt du tabac et des bronchodilatateurs. 


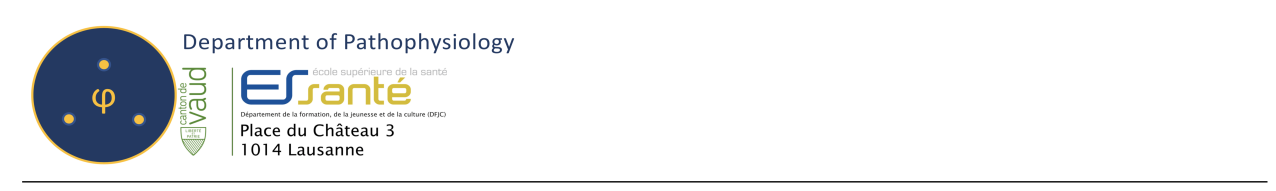

Ventilation et perfusion pulmonaire L'espace mort anatomique (150ml) est le volume d'air se trouvant dans les parties du système respiratoire qui ne contribuent pas aux échanges, par exemple la trachée.

La ventilation alvéolaire se définit comme le volume se soumettant à l'échange alvéolaire (ventilation minute - volume de l'espace mort). Le débit sanguin pulmonaire est le volume de sang par minute passant par les artères pulmonaires et participant aux échanges alvéolo-capillaire : il est égal à la ventilation alvéolaire, $5 \mathrm{~L} / \mathrm{min}$.

Le rapport ventilation/perfusion définit les concepts physiologiques du shunt et de l'espace mort.

Pour comprendre le shunt, il faudrait imaginer un poumon dont l'entrée bronchique serait bloquée totalement et la vascularisation intacte : la pression en $\mathrm{CO} 2$ augmenterait et celle en $\mathrm{O} 2$ diminuerait progressivement puisque l'échange alvéolo-capillaire serait inexistant.

Pour comprendre l'espace mort, il faudrait imaginer un poumon dont les capillaires sont bloqués mais l'entrée bronchique est libre : les pressions en CO2 et $\mathrm{O} 2$ dans l'alvéoles deviendront progressivement celles de l'atmosphère.

Embolie pulmonaire Lors d'une embolie pulmonaire, un thrombus est envoyé dans l'arbre vasculaire du tronc pulmonaire obstruant la circulation pulmonaire et causant de facto un espace mort puis un shunt pathologique.

La maladie thromboembolique veineuse regroupe la thrombose veineuse profonde (TVP) et l'embolie pulmonaire (EP).

Il s'agit d'une maladie multifactorielle dont les facteurs de risques principaux sont une chirurgie récente, traumatisme aux membres inférieurs, hospitalisation récente, cancer avec chimiothérapie, contraception orale, traitement 


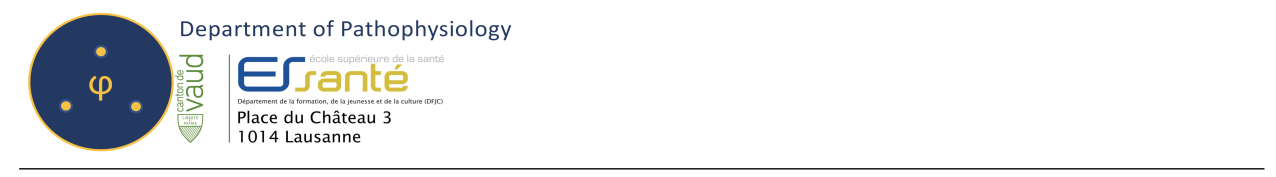

hormonal substitutif, une grossesse/post-partum récent, des antécédents thromboemboliques, une insuffisance cardiaque congestive (certains de ces critères constituent le score de Genève).

La stase veineuse et les lésions endothéliales prédisposent à la thrombose, les thrombus provenant surtout des veines profondes des membres inférieurs et du pelvis.

L'obstruction du circuit artériel pulmonaire par le thrombus cause une augmentation de la pression artérielle pulmonaire et la postcharge du ventricule droit.

L'obstruction cause l'effet espace mort, tandis que l'effet shunt est causé par la libération de médiateurs broncho. Le cœur essaiera de compenser par une tachycardie et une augmentation du travail ventriculaire droit. Cette situation entraine une surconsommation en oxygène du ventricule droit qui constituera un obstacle à la contraction du cœur gauche (le septum va dévier vers la gauche, cette situation dénommée septum paradoxal).

Un choc obstructif est la conclusion physiopathologique de l'embolie pulmonaire. L'effet espace mort et shunt causeront d'abord une hypoxémie, puisque l'oxygène ne parvient pas au cœur gauche, puis, suite à une tachypnée (le corps veut composer l'hypoxémie en respirant plus vite), une hypocapnie. Les symptômes comprennent dyspnées et hémoptysies.

Le diagnostic de l'embolie pulmonaire se fait selon un algorithme basé sur le risque clinique. Les méthodes diagnostiques comprennent le dosage des d-dimères, produit de dégradation de la fibrine (surtout chez les personnes à faible risque clinique) ainsi que l'angioscanner, l'échographie doppler des membres inférieurs et la scintigraphie ventilation perfusion. Le traitement se fera par anticoagulants (héparine non fractionnée avec relai par antivitamine $\mathrm{K})$. 


\section{Équilibre acido-basique pulmonaire}

Tampon bicarbonate La valeur normale du pH est située à 7.4.

Un tampon maintient le $\mathrm{pH}$ stable en libérant des $\mathrm{H}+$ ou en reprenant des $\mathrm{H}+$ selon le besoin. Le bicarbonate est un tampon essentiel du corps humain. La concentration en $\mathrm{CO} 2$ est proportionnelle en $\mathrm{H} 2 \mathrm{CO} 3$.

Pour contrer la production d'ions hydrogène, le corps va produire plus de HCO3-. Pour contrer l'absence d'ions hydrogène, le corps va libérer dans les urines des quantités majeures de HCO3-.

Le bicarbonate constitue un système ouvert puisque le $\mathrm{H} 2 \mathrm{CO} 3$ peut être converti en $\mathrm{CO} 2$ et expulsé via l'expiration.

La compensation rénale d'un déséquilibre est lente.

Diagramme de Davenport et désordres acidobasiques Le diagramme de Davenport illustre l'évolution du bicarbonate sanguin en fonction du $\mathrm{pH}$.

Le point de départ (A) concerne l'équilibre acidobasique idéal ; un pH de 7.4 pour une concentration en bicarbonate normale (environ $25 \mathrm{mEq} / \mathrm{L}$ ).

Lors de l'acidose respiratoire (par exemple lors d'un arrêt respiratoire), le $\mathrm{CO} 2$ augmente et le $\mathrm{pH}$ diminue $(\mathrm{B})$; le rein va compenser par retenir du HCO3- (D) (compensation rénale d'une acidose respiratoire).

Lors d'une alcalose respiratoire (par exemple lors d'une hyperventilation), le $\mathrm{CO} 2$ diminue et le $\mathrm{pH}$ monte $(\mathrm{C})$; le rein va compenser par libérer dans les urines une quantité majeure de HCO3- (F) (compensation rénale d'une alcalose respiratoire). Lors d'une acidose métabolique (par exemple lors d'une acidocétose diabétique, présence excessive d'acides) la concentration en HCO3- diminue $(\mathrm{G})$; les poumons vont compenser en provoquant une hyperventilation (F) (compensation respiratoire d'une acidose métabolique). 


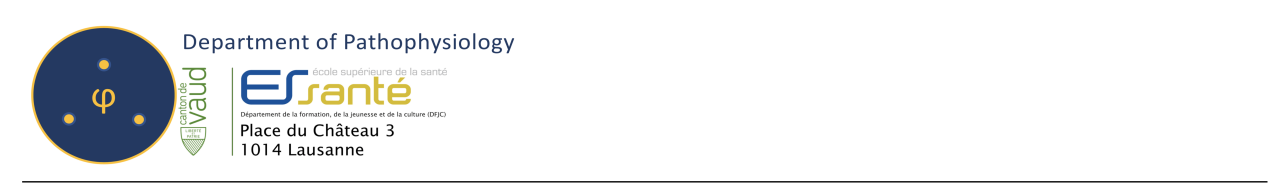

Lors d'une alcalose métabolique (par exemple lors de vomissements répétés, manque d'acide gastrique), la concentration en HCO3- est trop importante par rapport à celle des ions hydrogène $(\mathrm{E})$; les poumons vont compenser en diminuant la ventilation minute (D) (compensation respiratoire d'une alcalose métabolique).

\section{Physiopathologie digestive}

\subsection{Introduction et histologie digestive générale}

Le tube digestif débute au niveau de la cavité orale et se termine par l'anus, sans interruption mais formé de segments spécialisés.

Le tube digestif accomplit 4 tâches de base : la motilité, la sécrétion, la digestion et l'absorption. Le tube digestif présente au niveau histologique quatre couches : la muqueuse, la sous muqueuse, la musculeuse et l'adventice. La muqueuse varie selon les régions et comporte un revêtement épithélial et soutenue par le chorion. Elle est séparée de la sous-muqueuse par la muscularis mucosae, une couche de muscle lisse.

La sous-muqueuse est formée par du tissu conjonctif lâche et contient les vaisseaux ainsi que le plexus nerveux de Meissner (plexus nerveux sousmuqueux). La musculeuse est le plus souvent constituée de deux couches musculaires lisses, une interne circulaire et une externe longitudinale; elle contient le plexus nerveux d'Auerbach (plexus myentérique).

L'adventice est une couche externe de tissu conjonctif lâche qui contient les gros vaisseaux et nerfs.

La séreuse est une portion d'adventice recouverte d'épithélium pavimenteux simple. 


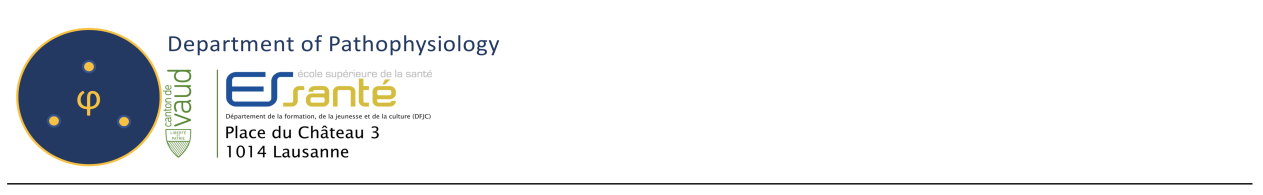

Muscle lisse intestinal Les muscles lisses présents dans l'intestin présentent trois fonctions principales : le malaxage des aliments (fragmentation et mélange avec les enzymes), la propulsion (faire avancer les aliments) et la fonction de sphincter (séparer deux zones différentes pour empêcher les aliments de passer).

Des contractions spontanées se propagent de proche en proche le long de la paroi de l'intestin.

Certaines substances modifient la perméabilité membranaire du muscle lisse aux ions : par exemple, l'adrénaline modifie la perméabilité au potassium (et ralentit les contractions pour digérer moins vite) tandis que l'acétylcholine modifie la perméabilité au calcium (et augmente les contractions pour digérer plus vite).

Maladie de Hirschprung La maladie d'Hirschprung (aussi appelée mégacôlon aganglionique ou aganglionose intestinale congénitale, incidence 1/5000 nouveau-nés) consiste en l'absence de développement des plexus de Meissner et Auerbach au niveau du colon terminal.

Le sphincter anal interne ne se dilate pas, ce qui cause une constipation entrainant un mégacôlon (colon distendu) en amont du segment non fonctionnel.

On suspecte la maladie d'Hirschprung lorsque le nouveau-né présente des difficultés à expulser le méconium (premières selles) après 48 heures de la naissance.

Le traitement se fait généralement par chirurgie avec résection du segment non fonctionnel.

Régions de la paroi abdominale La région supérieure droite correspond à l'hypochondre droit. 


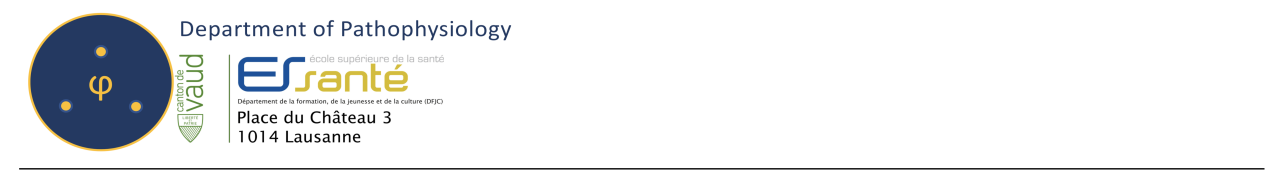

La région supérieure centrale correspond à la région épigastrique.

La région supérieure gauche correspond à l'hypochondre gauche.

La région moyenne droite correspond au flanc droit.

La région moyenne centrale correspond à la région ombilicale.

La région moyenne gauche correspond au flanc gauche.

La région inférieure droite correspond à la fosse iliaque droite.

La région inférieure centrale correspond à la région supra-pubienne.

La région inférieure gauche correspond à la fosse iliaque gauche.

\subsection{Cavité orale, pharynx et oesophage}

La cavité orale (ou buccale) est la cavité où les aliments sont introduits. La manducation (ou mastication) est un mouvement qui permet de les broyer et les mélanger à la salive (alcaline, produite à hauteur de 0.5 à $2 \mathrm{~L}$ par jour) pour constituer le bol alimentaire.

La déglutition est définie comme les deux phases permettant au bol alimentaire de se retrouver dans l'œsophage : la partie volontaire consiste à pousser le bol vers l'arrière de l'oropharynx (partie du pharynx postérieure à la cavité orale); les voies aériennes se ferment, avec l'épiglotte bloquant le passage vers le larynx, et le bol peut passer de l'oropharynx à l'hypopharynx (partie du pharynx postérieure au larynx et accessible quand l'épiglotte est fermée sur le larynx) et successivement vers l'œsophage.

L'œesophage est un tube d'environ $25 \mathrm{~cm}$ reliant l'hypopharynx à l'estomac et traversant donc les régions cervicales, thoraciques et abdominales (il accède à l'abdomen via le hiatus œesophagien, trou dans le muscle diaphragme) . Il est situé postérieurement à la trachée (dans sa portion supérieure) et au cœur (dans sa portion inférieure). Il est situé antérieurement aux vertèbres. 


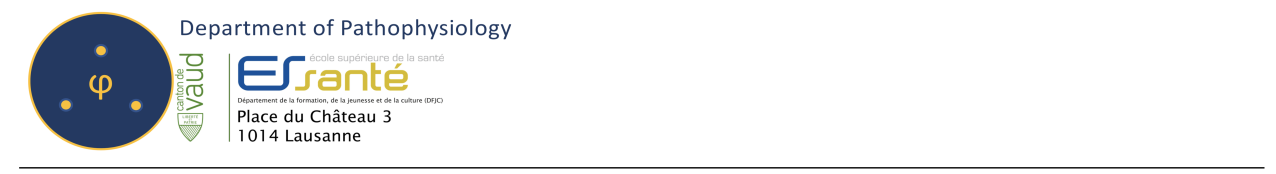

L'œsophage est équipé de deux couches musculaires, une permet au bol alimentaire d'avancer vers l'estomac.

Hernie hiatale Le hiatus oesophagien se retrouve élargi lors de la hernie hiatale : l'œsophage ainsi que d'autres parties du tube digestif peuvent remonter dans le thorax. La hernie hiatale comporte un dysfonctionnement du sphincter oesophagien inférieur (le cardia), provoquant un reflux oesophagien.

Reflux gastro-oesophagien Le cardia (ou sphincter oesophagien inférieur) protège l'œsophage de l'acidité gastrique.

Lorsque le sphincter oesophagien inférieur dysfonctionne (par exemple, lors d'une hernie hiatale), l'acide gastrique remonte vers l'œsophage, qui n'est pas équipé d'un épithélium pertinent à la protection contre les pH bas.

Ce phénomène provoque à long terme un changement d'épithélium (métaplasie) vers un type glandulaire : cet état histologique est précancéreux et est dénommé œsophage de Barrett. Le patient ressentira le brûlant, sensation de brûlure rétrosternale. L'endoscopie est l'examen de choix pour investiguer le reflux gastroœsophagien ainsi que ses répercussions sur l'œsophage et l'estomac : plusieurs biopsies seront réalisées.

Le traitement est surtout médicamenteux (antiacides dont la ranitidine et le pantoprazole) et en dernier recours, des méthodes chirurgicales par voie laparoscopique comme la fundoplicature selon Nissen (manchonner le fundus gastrique à 360 degrés autour du cardia) existent. Des mesures hygiénodiététiques (régime équilibré, diminuer l'obésité abdominale, dormir avec la tête surélevée par rapport au reste du corps, etc.) sont aussi efficaces. In fine et si non traité, le reflux chronique conduit à un processus néoplasique, le cancer de l'œsophage. 


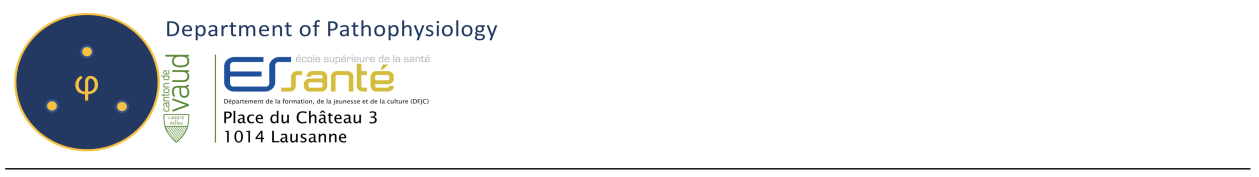

\subsection{Estomac}

L'estomac est une portion dilatée digestif, une poche située entre l'œesophage et le duodénum.

L'estomac commence avec le cardia, valve de connexion entre l'œsophage et l'estomac, et se termine par le pylore, valve de connexion entre l'estomac et le duodénum.

Le tiers supérieur de l'estomac est constitué par le fundus ou la poche à air (partie d'estomac généralement non remplie par de la nourriture mais de l'air puisque supérieure). En dessous du fundus se situe le corps, tiers moyen de l'estomac et aussi la partie la plus volumineuse. Le tiers inférieur s'appelle antre.

L'estomac présente une forme de $\mathrm{J}$ avec une grande courbure à sur le côté gauche) et une petite courbure (sur le côté droit). L'estomac accumule les aliments et sécrète le suc gastrique ( $\mathrm{pH}$ très acide).

Il possède une musculature puissante qui lui permet de se contracter et malaxer le bol alimentaire avec l'acide produit pour le transformer en chyme. Dans l'antre, certaines protéines commencent à être digérées grâce à la sécrétion de pepsinogène.

L'acide chlorhydrique $(\mathrm{HCl})$ est produit pour dénaturer les protéines et tuer les microorganismes pénétrant dans l'estomac (qui est stérile si l'individu est en bonne santé). Le mucus est produit par les cellules de la muqueuse pour la protéger d'une autodigestion. L'estomac produit également le facteur intrinsèque, qui permet d'absorber plus loin la vitamine B12, essentielle pour la production des globules rouges.

L'estomac présente 3 couches musculaires : une longitudinale externe, une circulaire intermédiaire et une interne oblique, pour permettre une torsion optimale de l'organe visée au malaxage des aliments. 


\section{Gastrite}

Gastrite secondaire aux AINS La gastrite secondaire aux antiinflammatoires non stéroïdiens (AINS) est le type de gastrite aigue la plus fréquente.

Les AINS bloquent la Cyclo-oxygénase 1 (COX1) et la Cyclo-oxygénase 2 (COX2); la COX1 stimule au niveau de l'estomac la protection via la production de mucines. Suite à l'inhibition, moins de mucus protectif est produit, ce qui augmente les dégâts apportés par l'acide à la paroi gastrique, causant l'apparition d'inflammation et d'ulcères (perte de continuité de la paroi muqueuse).

Les infections (autres que Helicobacter pylori), le stress, l'alcool et les radiations (lors d'une radiothérapie) sont d'autres causes de gastrite aigue.

Gastrite chronique à Helicobacter Pylori La gastrite à Helicobacter pylori est une infection causant une inflammation de l'estomac, évoluant vers une atrophie totale et progressive de la muqueuse gastrique et une métaplasie de type glandulaire avec un risque de cancer important. Les symptômes seront des douleurs épigastriques, Le diagnostic se fait par biopsie lors d'une gastroscopie, et le traitement combine une thérapie antibiotique et des antiacides (inhibiteurs de pompe à protons). L'éradication totale de la bactérie est nécessaire.

Ulcère gastroduodénal La cause de la perte de continuité muqueuse au niveau de l'estomac ou du duodénum est principalement due à un déséquilibre entre l'agression acide et la défense.

La principale force défensive est le mucus de surface dont la sécrétion peut être diminuée par l'utilisation d'AINS. Helicobacter pylori est la cause la 


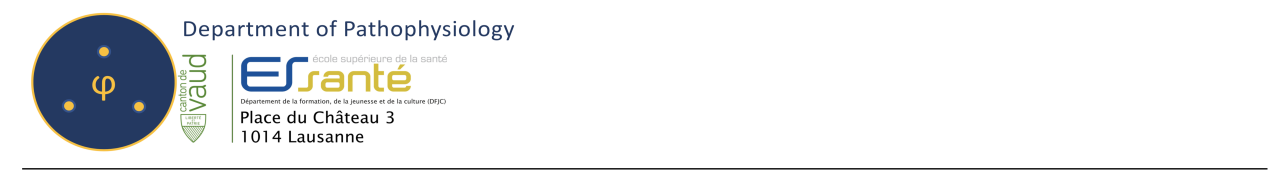

plus fréquente d'ulcère gastroduodénale $(90 \%)$.

Les complications les plus fréquentes de l'ulcère sont l'hémorragie, la perforation (ressentie comme une douleur en coup de poignard brutal), la sténose (rétrécissement de la lumière de l'organe) et la cancérisation.

Le traitement est médicamenteux (comme celui de la gastrite chronique incluant l'éradication de la bactérie) mais peut être chirurgical si l'ulcère est compliquée ou récidivante.

Obésité morbide Le BMI se définit comme le rapport entre la masse (en $\mathrm{kg}$ ) et le carré de la taille. Le poids normal se définit comme un BMI entre 18.4 à 24.9. L'obésité comporte un BMI supérieur à 30 .

L'obésité est une pathologie ayant des causes multifactorielles (environnementales et génétiques) dont les conséquences néfastes s'étendent sur plusieurs systèmes : métaboliques (hypercholestérolémie, intolérance au glucose), cardiovasculaire (hypertension artérielle, athérosclérose, maladie cardiaque ischémique), ostéoarticulaire (arthrose), respiratoire (syndrome d'apnée du sommeil, restriction de la capacité pulmonaire totale), digestives (le reflux gastroœsophagien est favorisé), gynécologiques (infertilité) et psychiatriques (dépression).

L'obésité réduit globalement l'espérance de vie de 7.1 ans chez la femme et 5.8 ans chez l'homme. Elle induit de nombreux surcoûts de santé et cause une altération de la qualité de vie (discrimination sociale, stigma). 80\% des adultes obèses présentent un facteur de comorbidité à l'obésité : diabète, dyslipidémie, pathologie coronarienne, hypertension artérielle, maladies du foie (stéatose hépatique non alcoolique), maladies de la vésicule biliaire (lithiases), etc.

Les mesures hygiéno-diététiques (régime, exercice physique) sont peu effi- 


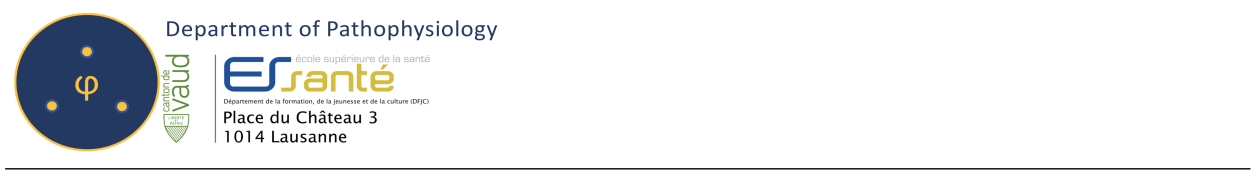

caces généralement chez le patient avec une obésité morbide. Des traitements chirurgicaux sont proposés après un an de traitement hygiéno-diététique conduit correctement et échoué. Les indications de chirurgie de l'obésité morbide varient selon les pays et leur législature.

Les deux traitements chirurgicaux principaux sont le bypass gastrique et la gastrectomie en sleeve, selon que le patient soit grignoteur ou mangeur de volume. Les chirurgies de l'obésité présentent, parmi leur complications nombreuses, des carences alimentaires en fer, calcium, vitamine D et B1, B6 et B12.

Vomissements Le vomissement consiste en une expulsion du contenu du tube digestif par la cavité orale.

Le vomissement cause une déperdition de plusieurs substances causant un schéma physiopathologique particulier.

La perte de sodium entraine un déficit qui diminue la pression osmotique $\mathrm{du}$ volume extracellulaire, qui diminue (l'eau suit le sodium) et entraine l'activation du système rénine angiotensine aldostérone visant à retenir de l'eau et des sels au niveau du processus de formation d'urine, dans le rein). La pompe $\mathrm{Na} / \mathrm{K} / \mathrm{ATPase}$ est ainsi activée par ce système, ce qui cause une perte rénale de potassium.

La perte d'acide chlorhydrique (contenu dans l'estomac) cause une alcalose métabolique.

L'apport alimentaire de potassium est accessoirement diminué par le vomissement lui-même. Le déficit en potassium résultant aggrave une perte d'ions hydrogène rénale (le rein récupère $\mathrm{du} \mathrm{H}+$ en excrétant du $\mathrm{K}+$ ) ce qui contribue à l'alcalose. 


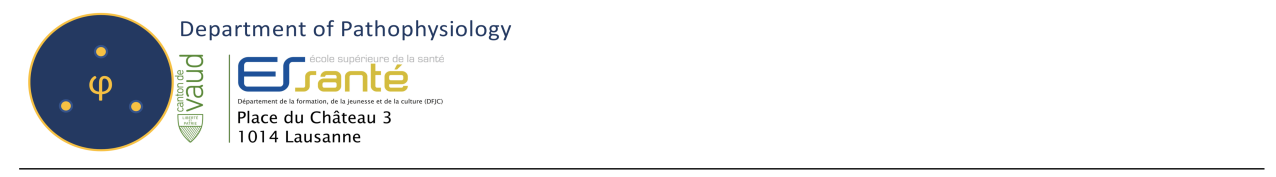

\subsection{Intestin grêle et côlon}

L'intestin grêle est le lieu principal de digestion et absorption.

La digestion des glucides et protéines se termine, tandis que la digestion des lipides se déroule complètement dans la lumière de l'intestin grêle. Il est divisé en duodénum (segment fixe), jéjunum (segment mobile) et iléon (segment mobile).

Le duodénum est la première portion de l'intestin grêle et mesure environ 30 cm. Sa paroi postérieure est accolée aux gros vaisseaux abdominaux (aorte abdominale et veine cave inférieure) ainsi que les vertèbres. Il est divisé en 4 portions.

La portion I est supérieure et horizontale (poursuit le pylore gastrique). La portion II est descendante et accueille le canal pancréatique de Wirsung et Santorini dont la fonction est de déverser les enzymes du suc pancréatique(lieu d'abouchement est appelé papille duodénale mineure) ainsi que canal cholédoque dont la fonction est de déverser la bile (lieu d'abouchement est appelé papille duodénale majeure). L'ampoule de Vater est le lieu de réunion entre les canaux pancréatiques et le cholédoque. La portion III est horizontale et la portion IV est ascendante; l'angle entre la portion IV et le jéjunum est définie comme l'angle de Treitz.

Le jéjuno-iléon est une continuité de anses horizontales (jéjunum) et verticales (iléon) de plusieurs mètres de long.

Les glucides, protéines et lipides sont absorbés dans la lumière du tractus grâce à une muqueuse plissée pour augmenter la surface d'échange. Le jéjuno-iléon se termine au niveau de la valvule iléo-caecale de Bauhin reliant l'iléon au caecum. Le gros intestin fait suite au jéjuno-iléon. Sa lumière est plus grande et sa paroi est caractérisée par des haustrations, qui sont des plis semi-lunaires de la muqueuse; des appendices épiploiques (fibres mus- 


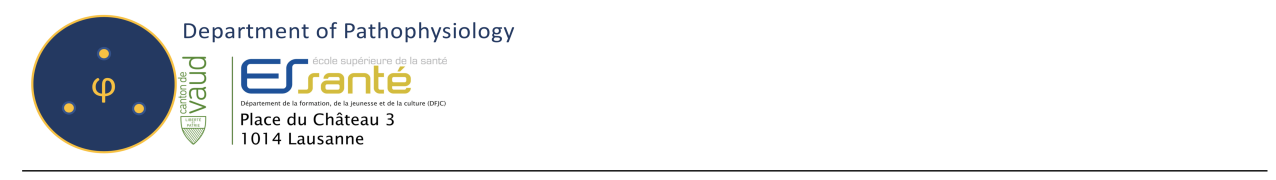

culaires longitudinales recouvertes par de la graisse) sont présentes.

Dans le gros intestin, les résidus non digérés de l'alimentation et des déchets biliaires se concentrent dans les fèces. Le gros intestin a un rôle d'absorption d'eau et d'électrolytes .

Le gros intestin est divisé en caecum (plus appendice), colon (ascendant, transverse, descendant) et rectum. Les appendices épiploiques (aussi appelées tænia coli) débutent sur l'insertion de l'appendice caecale et se terminent au début du rectum.

Le canal anal se termine in fine par l'anus.

Diarrhées Les diarrhées sont définies comme des selles plus fréquentes et consistantes par rapport à la norme. Elles sont causées le plus souvent par un déficit du transport intestinal (des ions, de l'eau, etc.).

Les diarrhées osmotiques sont causées par la présence dans la lumière de l'intestin d'une substance avec un grand pouvoir osmotique (appel à l'eau); les causes les plus fréquente sont les diarrhées sur usage de laxatif ou de magnésium.

Les diarrhées sécrétoires sont causées par un déficit de transport des électrolytes ; les causes les plus fréquentes sont les laxatifs irritants, une malabsorption des sels biliaires, les colites microscopiques ou encore des tumeurs endocrines. Elles sont très volumineuses et sont souvent accompagnées par les troubles électrolytiques.

Les diarrhées motrices sont causées par une accélération du transit intestinal; les causes les plus fréquentes sont la prise d'alcool, le côlon irritable ou la résection colique.

Les diarrhées inflammatoires sont caractérisées par la présence de sang, mucus et température. 


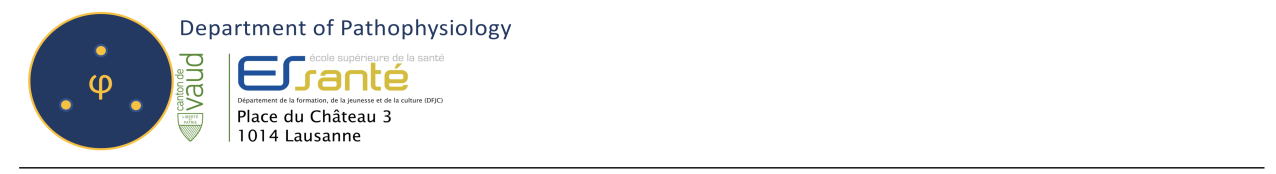

Les premières causes de diarrhée inflammatoire sont la maladie de Crohn et la rectocolite ulcéro-hémorragique (RCUH).

Les diarrhées accompagnées de stéatorrhées (excrétion abondante de graisses dans les selles) sont causées par une mal digestion (par exemple lors d'une insuffisance pancréatique ou biliaire) ou par une mal absorption (causée par une atteinte des cellules de la lumière intestinale ou par un déficit du transport vasculaire).

Constipation La constipation est définie comme des défécations peu fréquentes (moins de 3/semaine) avec ou sans difficulté d'exonération.

Les constipations peuvent être secondaires à des médicaments des tumeurs bloquant le passage, l'hypothyroïdie (le fonctionnement entier du corps est mis au ralenti par manque d'hormones thyrö̈diennes), le diabète ou une immobilisation.

Les constipations primaires se divisent en hypotoniques (transit ralenti, comme lors du côlon irritable), spastique (contractions exagérées avec selles petites et dures) et terminales (causées par des lésions neurologiques de la moelle, les selles s'accumulent distalement dans le côlon).

Maladie coeliaque La maladie cœliaque se présente comme un ensemble de diarrhées, perte de poids, troubles de la croissance, malnutrition (B9, B12, fer), douleurs osseuses et neuropathies périphériques causées par une allergie au gluten.

Le diagnostic se pose par une recherche d'anticorps IgA anti gliadine et une endoscopie duodénale : l'histologie montrera une atrophie des villosités accompagnée d'une hyperplasie lymphocytaire et une infiltration du chorion. 


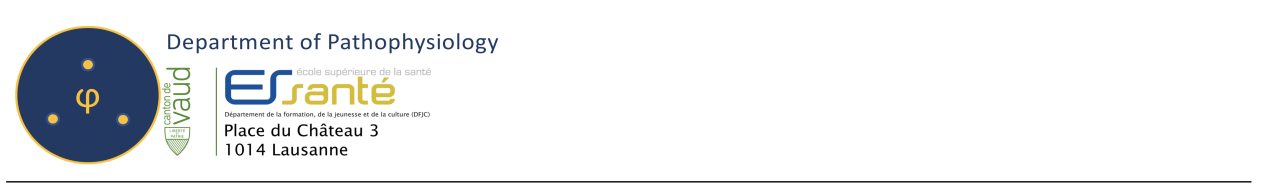

Colon irritable Le côlon irritable est une pathologie caractérisée par une hyper motilité colique après les repas, dont les crises douloureuses et les troubles de transit varient au cours du temps. Elle est prédominante chez la femme avant 30 ans. Le traitement est symptomatique (la physiopathologie de la maladie étant partiellement comprise).

Maladie de Crohn La maladie de Crohn fait partie des maladies inflammatoires chroniques de l'intestin (Inflammatory Bowel Diseases, IBD). La maladie débute sur un terrain génético-immunitaire prédisposant. Il s'agit de lésions discontinues et transmurales (= traversant l'entièreté de la paroi de l'intestin).

Ces lésions sont accompagnées d'ulcérations et de sténoses (causées par l'épaississement secondaire de la paroi).

La maladie évolue par poussées inflammatoires : diarrhées prolongées sur une durée majeure à 6 semaines, douleurs abdominales, atteintes anales et péri-anales.

La maladie de Crohn est connectée à des complications systémiques telles que la spondylarthrite ankylosante, la cholangite sclérosante, la stéatose hépatique et la lithiase tant biliaire que rénale. La lithiase est en particulier activée par la malabsorption des graisses.

Le diagnostic se pose par endoscopie et analyse anatomopathologique, la tomodensitométrie étant un examen de deuxième ligne pour distinguer les typologies de la manifestation clinique.

Le traitement routinier se base sur un contrôle du régime ainsi que des corticostéroïdes et d'autres immunosuppresseurs. Le traitement chirurgical est considéré en cas d'échec médicamenteux et ce pour réséquer les segments peu ou pas fonctionnels. 
Rectocolite ulcéro-hémorragique (RCUH) La rectocolite ulcéro-hémorragique (RCUH) fait partie des maladies inflammatoires chroniques de l'intestin (Inflammatory Bowel Diseases, IBD). Il s'agit d'une inflammation chronique de la muqueuse du rectum et du colon superficielle mais continue. La RCUH se présente avec du sang dans les selles, des ténesmes (besoin impérieux d'exonérer), des douleurs crampoïdes, de l'asthénie (fatigue), de la fièvre et des amaigrissements. Le diagnostic se pose par endoscopie et analyse anatomopathologique. Elle se traite par voie médicamenteuse (corticostéroïdes, immunosuppresseurs) ou par voie chirurgicale lors de l'échec médicamenteux ou lors de complications.

Entérocolites d'étiologies connues Les entérocolites sont des infections, causées par des bactéries (E. Coli, S. Aureus, Shigella, Salmonella, Campylobacter), par des virus (Rotavirus, Norwalk virus, CMV, Herpes), parasitaire (Giardia Lamblia, Schistosoma) et des champignons (Candida, Histoplasma, chez l'immunodéprimé surtout).

Les entérocolites invasives (avec atteinte de la muqueuse) atteignent surtout le colon, tandis que les entérocolites non invasives (sans atteinte de la muqueuse) atteignent le grêle.

La symptomatologie sera moins inquiétante lors des diarrhées non invasives (diarrhée non sanglante, nausée, vomissements) que lors des invasives (diarrhées sanglantes, douleurs abdominales, température). L'investigation se fait généralement par coproculture.

Diverticulose et diverticulite colique La diverticulose est une maladie caractérisée par la présence de diverticules des hernies de la muqueuse colique passant à travers des couches musculaire.

La diverticulite est l'inflammation du diverticule, pouvant causer des abcès, 


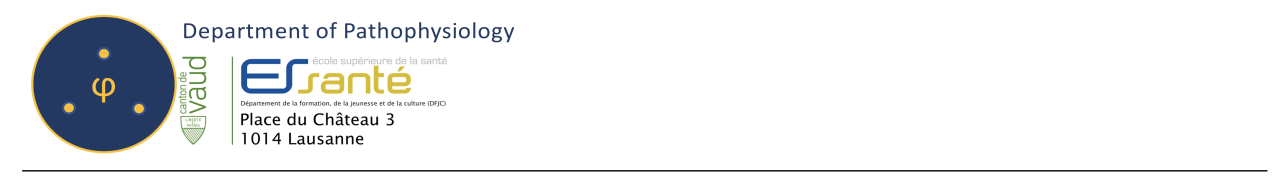

des sténoses ou des fistules. Le diverticule est causée par une hyperpression sur la paroi colique due le plus souvent à des troubles de la motricité intestinale et un régime pauvre en fibre.

Appendicite aigue Maladie très fréquente, l'appendicite est l'inflammation de l'appendice vermiforme caecale. Elle peut être causée par un corps étranger, une hyperplasie des follicules lymphoïde, un fécalome.

L'évolution se fait vers la péritonite. Elle se présente comme des douleurs abdominales localisées dans la fosse iliaque droite. L'appendicite se met en évidence via un examen clinique abdominal soigneux mais aussi à l'aide de la biologie sanguine (CRP) échographie et laparoscopie exploratrice.

Le traitement consiste en la résection et une antibiothérapie. Lors d'une péritonite, la séquestration liquidienne dans le péritoine due à l'inflammation cause une hypovolémie et un choc correspondant; ces caractères la rendent une urgence chirurgicale absolue.

\subsection{Foie et vésicule biliaire}

Le foie est le plus gros organes du corps $(1,5 \mathrm{~kg})$.

Il est essentiellement situé dans l'hypochondre droit mais il occupe également la région épigastrique et l'hypochondre gauche. Il intervient dans les phénomènes de digestion et d'absorption des lipides grâce aux sels biliaires, dans la détoxication, dans la synthèse des facteurs de coagulation, dans le stockage du glycogène, fer, cuivre, vitamines, dans l'élimination des bactéries et des globules rouges en fin de vie.

Il est rattaché au tube digestif via la veine porte, le cholédoque et l'artère hépatique propre.

Le foie présente une face diaphragmatique, ou seront visibles les ligaments 


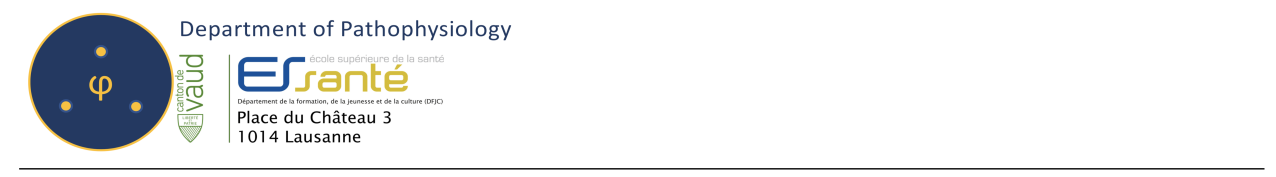

falciforme, coronaire et triangulaire et une face viscérale où seront visibles les empreintes pour les organes avoisinants (vésicule biliaire, estomac, colon ascendant).

Le foie présente une segmentation. L'axe passant par la vésicule biliaire et la veine cave inférieure divise les deux lobes gauche et droit du foie. Huit segments se suivent en sens horaire. La segmentation est utile pour le repérage lors de la chirurgie des métastases du foie.

La bilirubine est le résultat du catabolisme d'hémoprotéines, l'hémoglobine en particulier. La stercobiline est produite du métabolisme de la bilirubine par les bactéries intestinales, et est le pigment des matières fécales.

Les acides biliaires primitifs, l'acide cholique et chenodesoxycholique sont synthétisés par le foie à partir du cholestérol. Les acides lipophiles sont conjugués avec la glycine : les formes conjugués sont solubles dans l'eau mais contiennent donc un segment lipophile (micelles). Au pH neutre, ils sont ionisés et donc existent sous la forme de sels de cations (avec le sodium) : pour cette raisons, les acides biliaires sont appelés sels biliaires.

Des acides biliaires secondaires sont formés par déconjugaison et déhydroxylation par les bactéries intestinales : les deux sels formés sont l'acide désoxycholique et l'acide lithocholique (hépatotoxique et dès lors éliminé en conditions normales). Lorsque les sels biliaires se concentrent, ces dernières forment des complexes appelés micelles (partie hydrophile extérieure, partie hydrophobe à l'intérieur) : ils peuvent dès lors transporter des matières lipophiles au niveau de l'intestin. Les sels biliaires sont réabsorbés dans l'iléon distal et peuvent être recyclés : ce processus est appelé le cycle entérohépatique.

Le manque de réabsorption cause une stéatorrhée et des lithiases vésiculaires, puisque les graisses ne sont pas réabsorbées. Le fonctionnement microscopique du foie est focalisé sur l'acinus hépatique, de forme polyédrique et 


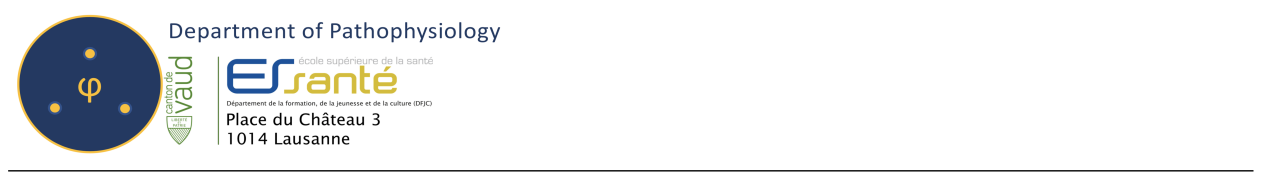

composé d'hépatocytes (cellules hépatiques) ainsi que de sinusoïdes veineux s'abouchant sur une veine centrale (conduisant le sang vers la veine sushépatique puis la veine cave inférieure), et des conduits biliaires allant vers le conduit hépatique.

Les conduits biliaires se regroupent en conduit hépatique droit et gauche, qui correspondent aux lobes du foie. Ils se réunissent pour former le conduit hépatique commun qui se réunit avec le canal cystique pour former le cholédoque, s'abouchant dans l'ampoule de Vater.

La vésicule biliaire est divisée en corps, fond, et col. Elle peut contenir 50 $\mathrm{ml}$ de bile.

Hyperbilirubinémie L'ictère est la couleur jaunâtre de la peau et d'autres tissus secondaire à des niveaux sanguins anormalement hauts de bilirubine, ou hyperbilirubinémie. Cette dernière n'est pas une pathologie mais plutôt un symptôme de trois groupes de pathologies.

L'hyperbilirubinémie pré-hépatique provient de la destruction excessive de globules rouges, caractéristique de l'anémie hémolytique. La fonction est normale mais elle est incapable de gérer la bilirubine en excès. Le nouveauné peut développer de façon physiologique un ictère après 2 ou 3 jours puisque son foie est immature : ce processus s'appelle l'ictère physiologique du nouveau-né.

L'hyperbilirubinémie intrahépatique provient d'un foie pathologique, par exemple lors d'une hépatite ou lors d'une cirrhose hépatique. La conjugaison de la bilirubine par les hépatocytes est défaillante.

L'hyperbilirubinémie post-hépatique est causée par l'obstruction des canaux hépatiques, ce qui cause un obstacle à l'excrétion de la bilirubine conjuguée. Des exemples de pathologie pouvant donner une hyperbilirubinémie post- 


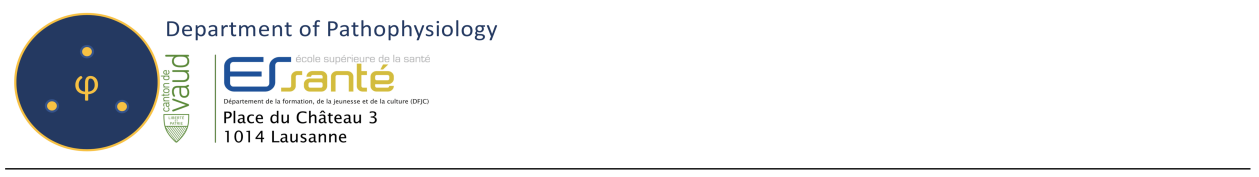

hépatique sont l'atrésie congénitale des conduits biliaires, l'obstruction par cholélithiase, l'inflammation du foie ou une tumeur.

Les niveaux de bilirubine non conjuguée sont élevés chez les individus avec hyperbilirubinémie pré-hépatique (puisque la bilirubine n'est pas encore passée par la conjugaison dans les hépatocytes). Les niveaux de bilirubine conjuguée sera élevée chez les individus avec hyperbilirubinémie posthépatique (puisque la bilirubine est déjà passée par la conjugaison dans les hépatocytes).

Le traitement d'une hyperbilirubinémie dépend de sa cause.

Hépatites Les hépatites sont des inflammations du foie. Elles peuvent être idiopathiques (foie stéatosique), infectieuses locales (hépatite virale) ou infectieuses dues à des infections ailleurs dans le corps (par exemple une mononucléose ou une amibiase). Au vu des nombreuses fonctions du foie, un dysfonctionnement de ce dernier cause des nombreux effets négatifs sur le reste du corps, mais heureusement, le pouvoir de régénération du foie est élevé.

Hépatites virales Les virus des hépatites A, B, C, D, E, et V causent les hépatites virales. D'autres types d'hépatites sont identifiées temporairement comme F, G et non-A et non E. Les cellules du foie sont endommagées de deux façons : par action directe du virus (hépatite C) ou par l'intermédiaire de la réponse immune contre le virus (hépatite B). Le degré d'inflammation et dégâts varie.

Hépatite A L'hépatite A est transmise par le cycle oro-fécal, souvent par des eaux contaminées, ainsi que des rapports sexuels. La période d'incubation est de 2 à 6 semaines. L'infection est aigue et ne se développe pas 


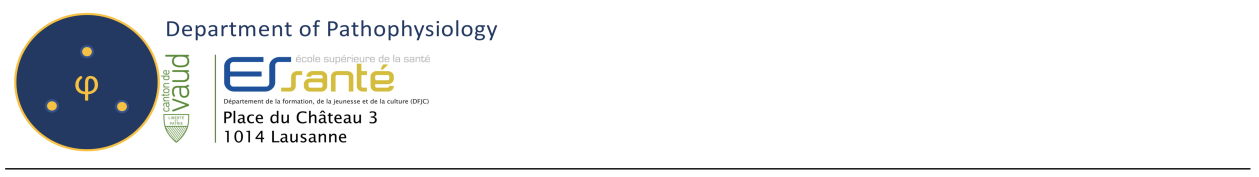

en une condition chronique. La période contagieuse précède l'état symptomatique et débute plusieurs semaines auparavant. A ce moment, les anticorps IgM-HAV apparaissent, suivis des IgG-HAV qui restent dans le sérum pendant des années et immunisent le sujet contre les infections futures. Un vaccin est disponible pour les sujets qui voyagent dans des zones endémiques ou des patients avec des pathologies hépatiques.

Hépatite B Le virus de l'hépatite B (HBV) est partiellement composé d'un $\mathrm{ADN}$ à double hélice; il contient trois antigènes, deux antigènes core, $\mathrm{HBcAg}$ et $\mathrm{HBeAg}$ et un antigène de surface, HBsAg. Chaque antigène stimule une production d'anticorps dans le sang, qui sont utilisés pour monitorer l'état de l'évolution clinique de l'hépatite. Par exemple, des grosses concentrations de HBsAg sont produites par les cellules infectées tôt dans l'évolution clinique de l'infection : cela signifie que l'infection est active ainsi que les dégâts hépatiques. La période d'incubation de l'hépatite B est long et dure environ 2 mois, ce qui complique l'investigation sur l'origine de la contamination. Le virus de l'hépatite B se transmet principalement par sang infecté (transfusions essentiellement, mais aussi des consommateurs de drogues intraveineuses) mais aussi par des secrétions corporelles (et donc via rapports sexuels). Les piercing et tatouages présentent également un risque de transmission du virus. L'HBV peut être transmis au foetus lors de la grossesse. Un vaccin de l'HBV existe pour une protection long terme, surtout pour les populations à haut risque comme les professionnels de la santé et est maintenant administré de façon routinière aux enfants. L'immunoglobuline HBV est aussi disponible comme mesure temporaire.

Hépatite C L'hépatite C est le type d'hépatite plus communément transmis via transfusion sanguine. Le virus de l'hépatite C (HCV) est un 


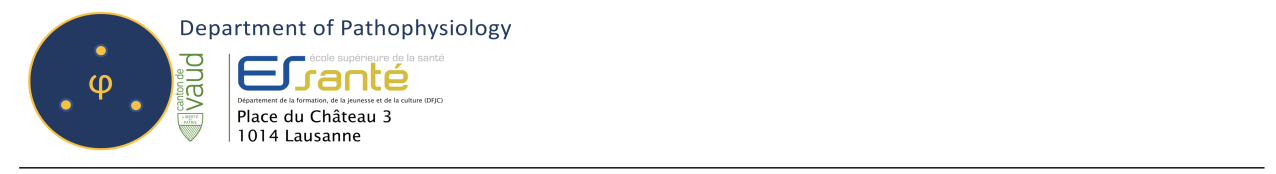

virus ARN simple brin. La moitié des patients infectés développe un état chronique. L'hépatite $\mathrm{C}$ augmente le risque de carcinome hépatocellulaire.

Hépatite D L'hépatite D est causée par un virus (HDV) ARN incomplet. La présence d'HBV (HBsAg) est indispensable pour la réplication et infection active.

Hépatite E L'hépatite E est causée par un virus (HEV) ARN simple brin et se propage via cycle oro-fécal. L'hépatite E est similaire à la A et est dépourvue d'un état chronique.

Manifestation clinique de l'hépatite L'état pré-ictérique est caractérisé par un début insidieux de fatigue et malaise, anorexie, nausée et douleurs musculaires ainsi que des douleurs dans l'hypochondre droit avec fièvre et maux de tête; cet état est caractérisé par la présence sérique de niveaux élevés de aspartate aminotransférase (AST) et/ou alanine aminotransférase (ALT).

L'état ictérique est caractérisé par l'apparition de l'ictère (accompagné naturellement par des niveaux de bilirubinémie élevés dans le sérum). Une hépatomégalie douloureuse peut être retrouvée, et la synthèse de facteurs de coagulation est ralentie. Ce stade dure plus longtemps chez les patients atteints d'hépatite B.

L'état post-ictérique est caractérisé par une diminution des signes cliniques. En moyenne, l'état aigu de l'hépatite A dure 10 semaines tandis que celui de l'hépatite $\mathrm{B}$ dure en moyenne 16 semaines. Les hépatites $\mathrm{B}$ et $\mathrm{C}$ chroniques peuvent être traitées par interféron alpha et lamivudine pour diminuer la réplication virale, mais le traitement est efficace chez maximum $40 \%$ des patients. Une combinaison de Ribavirin avec interféron a réduit la 


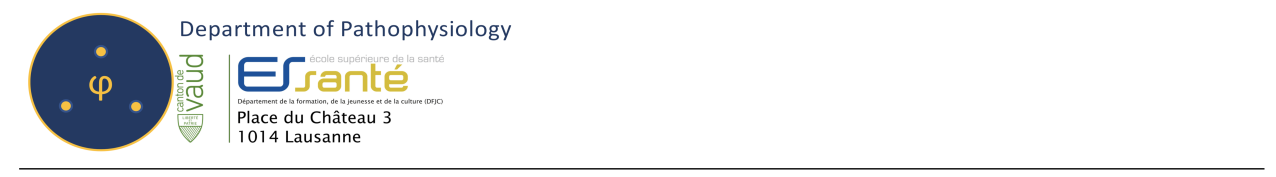

réplication de virus chez $80 \%$ des patients HCV. Dans les autres cas, une destruction progressive du foie se présente et conduit à une cirrhose ou un cancer hépatocellulaire.

Cirrhose La cirrhose est une maladie de destruction progressive du foie conduisant à une insuffisance hépatique quand $80 \%$ du foie est détruit. Les changements structurels sont liés à quatre catégories : les hépatites alcooliques, les cirrhoses biliaires, la cirrhose post nécrotique, l'hépatite métabolique, et l'hépatite stéatosique non alcoolique (NASH).

Histologiquement, la cirrhose se distingue par une fibrose diffuse et une perte de l'organisation des hépatocytes. Chez les patients avec une hépatite alcoolique (ainsi que la NASH), le premier changement est l'accumulation de graisses dans les hépatocytes, causant une stéatose hépatique alcoolique, suivie d'une nécrose cellulaire.

Les patients avec cirrhoses présentent une première vague d'effets de perte fonctionnelle : il existe en effet une altération importante de la conjugaison de la bilirubine (ictère), la production de la bile, la digestion des nutriments (fatigue, anorexie, mal digestion, perte de poids), la production des facteurs de coagulation et protéines plasmatiques, le métabolismes du glucose, le stockage de fer et vitamine B12 - K (saignement augmenté, purpura), les hormones aldostérone (œdème généralisé) et œstrogènes (gynécomastie, impotence, menstruations irrégulières) et l'excrétion de toxiques (leucopénie, thrombocytopénie, encéphalopathie hépatique, confusion, coma).

La deuxième série d'effets est causée par le manque d'écoulement de la bile : l'accumulation de la bile cause un ictère obstructif, bloquant l'arrivée du sang au foie et causant une hypertension portale, ce qui cause une ascite, une splénomégalie et des varices œesophagiennes par augmentation de la pres- 


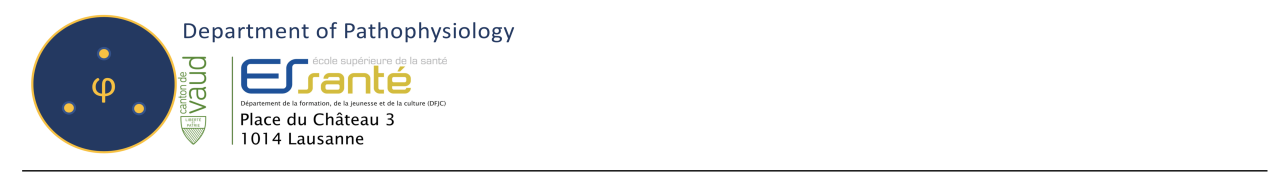

sion hydrostatique intravasculaire.

Cholélithiase et cholécystite La cholélithiase est la formation de calculs (calculi en latin) dans la vésicule biliaire. La cholécystite est l'inflammation de la vésicule biliaire et le conduit cystique.

Les calculs se forment à partir de cholestérol et bilirubine. Ils surviennent deux fois plus fréquemment chez les femmes, et plus fréquemment chez les individus ingérant d'importantes quantités de cholestérol. La lithiase biliaire est souvent asymptomatique, mais des gros calculs peuvent obstruer les conduits et causer des coliques (intervalles douloureux) dans l'hypochondre droit, accompagnée de nausées et vomissements.

Une inflammation importante et secondaire à l'obstruction cause la cholécystite aigue.

Le traitement se fait par voie chirurgicale en réséquant la vésicule biliaire.

\subsection{Pancréas}

Anatomie et physiologie pancréatique Le pancréas est une glande exocrine et endocrine. Il est divisé en quatre parties.

La tête est située à droite de l'aorte abdominale, est encadrée par le duodénum et présente le processus uncinatus inférieurement (aussi appelé le crochet du pancréas). Le col (ou isthme) pancréatique est aussi situé à droite de l'aorte ; le corps et la queue du pancréas sont situés à gauche de l'aorte.

La fonction exocrine du pancréas sert à la production d'inhibiteurs de trypsine (enzyme empêchant l'activation de trypsine dans le conduit pancréatique pour éviter l'autodigestion), la lipase pancréatique (pour digérer les gouttelettes de lipides dans les micelles formées par les sels biliaires) et les protéases pancréatiques (dont la trypsine, qui est une endopeptidase). 


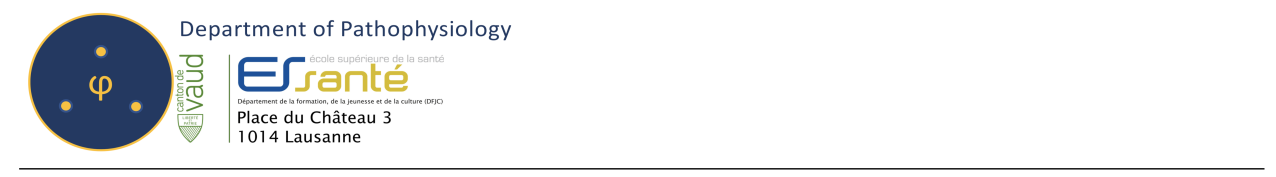

Il existe trois types différents de cellules décrites en histologie pancréatique : ces types de cellules sont souvent regroupées pour former des îlots pancréatiques. Les cellules delta constituent la plus petite proportion de cellules des îlots pancréatiques (5\%), sont situées entre des cellules alpha et beta et sécrètent de la somatostatine, une hormone qui inhibe les processus de sécrétion. Les cellules bêta représentent $75 \%$ des cellules des îlots pancréatiques. Le produit de sécrétion est la préproinsuline, qui forme la proinsuline, qui est divisée pour produire l'insuline et le peptide C.

Les cellules alpha constituent $20 \%$ des cellules des îlots pancréatiques : elles sécrètent du glucagon.

Le flux sanguin rejoint d'abord les cellules bêta, récupère l'insuline, et rejoins les cellules alpha où l'insuline peut inhiber la sécrétion de glucagon. L'insuline phosphoryle les récepteurs qu'elle occupe et d'autres protéines pour faciliter l'absorption de glucose par certains tissus : des transporteurs de glucose sont alors inclus dans les membranes. Les tissus concernés sont principalement le tissu adipeux, le tissu musculaire au repos (en activité, le glucose entre tout seul), et le foie. Le tissu nerveux, le rein, l'intestin, les globules rouges et les cellules bêta du pancréas n'ont pas besoin de l'insuline pour absorber le glucose. L'insuline augmente le métabolisme du glucose dans les muscles et la graisse (c'est-à-dire, sa conversion en CO2 et eau), elle augmente la synthèse de glycogène, et diminue l'activité des enzymes qui clivent le glucose. L'insuline augmente la synthèse et l'absorption des protéines et lipides et en diminue la consommation (protéolyse et lipolyse). L'insuline stimule donc la lipogenèse en utilisant le glucose absorbé. L'insuline augmente aussi l'absorption du potassium dans les cellules en augmentant également l'activité de la pompe sodium potassium (et elle est donc utilisé lors des hyperkaliémies sévères). 


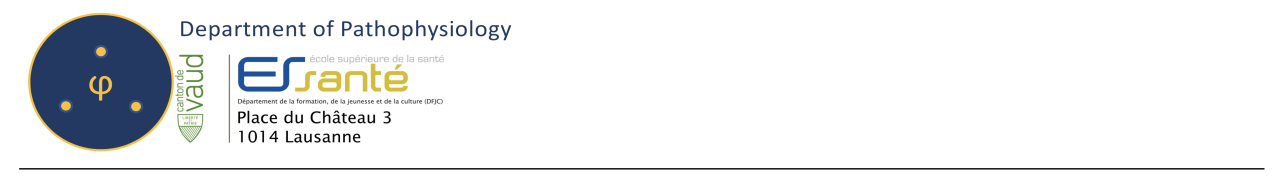

La somatostatine et la stimulation orthosympathique (via noradrénaline) inhibent la sécrétion d'insuline. Le niveau de glucose dans le sang, l'arginine, le glucagon, et les incrétines (peptide inhibiteur gastrique GIP et glucagonlike peptide GLP) augmentent la sécrétion d'insuline.

Le glucagon est un hormone peptidique agissant sur l'hépatocyte. Le glucagon augmente la glycogénolyse, augmente la gluconéogenèse, augmente la cétogenèse, diminue la lipogenèse, augmente l'uréogenèse, augmente la sécrétion d'insuline, et augmente la lipolyse. La sécrétion du glucagon est stimulée par l'hypoglycémie et l'arginine, et est inhibée par l'hyperglycémie, l'insuline et la somatostatine.

Pancréatite La pancréatite est une inflammation du pancréas dérivée d'une autodigestion et peut avoir une forme aigue ou chronique.

L'alcool, l'obstruction du tractus biliaire, un cancer peuvent précipiter l'activation des enzymes pancréatiques dans le conduit pancréatique, ce qui cause l'autodigestion du tissu pancréatique, de la nécrose et inflammation sévère du pancréas.

L'inflammation s'étend et cause une hémorragie, un choc hypovolémique, une péritonite, une coagulation intravasculaire et un syndrome de détresse respiratoire de l'adulte.

La douleur est généralement épigastrique transfixiante augmentant lorsque le patient est couché. Les signes du choc sont une pression artérielle basse, pâleur, sueur, et tachycardie. Le diagnostic se pose par le dosage des lipases/amylases sériques. Le traitement se base sur l'arrêt de l'alimentation orale et des antidouleurs.

Diabète de type II Le diabète de type II représente environ $90 \%$ de tous les cas de diabète. Le sujet est généralement quinquagénaire, obèse 


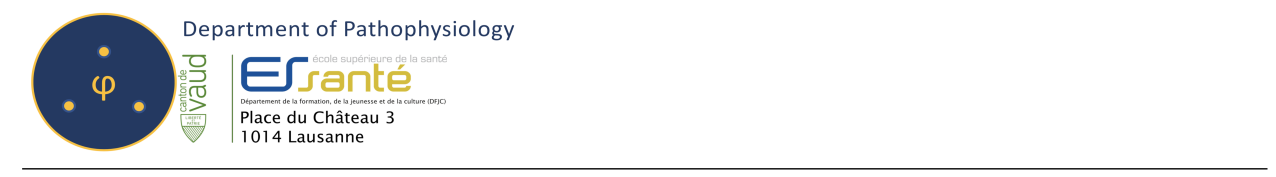

et possède une composante génétique. Le nombre de sujets jeunes avec un diabète de type II augmente néanmoins.

Le diabète de type II est caractérisé par une résistance aux effets de l'insuline, une sécrétion d'insuline diminuée, et une sécrétion augmentée de glucose hépatique. Le régime et le niveau d'activité physique influencent grandement cette pathologie et un contrôle des deux peut dans les cas débutants faire disparaître les symptômes du diabète et limiter sa progression.

Dans les étapes initiales, le déficit en insuline ou la résistance à l'insuline déclenchent une hyperglycémie par la diminution de l'absorption du glucose dans les cellules. Le glucose en excès est expulsé dans les urines (glycosurie), ce qui cause une augmentation de la pression osmotique dans ces dernières, attirant de l'eau, et causant la libération de grandes quantités d'urines (polyurie).

La déshydratation conséquente cause une soif (polydipsie) et le manque de glucose absorbé cause une augmentation de l'appétit (polyphagie). Si le déficit ou la résistance à l'insuline sont prolongés, une cétoacidose diabétique s'installe : en effet, le déficit de glucose dans les cellules cause une augmentation du catabolisme des graisses et protéines, ce qui augmente la concentration de leurs métabolites, les corps cétoniques, dont le $\mathrm{pH}$ est acide. Les corps cétoniques sont secrétés dans les urines (cétonurie) : suite à la déshydratation, l'excrétion rénale diminue et la cétoacidose ne sera plus compensée, causant une acidose métabolique décompensée. Cette dernière peut causer un coma diabétique et a des conséquences engageant le pronostic vital.

Les sujets diabétiques gagnent généralement du poids, présentent de la fatigue, de la polyurie, polydipsie et polyphagie. Les complications directes du diabètes sont l'hypoglycémie : le manque de glucose affecte directement le 


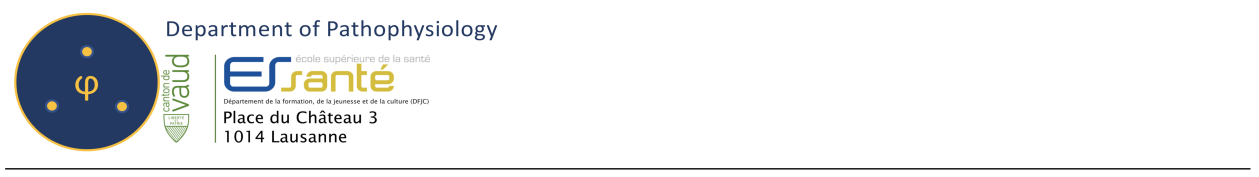

système nerveux central. Les symptômes principaux sont la baisse de concentration, langage perturbé et manque de coordination. Le système nerveux périphérique est aussi touché et le patient présentera une augmentation du rythme cardiaque, pâleur, anxiété, transpiration, tremblements et perte de conscience (dans les hypoglycémies plus sévères).

Les macroangiopathies sont des complications chroniques du diabète de type II, ayant comme conséquences des infarctus myocardiques, des accidents vasculaires cérébraux et des maladies vasculaires systémiques comme la gangrène (surtout dans les membres inférieurs), de l'hypertension : le mécanisme principal est l'athérosclérose modifiant la paroi des artères.

Les microangiopathies font aussi partie des conséquences chroniques : la néphropathie diabétique, la rétinopathie oculaire et neuropathies (causant une baisse de la sensibilité et motricité ainsi que les fonctions autonomes) sont causées par l'augmentation de l'épaisseur des parois capillaires. La guérison des plaies est perturbée et les infections sont plus fréquentes et sévères.

Le diagnostic du diabète se fait par le dosage de la glycémie à jeun.

Le traitement du diabète se fait par des antidiabétiques oraux ou par insuline.

\section{Physiopathologie urinaire}

\subsection{Anatomie et physiologie urinaire}

Le rôle principal du système urinaire est de maintenir l'homéostasie par rapport au volume et composition des liquides corporels et du sang; ce rôle est accompli par les reins. Les reins filtrent de grosses quantité de liquides à partir du sang et éliminent les déchets nitrés, les médicaments et toxines 


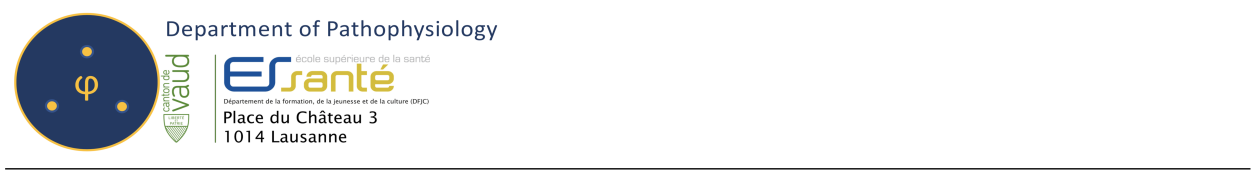

(filtration et excrétion). En régulant la balance eau-sels, les reins gardent un volume optimal de sang dans le corps. Les reins régulent aussi le $\mathrm{pH}$ en équilibrant les ions hydrogène avec des tampons (et ce avec le système respiratoire). Le rein produit également l'enzyme rénine (dans le système rénine angiotensine aldostérone, SRAA) qui permet d'ajuster la pression sanguine et la pression de filtration. Le rein produit aussi l'érythropoiétine (EPO, hormone pour stimuler la production de globules rouges dans la moelle osseuse rouge), et la vitamine $\mathrm{D}$ (conversion en forme active, pour le développement normal des os et dents, ainsi que le contrôle du calcium et phosphore).

Les reins sont des organes paires situés postérieurement dans la cavité abdominale. Le rein mesure en moyenne $11 \mathrm{~cm}$ de long, $6 \mathrm{~cm}$ de large et 2,5 $\mathrm{cm}$ en épaisseur. Le rein gauche est situé supérieurement au droit à cause du développement du foie. Le rein présente un hile au bord médial : il s'agit du lieu du passage de l'artère rénale, de la veine rénale et du lieu de sortie l'uretère. Intérieurement, le rein est composé essentiellement d'un cortex et d'une médullaire.

Le cortex est la partie périphérique, où sont retrouvés les tubes excréteurs et une partie des tubes collecteurs ainsi que les colonnes rénales, s'alternant entre les pyramides.

La médullaire est la partie interne, où sont retrouvés les tubes collecteurs et les pyramides rénales alternées aux colonnes du cortex. Les tubes déversent l'urine dans les calices mineurs. Les calices mineurs se regroupent pour former un calice majeur (2-3 calices mineurs pour un calice majeur), les calices majeurs se réunissent pour former le bassinet se terminant dans l'uretère (2-3 calices majeurs).

Le rein est surmonté par la glande surrénale dont la partie corticale sécrète des corticostéroïdes et androgènes et la partie médullaire de la glande surrénale 


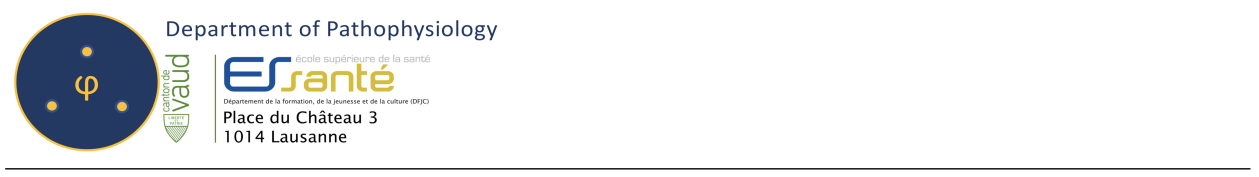

sécrète l'adrénaline et la noradrénaline.

L'unité fonctionnelle du rein est le néphron. Le néphron débute par la capsule glomérulaire de Bowman (globe avec une double membrane). Une couche pariétale et viscérale de la capsule de Bowman forment la membrane endothéliale capsulaire, lieu de filtration de l'eau et solutés.

Les deux pressions importantes pour la filtration glomérulaire sont la pression dans l'artériole afférente (celle qui amène le sang à filtrer à la capsule de Bowman) et la pression dans l'artériole efférente (celle qui récupère le sang filtré par la capsule de Bowman).

Lorsque l'artériole afférente est dilatée, le flux sanguin augmente : la pression hydrostatique dans le glomérule augmente (puisque la différence de pression entre l'artériole efférente et l'artériole afférente est positive), ce qui permet d'augmenter la quantité de sang filtré.

Lorsque l'artériole efférente est constrictée, la pression hydrostatique glomérulaire augmente également (la pression dans l'artériole efférente augmente, ce qui rend la différence de pression entre l'artère efférente et afférente positive) et la filtration augmente.

Lorsque l'artériole afférente est constrictée, la différence de pression entre l'artériole efférente et afférente diminue (puisque la pression augmente localement dans l'artère afférente), et la filtration diminue.

Lorsque l'artériole efférente est dilatée, la différence de pression entre l'artériole efférente et afférente diminue (puisque la pression diminue localement dans l'artériole efférente), et la filtration diminue.

La clairance rénale est définie comme le volume virtuel de plasma débarrassé complètement d'une substance par unité de temps.

$$
C=\frac{U V}{P}
$$




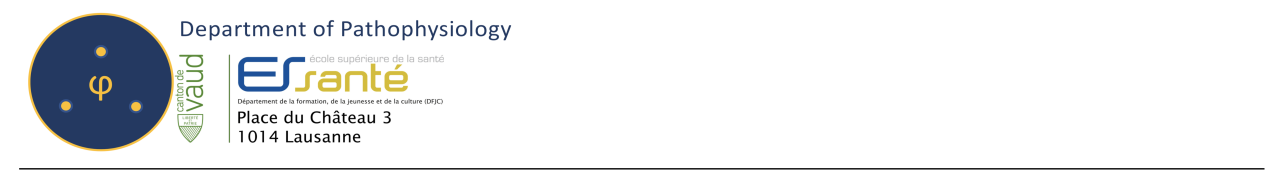

C est la clairance de la substance. U est la concentration urinaire de la substance. P est la concentration plasmatique de la substance. L'excrétion rénale se présente comme suit.

$$
\text { Excretion }=\text { Filtration }+ \text { Secretion }- \text { reabsorption }
$$

La clairance d'une substance illustre donc la fonction rénale. Pour la mesurer, il faut suivre une composante sanguine qui est filtrée, non réabsorbée et non sécrétée : le composé de choix est la créatinine (produit de dégradation de la créatine) en clinique, même si elle est sécrétée en petite quantités par le rein. Le dosage de créatinine surestime donc de peu la fonction rénale. Le rein filtre en moyenne $180 \mathrm{~L}$ de sang par $24 \mathrm{~h}$, donc $125 \mathrm{ml}$ par minute : ce dernier chiffre correspond of GFR (glomerular filtration rate, ou DFG en français pour débit de filtration glomérulaire).

L'appareil juxtaglomérulaire est une structure endocrine composée de la macula densa, cellules mésangiales extraglomérulaire et juxtaglomérulaires.

Les cellules juxtaglomérulaire répondent aux stimulations adrénergiques, à la diminution de la pression de perfusion rénale, détectée par les cellules à rénine, ainsi qu'à diminution de l'absorption du $\mathrm{NaCl}$ dans la macula densa (effet d'une diminution de la filtration glomérulaire).

Les cellules mésangiales extraglomérulaire produisent de l'EPO.

La macula densa détecte la concentration de $\mathrm{NaCl}$ pour le contrôle fin de la pression de filtration.

Le liquide filtré passe dans le tubule contourné proximal, ou se fait une grosse portion de l'absorption des ions.

Le segment suivant est l'anse de Henlé, où l'eau est absorbée.

Dans l'anse épaisse ascendante de Henlé des transporteurs supplémentaires 


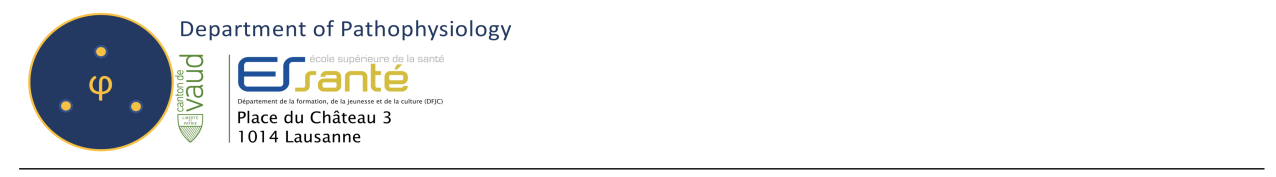

sont retrouvés qui absorbent les ions principaux.

Le tubule contourné distal et le tubule collecteur sont les étapes finales du trajet de l'urine.

La sécrétion d'ions se fait essentiellement lors du trajet distal.

La rénine est une enzyme qui convertit l'angiotensinogène en angiotensine I. L'enzyme de conversion de l'angiotensine (ACE) convertit l'angiotensine I en angiotensine II. La rénine est régulée par la pression de perfusion du rein : au plus la pression de perfusion augmente, au moins la rénine est sécrétée. La rénine est régulée par le système orthosympathique via les récepteurs $ß 1$. La rénine est régulée par l'apport de $\mathrm{Na}+$ à la macula densa.

L'angiotensine a un double effet : l'augmentation de la pression artérielle (ce qui inhibe l'action de l'appareil juxtaglomérulaire qui l'a activé en premier lieu) et la production de l'aldostérone via une action sur les cellules glomérulaires. L'angiotensine est inhibée par spironolactone.

L'aldostérone augmente la réabsorption de sodium au niveau du tubule contourné distal et du tubule collecteur en activant la pompe $\mathrm{Na}+/ \mathrm{K}+$ ATPase et augmente le transport des canaux sodium endothéliaux (ENaC). En augmentant la réabsorption du sodium, la réabsorption augmente aussi. En revanche, ces mécanismes augmentent l'excrétion urinaire de potassium et d'ions hydrogènes, et la production de bicarbonate, ce qui induit une hypokaliémie et une acidose métabolique.

Les uretères sont des conduits musculomembraneux permettant aux urines de circuler depuis le rein jusque la vessie. Ils mesurent $30 \mathrm{~cm}$ de long et sont divisés en une partie lombaire et une partie pelvienne, selon la région qu'ils traversent. Le trajet des uretères est en crosse de hockey et postéroantérieur. Les uretères s'abouchent dans la vessie. La vessie urinaire est un réservoir de $300 \mathrm{ml}$, située immédiatement derrière le pubis et est antérieure 


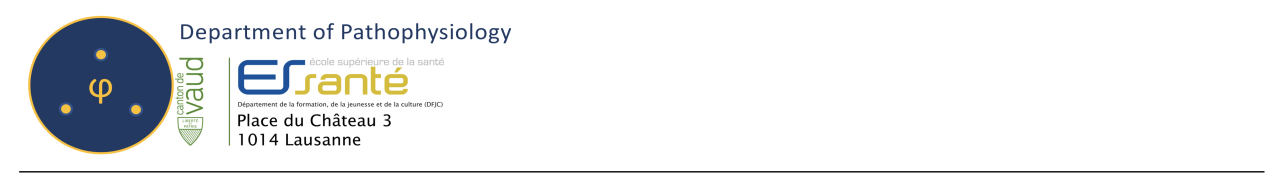

dans la cavité pelvienne. Chez la femme, l'utérus se situe derrière la vessie, chez l'homme c'est le rectum qui a un rapport postérieur direct avec la vessie. Le trigone de Lieutaud est le trigone formé par les trois orifices : deux orifices symétriques pour les uretères et un orifice de sortie pour l'urètre. La vessie est pourvue d'un muscle Detrusor urinaire qui est formé d'une couche longitudinale externe, une circulaire moyenne et une longitudinale externe. L'urètre est le segment terminal du système urinaire. Chez l'homme, il mesure $20 \mathrm{~cm}$ et il est divisé en urètre préprostatique (avant la prostate), prostatique (traverse la prostate), intermédiaire et spongieux. Chez la femme, l'urètre descend de manière rectiligne oblique inféro-antérieurement et parallèlement au vagin qui lui est postérieur.

\subsection{Néphrosclérose}

La néphrosclérose est la conséquence rénale de l'hypertension, similaire à l'athérosclérose. L'hypertension cause une diminution du flux sanguin dans les néphrons, ce qui cause une diminution de la filtration glomérulaire. Cette dernière stimule le système rénine angiotensine aldostérone (rénine est régulée finement par la pression de filtration), ce qui aggrave la vasoconstriction systémique et cause une rétention d'eau et sels. La vasoconstriction et rétention des sels augmentent le volume total de sang circulant et donc l'hypertension (causant un cercle vicieux). La diminution du flux sanguin au rein cause une ischémie du tissu rénal sur fond chronique, ce qui entrainera à long terme une insuffisance rénale chronique.

\subsection{Insuffisance rénale aigue}

L'insuffisance rénale aigue est due à trois catégories de causes principales : néphrotoxicité, ischémie et pyélonéphrite. Le symptôme principal sera 


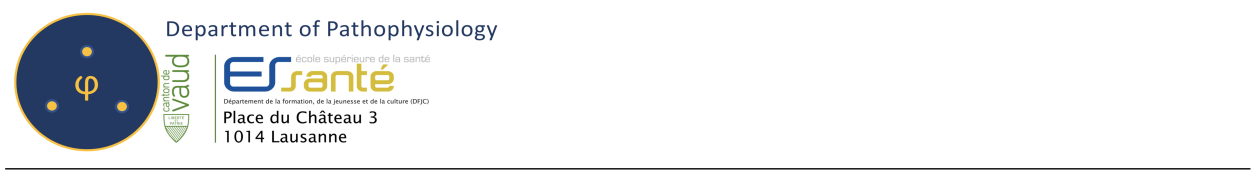

l'oligurie (absence d'excrétion d'urine). La néphrotoxicité est une oligurie dysfonctionnelle causée par des substances toxiques aux reins : notamment certains médicaments (anti-inflammatoires non stéroïdiens, acétaminophène, aspirine, pénicilline). Les toxines causent une obstruction du flux sanguin, au même titre qu'une lithiase rénale. L'ischémie peut être causée par un choc cardiovasculaire (manque de perfusion des organes), dû à une insuffisance cardiaque. Le rein est en effet le premier des organes dont le flux sanguin sera coupé lors d'une insuffisance cardiaque prolongée. La pyélonéphrite est une infection rénale caractérisée par des abcès et un tableau clinique particulier : le traitement se fait par antibiotiques. Le marqueur clinique à observer idéalement est le Blood Urea Nitrogen (BUN) qui augmente dès l'arrêt de fonction rénale. En pratique, la créatinine augmente en retard et de façon moindre. Une distinction ultérieure existe pour l'insuffisance rénale aigue en mettant en avant le lieu du dysfonctionnement : pré-rénale (interruption du flux vasculaire), intra-rénale (ischémie ou dysfonctionnement parenchymateux comme lors de la pyélonéphrite), et post-rénale (lors d'une lithiase).

\subsection{Insuffisance rénale chronique}

L'insuffisance rénale chronique est la destruction irréversible et chronique du rein. Elle peut résulter d'une maladie génétique comme la maladie rénale polykystique (des kystes se développent sur le parenchyme rénal ce qui empêche la filtration normale) ou secondaire à l'hypertension (comme dans le cas de la néphrosclérose). Lors du stade précoce (jusqu'à 60\% de néphrons perdus) on n'observe pas de changements fonctionnels). Lors du stade d'insuffisance rénale (jusqu'à $75 \%$ de néphrons perdus), des changements dans la chimie sanguine sont observés : le GFR diminue d'environs $20 \%$, et l'urée et créatinine augmentent. Les tubules n'arrivent pas à concen- 


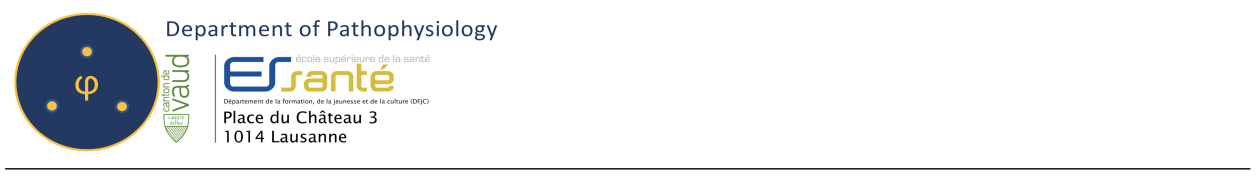

trer l'urine, ce qui induit l'excrétion de larges quantités d'urine. L'insuffisance rénale au stade terminale (i 90\% de néphrons perdus), le GFR est presque nul ou nul; le patient doit recourir à une dialyse (filtration artificielle du sang par une machine) ou à une transplantation rénale. Les signes généraux précoces sont la fatigue, l'anorexie, la nausée, l'anémie (manque de production de EPO), perte de poids, intolérance à l'exercice, nycturie, polyurie, pression artérielle élevée (compensation du manque de filtration). Les signes de la maladie terminales sont appelées signes urémiques et comprennent : oligurie, peau hyper pigmentée, neuropathie périphérique, impotence et irrégularités menstruelles, encéphalopathies, insuffisance cardiaque congestive (surcharge de liquides), arythmies. Le rein ne peut pas activer la vitamine D pour l'absorption du calcium, ce qui cause une augmentation du niveau de parathormone causant une déminéralisation osseuse pour mettre en circulation plus de calcium.

\section{Physiopathologie neurologique}

\subsection{Neuroanatomie et neurophysiologie}

L'étude anatomique du cerveau nécessite un repérage différent de celui commun aux autres régions anatomiques. Le cerveau présente un axe longitudinal le traversant.

Ainsi, dans le cerveau, les axes antérieur, postérieur, supérieur et inférieur, latéral et médial sont toujours d'applications, viennent s'ajouter les synonymes rostral (antérieur), caudal (postérieur), ventral (inférieur au plan perpendiculaire à l'axe longitudinal du cerveau) et dorsal (supérieur au plan perpendiculaire à l'axe longitudinal du cerveau). La moelle épinière est aussi traversée longitudinalement par un axe virtuel : le plan perpendiculaire à 
cet axe divise la moelle en une partie ventrale (antérieure) et une partie dorsale (postérieure). Ce qui est supérieur est crânial ou rostral, et ce qui est inférieur est caudal.

Caudalement à rostralement sont retrouvés pour le système nerveux : la moelle épinière, le tronc cérébral (bulbe, protubérance, bulbe) et le cervelet (postérieur à la protubérance). Le bulbe est aussi appelé moelle allongée ou medulla oblungata et la protubérance est aussi appelée pont ou pons. Rostralement au tronc cérébral sont retrouvés le diencéphale (hypothalamus, thalamus, épithalamus ou épiphyse ou glande pinéale), et le télencéphale (aussi appelé cerveau ou cerebrum, composé des lobes frontaux, pariétaux, occipitaux, temporaux et insulaires). Pour rappel, la substance grise contient les corps cellulaires des neurones, la substance blanche contient les axones et le cerveau est composé de substance grise superficiellement, substance blanche intérieurement

Hémisphères cérébraux Un gyrus (pluriel : gyri) est une crête des hémisphères cérébraux.

Un sulcus (pluriel : sulci) est un sillon des hémisphères cérébraux.

La scissure de Sylvius est une scissure latérale séparant le lobe temporal des lobes frontaux et pariétaux.

Le sulcus central ou Scissure de Rolando est une scissure verticale séparant le lobe frontal du lobe pariétal.

Le sulcus pariéto-occipital est une scissure oblique séparant le lobe occipital des lobes pariétaux.

Les hémisphères sont divisés en lobes.

Les lobes se subdivisent en aires de Brodmann, chaque aire est responsable 


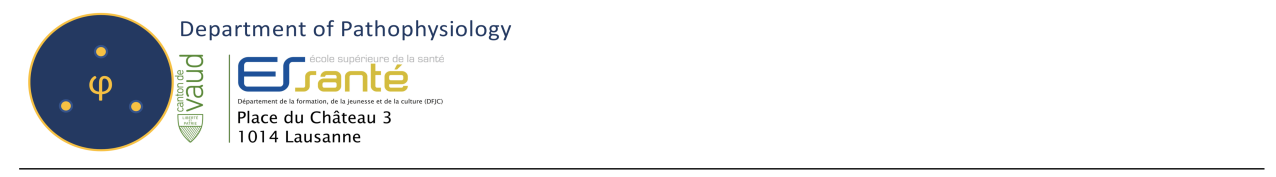

d'une fonction spécifique, primaire ou associative (regroupement et coordination d'informations).

Le lobe frontal est composé de plusieurs cortex.

Le cortex moteur primaire (gyrus précentral) est responsable du mapping moteur du coté controlatéral (hémisphère gauche est responsable de l'hémicorps droit). Un homunculus moteur peut être identifié en regard du cortex moteur primaire : chaque zone sera responsable d'une région de motricité.

Le cortex prémoteur est responsable de l'activation du cortex moteur primaire. Une lésion du cortex prémoteur induit une ataxie : il s'agit d'une interruption de l'exécution de mouvements moteurs appris ; les mouvements individuels seront corrects, mais les séquences de mouvement seront désordonnées. Le cortex préfrontal est localisé antérieurement au cortex prémoteur. Il est responsable de l'organisation et du planning du comportement émotionnel et intellectuel.

L'aire de Broca est responsable du stockage du vocabulaire linguistique. Une lésion de l'air de Broca entraine une aphasie de Broca, qui est une aphasie non fluente (le patient ne trouve pas les mots pour exprimer ce qu'il veut). Le cortex somatosensoriel présent dans le lobe pariétal est postérieur au sulcus central et contient le gyrus post central (homunculus sensitif), responsable du mapping sensitif de l'hémicorps controlatéral.

Une lésion du cortex somatosensoriel entraine une astéréognosie : il s'agit de l'impossibilité de distinguer les objets en les touchant.

L'aire de Wernicke est retrouvée dans la partie inférieure du lobe pariétal et dans la partie supérieure adjacente du lobe temporal. L'aire de Wernicke est responsable de la compréhension du langage parlé. Une lésion de l'aire de Wernicke entraine une aphasie de Wernicke (fluente) : le patient ne comprend pas ce qu'on lui dit et mène une discussion en enchainant des mots 


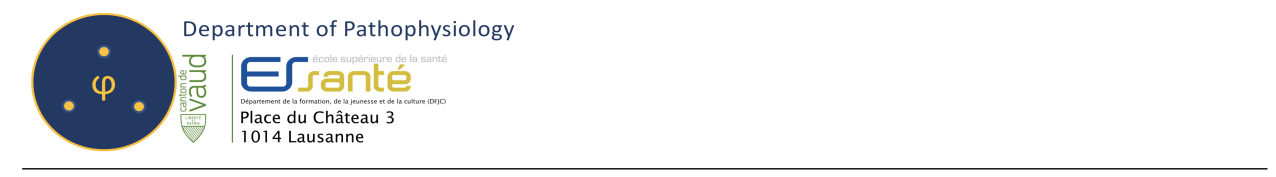

sans un sens logique.

Dans le lobe occipital, le cortex visuel primaire est responsable de gérer l'output visuel controlatéral. Une lésion unilatérale du cortex visuel primaire entraine une hémianopsie homonyme controlatérale (le patient ne voit pas le champ visuel de l'œil controlatéral).

Le lobe temporal contient le cortex auditif primaire et l'aire de Wernicke. Le corps calleux est essentiellement formé par les axones des neurones corticaux : il est situé entre les deux hémisphères et sert à transmettre l'information du cortex à la moelle épinière via le cortex cérébral.

Thalamus Le thalamus est le relai sensitif ascendant pour le tact, vision, audition et goût. Le relai est ascendant : il part de la moelle et se termine dans le cortex. Les ganglions de la base et le cervelet (motricité) font aussi des relais dans le thalamus. Le pulvinar est chargé de l'intégration visuelle, auditive et somesthésique.

Le corps géniculé médial reçoit un stimulus auditif du colliculus inférieur et le renvoie vers le cortex auditif primaire.

Le corps géniculé latéral reçoit un stimulus visuel provenant du le tractus optique et le renvoie vers le cortex visuel primaire.

Le noyau ventro-postéro-latéral reçoit un stimulus sensitif du corps et des membres et le renvoie vers le cortex somatosensoriel.

Le noyau ventro-postéro-médial reçoit un stimulus sensitif de la face, goût et le renvoie vers le cortex somatosensoriel. Le noyau médiodorsal est impliqué dans les processus de mémoire.

Les noyaux ventro-latéral et ventro-antérieur reçoivent le stimulus moteur depuis les noyaux de la base et le renvoient vers cortex somatosensoriel. 


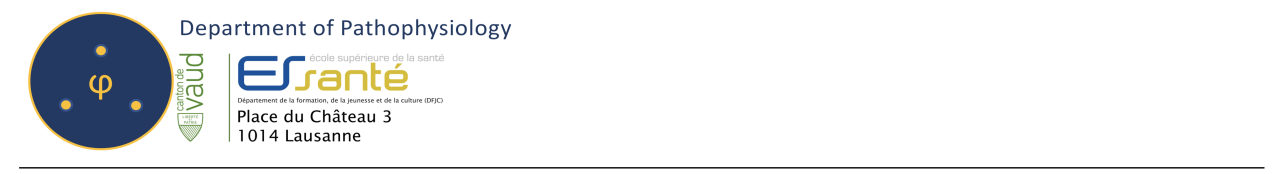

Le noyau antérieur reçoit le stimulus mémoire depuis le noyau mamillaire et le renvoie vers gyrus cingulé (ce relai fait partie du circuit de Papez).

Hypothalamus Le noyau latéral constitue le centre de la faim.

Le noyau ventro-médial est le centre de la satiété.

Le noyau suprachiasmatique est responsable du rythme circadien.

Le noyau supraoptique et le noyau paraventriculaire sont responsable de la stimulation de la sécrétion de l'ADH (hormone antidiurétique chargée de l'absorption de l'eau via porines dans le néphron) et de l'ocytocine (rôle dans l'accouchement et la lactation).

Les corps mamillaires participent au circuit de Papez.

Le noyau arqué est responsable de la production de facteurs stimulants et inhibiteurs hypothalamiques (neurones à dopamine).

Les régions postérieure et antérieure hypothalamiques sont responsables de la régulation température.

L'aire préoptique est responsable du relargage $\mathrm{GnRH}$ (hormone gonadotrophique pour le développement des gonades).

Le noyau dorsomédial est responsable du comportement sauvage.

L'épithalamus, aussi appelé glande pinéale est responsable de la sécrétion de mélatonine contribuant à la régulation du rythme circadien.

Le subthalamus est la localisation des circuits des noyaux de la base.

Ganglions de la base Le noyau caudé est supérieur.

Les noyaux pyramidaux sont intermédiaires et composés du : Putamen (externe), du Globus pallidus externe du Globus pallidus interne.

Le noyau basal de Meynert est inférieur. 


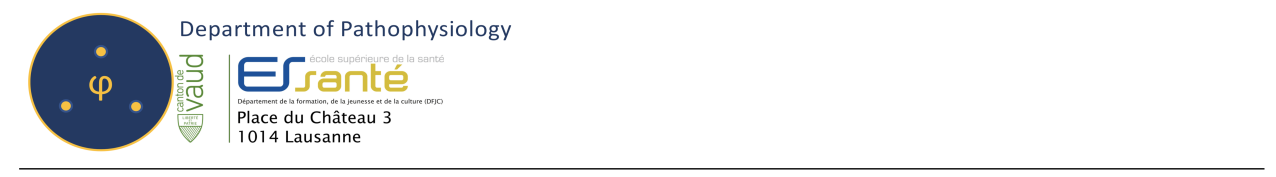

Entre le noyau caudé et les noyaux pyramidaux se trouve la capsule interne. La compréhension fonctionnement des ganglions de la base est indispensable pour comprendre la physiopathologie de la maladie de Parkinson.

Trois lobes sont retrouvés dans le cervelet : le lobe antérieur, le lobe flocculonodulaire et le lobe postérieur.

Le vermis est chargé de l'exécution motrice à partir de signaux de la moelle épinière.

Les hémisphères du cervelet sont chargés de la coordination/planning à partir des signaux du cortex cérébral et des noyaux olivaires.

Le lobe flocculonodulaire est chargé de l'équilibre et mouvements oculaires à partir des signaux provenant des noyaux vestibulaires (nerf crânien VIII vestibulo-cochléaire ou auditif).

Tronc cérébral Le mésencéphale est supérieur et présente différentes structures anatomiques : les pédoncules cérébraux, l'aqueduc de Sylvius (cérébral, allant vers le 4ème ventricule), le noyau du nerf crânien III (oculomoteur commun) et le noyau d'Edinger-Westphal, , le lemniscus médian (responsable de la voie lemniscale, signalant le tact discriminatif, vibratoire et proprioceptif), le tractus spinothalamique (responsable de la voie spinothalamique, chargée de la sensibilité thermo-algésique), le faisceau corticospinal et corticobulbaire (voie pyramidale du mouvement) et le faisceau longitudinal médian (trajets des nerfs crâniens oculomoteurs III, IV, VI). La protubérance présente supérieurement : le faisceau longitudinal médian (trajet des nerfs crâniens oculomoteurs III, IV, VI), le faisceau spinothalamique (pour la thermo-algésie), le lemniscus médian (pour le tact discriminatif proprioceptif vibratoire), les faisceaux corticospinal et corticobulbaire 


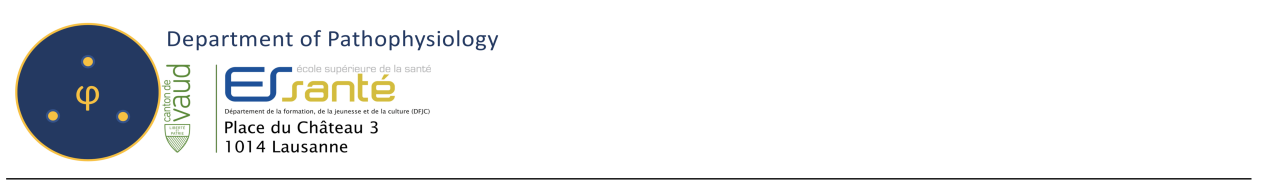

(pour la voie pyramidale du mouvement), le pédoncule cérébelleux supérieur, le 4ème ventricule, le noyau sensoriel et le noyau moteur du nerf crânien V (trijumeau).

Inférieurement, la protubérance présente : le noyau denté, le noyau des nerfs crâniens VI (oculomoteur externe) et VII (facial), et le noyau olivaire supérieur.

Le bulbe présente supérieurement : les noyaux du nerf crânien VIII (vestibulocochléaire ou auditif), le pédoncule cérébelleux inférieur, le faisceau longitudinal médian (pour les nerfs crâniens III, IV, VI oculomoteurs), le noyau du nerf crânien XII (hypoglosse), le faisceau spinothalamique (pour la thermoalgésie), le tractus spinal du nerf crânien VI (oculomoteur externe), les noyaux des nerfs crâniens X (vague) et XI (spinal ou accessoire), le noyau olivaire inférieur, la pyramide bulbaire (faisceau corticospinal), et le lemniscus médian (voie lemniscale pour le tact discriminatif, proprioceptif et vibratoire).

Inférieurement, le bulbe présente la décussation de la voie pyramidale.

Nerfs crâniens Les nerfs crâniens sont numérotés de I à XII :

Nerf I : Olfactif (S), passe par la lame criblée de l'os ethmoïde et est responsable de la sensibilité olfactive.

Nerf II : Optique (S) passe par le canal optique de l'os sphénoïde et est responsable de la sensibilité de la vision.

Nerf III : Oculomoteur commun (M).

Nerf IV : Abducens ou oculomoteur externe (M).

Nerf VI : Oculomoteur externe (M).

Les nerfs crâniens III, IV, VI passent dans fissure orbitaire supérieure de l'os 
sphénoïde avec le V1. Ils sont responsables du mouvement du globe oculaire Nerf V : Trijumeau (SM) est responsable de la sensibilité et motricité de la face et oropharynx. Il est subdivisé en trois nerfs différents.

V1 : Nerf Ophtalmique, passe avec les oculomoteurs.

V2 : Nerf Maxillaire, passe par le foramen rond de l'os sphénoïde.

V3 : Nerf Mandibulaire, passe par foramen ovale de l'os sphénoïde.

Nerf VII : Facial (SM) passe par le foramen stylomastoïdien de l'os temporal et est responsable de la motricité de la face et muscle stapédien ainsi que la sensibilité du V lingual.

Nerf VIII : Vestibulo-cochléaire ou Auditif (S) passe par méat acoustique interne dans l'os temporal et est responsable de la sensibilité de l'audition et reflexe vestibulo-oculaire.

Nerf IX : Glossopharyngien (SM) est responsable de la sensibilité derrière le V lingual et motricité de l'oropharynx.

Nerf X : Vague (SM) est responsable de la régulation autonome et phonation.

Nerf XI : Spinal ou Accessoire (M) est responsable de la motricité du muscle trapèze supérieur et scalène.

Les nerfs IX, X et XI passent dans le foramen jugulaire de l'os temporal.

Nerf XI : Hypoglosse (M) passe par le foramen hypoglosse de l'os occipital et est responsable de la motricité de la langue.

Moelle épinière La moelle épinière est formée de matière blanche externe et de matière grise interne (au contraire du cerveau).

La matière blanche est située dans les cordons postérieurs, intermédiaires et antérieurs. 


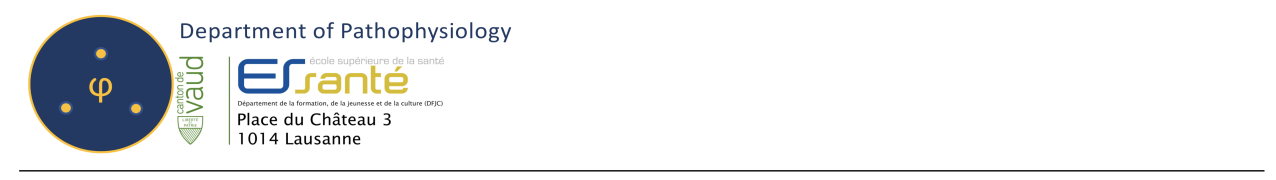

La matière grise est retrouvée dans les cornes ventrales et dorsales.

La transmission des signaux sensitifs a un parcours différent selon la localisation du neurone. La peau et muscles du dos et du cou envoient les signaux électriques vers le rameau dorsal, qui rejoint le ganglion dorsal, relié au cordon postérieur transmettant le signal à la corne postérieure (qui est sensitive). La peau et muscles du tronc antérieur et des membres font suivre le signal vers le rameau ventral, puis le ganglion dorsal, le cordon postérieur et la corne postérieure (sensitive). La corne postérieure envoie in fine le signal à la corne antérieure (qui a une fonction motrice), puis vers le rameau ventral et dorsal, reliés aux nerfs spinaux (31 paires) pour la motricité.

Méninges La dure mère colle avec le crane supérieurement. L'arachnoïde est interne à la dure mère, et la pie mère colle avec le cerveau et la moelle. Des espaces sont présents entre les méninges : épiduraux dans la moelle, sous duraux et arachnoïdien.

Neurophysiologie L'unité de base du système nerveux est le neurone, composé d'un corps neuronal ou soma, de dendrites (extrémités recevant le signal) et axone (extrémité envoyant le signal). Les neurones sont reliés par des synapses. Le potentiel d'action est le moyen de transmission des signaux dans le système nerveux. Le courant sodium dépolarise la membrane neuronale après avoir atteint un certain seuil (la membrane passe du repos à $-70 \mathrm{mV}$ au seuil de $-30 \mathrm{mV}$ ). Une synapse comporte différentes modifications de la forme du signal pour la transmission de l'information. Une cellule envoie l'information selon la méthode électrique du potentiel d'action. Une fois à la fente synaptique, le signal est sous forme chimique, pour se trans- 


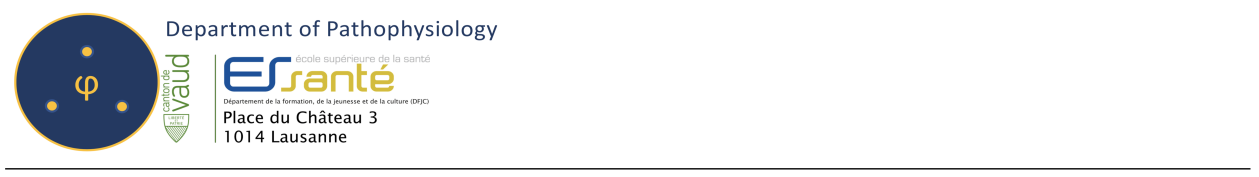

former de nouveau en électrique. On distingue donc les principaux acteurs de la synapse : les neuromédiateurs, les vésicules synaptiques, les récepteurs ligand-dépendants, et les canaux calcium voltage dépendants. La synapse compte cinque étapes.

Première étape - La dépolarisation : le potentiel se propage le long de l'axone, provoquant sur les terminaisons axonales, l'activation des canaux calcium voltage dépendants.

Deuxième étape - entrée de calcium. L'entrée de calcium dans la cellule est si importante à cause de sa quasi inexistante concentration intracellulaire : quelques ions sont suffisants pour faire augmenter la concentration.

Troisième étape - Fusion de vésicules synaptiques avec la membrane, et libération des neuromédiateurs dans l'espace synaptique.

Cette étape se fait en présence de calcium de la deuxième étape : les vésicules s'accrochent à la membrane et déversent leur contenu à l'extérieur. Cela est possible grâce à des protéines spécifiques attaches à la membrane cytoplasmique comme les Q-SNARE (qui contiennent la glutamine) dont la Syntaxine, et la SNAP-25, ce sont des doubles hélices, et les R-SNARE qui contiennent de l'arginine, dont on retrouve la synaptobrevine et la synaptotagmine, que l'on peut retrouver sous forme de simple helice. La synaptobrevine aide specifiquement en présence de calcium les autres hélices à fusionner avec la membrane.

Quatrième étape : les neuromédiateurs agissent sur les récepteurs spécifiques sur la membrane de l'autre neurone.

Cinquième étape : les récepteurs sont des canaux qui s'ouvrent quand le ligand se fixe, le mouvement des ions génère un courant qui se transforme en PA.

Les jonctions neuromusculaires se font entre un motoneurone et plusieurs 


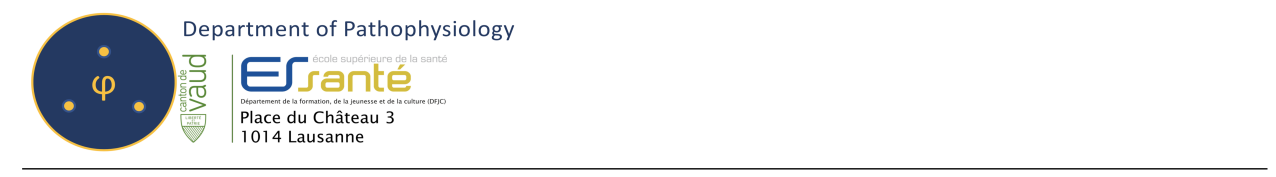

fibres musculaires auxquelles il est attaché. Il est clair qu'il faut stimuler de manière supra-maximale (au-dessus de la charge qu'il faut pour stimuler toutes les fibres) pour faire contracter le muscle entier, et étudier le comportement d'une fibre musculaire en particulier. La plaque motrice est l'ensemble des terminaisons axonales d'un neurone et la fibre musculaire à laquelle il est attaché. Le neuromédiateur pour la jonction neuromusculaire est l'acétylcholine. Elle se fixe sur un récepteur R-Nicotinique à l'acétylcholine. Quand le neuromédiateur se fixe, le canal s'ouvre et laisse passer des ions. Le potentiel de plaque motrice ou PPM est le potentiel présent si un canal cationique laisse passer le sodium et potassium : dure $15 \mathrm{~ms}$, divisé en deux parties, la dépolarisation dure $2 \mathrm{~ms}$ le reste est occupé par une repolarisation. On atteint une limite de potentiel qui est à mi-chemin entre les potentiels de repos des ions qu'il laisse passer. Pour $\mathrm{Na}+/ \mathrm{K}+$, il se situe à $-15 \mathrm{mV}$. La fin du PPM est en fait cachée par le potentiel d'action qu'il génère. La nicotine est une molécule agoniste de l'acétylcholine, et le curare est son antagoniste. Le curare empêche l'ouverture des canaux, ce qui cause la paralysie : il est utilisé dans les opérations chirurgicales.

Les canaux ligand-dépendants sont situés sur la plaque motrice de la fibre musculaire. Ils sont dépendants de l'ACh et quand ils s'ouvrent, ils laissent passer les ions pendant $2 \mathrm{~ms}$. Les ions qui passent sont le $\mathrm{Na}+$ et $\mathrm{K}+$ et entrainent la dépolarisation de la membrane jusqu'au potentiel d'équilibre de $-15 \mathrm{mV}$, une moyenne arithmétique des deux potentiels de repos des deux ions respectifs. Le retour au repos prend beaucoup plus de temps puisque le déchargement sur la résistance des canaux se fait pendant 13ms.

$\mathrm{Au}$ potentiel d'équilibre, il y a autant d'ions qui rentrent que d'ions qui sortent, ce qui entraine le fait que le courant soit nul. Le reste dépend du potentiel membranaire. Si le potentiel est situé à $-70 \mathrm{mV}$, le $\mathrm{Na}+$ rentre plus 
fort que le K sorte (puisque les charges négatives sont plus nombreuses), ce qui entraine une dépolarisation de la membrane et un courant rentrant. Si le potentiel est autour de -15 , le courant sera nul (potentiel d'équilibre). Si le potentiel est autour de +10 les $\mathrm{K}+$ sortent plus de ce que les $\mathrm{Na}+$ rentrent, un courant sortant et une repolarisation de la membrane seront obtenus.

Si on change les concentrations extracellulaires des ions qui passent par le canal $\mathrm{ACh}$, c'est à dire sodium et potassium, la relation linéaire entre le potentiel imposé et le courant sera déplacée à droite ou à gauche, car on varie le potentiel d'équilibre (où la droite rencontre l'axe des X).

Lorsqu'un PA arrive dans un motoneurone, il doit déclencher une contraction dans la fibre musculaire attachée. A l'extrémité d'un neurone 100 vésicules d'ACh sont libérées à chaque PA, dans chaque vésicule il y a 5000 molécules d'ACh, ce qui fait au total 500000 molécules d'ACh dans la fente synaptique. Sur les canaux à $\mathrm{ACh}$, il y a 40 millions de récepteurs, 1 seul desquels peut recevoir 2 molécules d'ACh : les molécules trouvent facilement la place.

La molécule d'ACh ne peut pas stimuler indéfiniment les récepteurs : après sa stimulation, elle est dégradée en deux morceaux, un acide acétique et une choline, par l'acétylcholinestérase. Si cette enzyme est inactivée, plusieurs potentiels d'action pour 1 seul potentiel de plaque motrice seront obtenus, ce qui causera des spasmes musculaires.

\subsection{Neuropathies}

\section{Caractéristiques électrophysiologiques de l'atteinte axonale et démyélinisante}

L'atteinte axonale est caractérisée par une diminution des amplitudes et une légère diminution des vitesses de conduction. L'atteinte démyélinisante est caractérisée par une forte diminution des vitesses de conduction (30 à 40\%) 


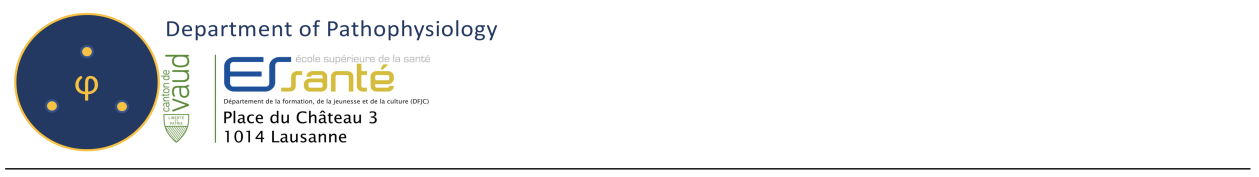

et une préservation des amplitudes de réponse. L'augmentation de la latence distale est l'augmentation du temps de réponse périphérique de la réponse musculaire, elle est observée dans les atteintes démyélinisantes. La dispersion temporelle, également présente dans les atteintes démyélinisantes est la dispersion des réponses musculaires enregistrées suites à la lésion du nerf qui crée des vitesses différentes. Le bloc de conduction, absence de réponse suite à une stimulation à un endroit défini du muscle, est présent lors d'une atteinte démyélinisante. La réponse $\mathrm{F}$ (ou onde $\mathrm{F}$ ) est la réponse tardive observée suite à la stimulation d'un axone : en stimulant au milieu d'un axone, la réponse primaire est celle allant de la zone de stimulation jusqu'en périphérie (réponse $\mathrm{F}$ ), tandis que la réponse $\mathrm{F}$ est la réponse tardive passant par le soma du neurone est redescendant l'axone. Cette onde est absente lors de l'atteinte démyélinisante d'un nerf. En résumé : l'atteinte axonale est caractérisée par une diminution des amplitudes, l'atteinte démyélinisante est caractérisée par une diminution de la vitesse de conduction, un bloc de conduction, une augmentation du temps de latence distale, une absence de l'onde $\mathrm{F}$ et une dispersion temporelle.

Amyloïdose familiale et acquise L'amyloïdose familiale est une maladie autosomique dominante avec une mutation de la transthyrétine (TTR) synthétisée dans le foie et les plexus choroïdes. Cette protéine mutante forme des dépôts de fibrilles d'amylö̈de dans le tissus graisseux, nerveux ou dans le rectum. Les dépôts favorisent l'accumulation de TTR, causant un cercle vicieux. Les symptômes se présentent dans l'âge moyen, avec un début de neuropathie périphérique et autonome, une cardiomyopathie et des opacités vitrées. Le traitement consiste essentiellement à une transplantation hépatique dès l'apparition des premiers symptômes de la maladie $(10 \%$ 


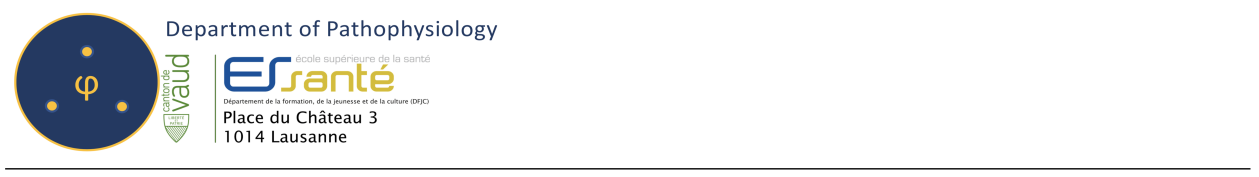

étant asymptomatiques on attend le début des symptômes). L'amyloïdose acquise est causée par des dépôts d'amyloïde causant une polyneuropathie périphérique et autonomique secondaire parmi d'autres signes (cardiomyopathie, hépatomégalie, protéinurie, macroglossie).

Neuropathie diabétique La neuropathie secondaire au diabète peut se présenter sous différentes formes. La neuropathie à prédominance sensitive s'étend au niveau des jambes, des mains et la partie antérieure du thorax en débutant au niveau des pieds (chaussettes), avec une aréflexie achilléenne. Si les petites fibres sont atteintes il y aura présence d'une altération de la température et de la douleur avec apparition d'ulcères, tandis que si les grosses fibres sont altérées le sens de position sera altéré. La neuropathie autonome peut se manifester avec des hypotensions, tachycardies, impuissance, anomalies de la miction, gastro parésie, diarrhées nocturnes. Le mécanisme de toxicité du diabète sur les nerfs est complexe et comprend différentes voies dont une voie métabolique (hyperglycémie et stress oxydatif, entrainant une pseudo-hypoxie et dysfonctionnement du nerf), une voie vasculaire (formation de plaque d'athérome dans vaisseaux vascularisant des nerfs) et une voie immunitaire (vasculites, provoquant une diminution du flux de sang destiné aux nerfs). Les fibres atteintes sont surtout celles de petit calibre. La neuropathie diabétique est liée au degré d'hyperglycémie. Un traitement intensif permet de diminuer les symptômes neurologiques.

Syndrome de Guillain-Barré Le syndrome de Guillain Barré consiste en une atteinte immunitaire aigue à évolution monophasique précédée dans 2/3 des cas par des antécédents d'infection (C. Jejuni, CMV, EBV, Mycoplasme ou HIV). Il s'agit d'une polyradiculonévrite aigue inflammatoire démyélinisante ou d'une neuropathie aigue motrice axonale. La gaine de 


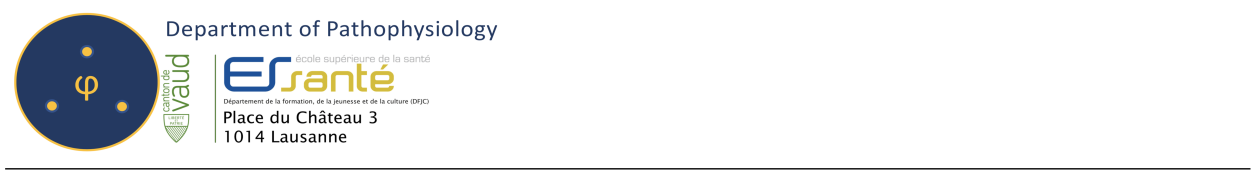

myéline est détruite par les anticorps, les lymphocytes $\mathrm{T}$ attaquant les peptides de la myéline ou par le système du complément dans une forme typique. La forme axonale est caractérisée par une destruction de l'axone par des anticorps sur le nœud de Ranvier ou par des macrophages envahissant le nœud. Les symptômes sont différents selon l'atteinte : par exemple, lors de la forme axonale Miller Fisher G1Qb détruit le nerf oculomoteur ou le nerf optique. Le traitement se fait par immunothérapie (plasmaphérèse/injection d'Ig intraveineuses) et accélère la récupération du syndrome en diminuant le temps de séjour en soins intensifs. Le risque principal de mort est dû à l'arrêt respiratoire.

Maladie de Charcot Marie Tooth La neuropathie de Charcot Marie Tooth (CMT) de type 1 est une neuropathie démyélinisante sensorimotrice (HMSN, neuropathie sensorimotrice héréditaire), caractérisée par une vitesse de conduction inférieure à $38 \mathrm{~m} / \mathrm{s}$. A caractère autosomique dominant, les gènes le plus souvent mutés se trouvent sur le chromosome 17 (17p11.2) codant pour la protéine PMP 22 (CMT1A), ou sur le chromosome 1q21-23 (CMT1B) codant pour la protéine MPZ, responsable de la compaction de la myéline et interagissant physiquement avec PMP22. La surexpression de l'une par rapport à l'autre due à la mutation du gène cause un défaut de compaction de la myéline responsable de la maladie.

La CMT1 débute le plus souvent durant la première décade de vie (75\%), et elle est rarement asymptomatique pendant la 3ème décade. Les symptômes initiaux sont des troubles de la marche, déformation du pied. Les signes plus fréquents sont l'aréflexie des membres inférieures chez la totalité des patients, la marche sur talon perturbée, l'atrophie des muscles du pied, l'hypertrophie des nerfs, le pes cavus et des tendons d'Achille raccourcis. 


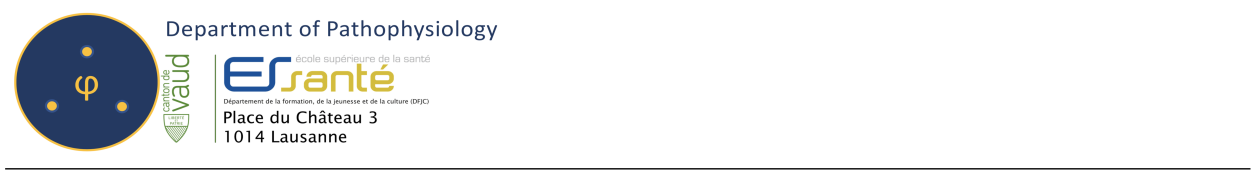

La production augmentée de myéline cause, dans les nerfs ou la perte d'axone est moins sévère, des bulbes d'oignons : la gaine de myéline est initialement plus épaisse que la normale, et tardivement les axones deviennent fins, et lorsque la maladie progresse, de moins en moins d'entre eux seront myélinisés. CMT2 est une neuropathie axonale sensitive dont la vitesse de conduction est supérieure à $38 \mathrm{~m} / \mathrm{s}$ par définition. CMT3 est principalement démyélinisante, tandis que CMT4 peut être soit axonale soit démyélinisante. CMTX est une neuropathie liée à l'X (gène GJB1) avec une diminution de la Connexine 32, homologue de la PMP22 dans la myéline non compacte. Chez l'homme CMTX se présente comme une neuropathie démyélinisante tandis qu'elle a une forme axonale chez la femme.

\section{Neuropathie tomaculaire (HNPP Hereditary Neuropathy with lia-} bility to Pressure Palsies) HNPP est une maladie autosomique dominante apparaissant principalement entre 10 et 30 ans (70\%). Liée à la CMT1A, qui est causée une copie extra de 1,5 Mb du gène codant pour la PMP22, la HNPP est causée par l'hérédité d'un chromosome manquant ce même gène (délétion). La forme principale est déclenchée suite à un trauma mineur relié à une augmentation de pression (mettre un sac à dos, s'étirer) qui comprime les nerfs atteints (fibulaire et ulnaire) causant un engourdissement et une faiblesse indolore qui prend parfois des mois à se résoudre (récupération complète 50\%). Chez certains individus la forme est chronique et plus sévère ressemblant au CMT1. Les signes sont : pied creux, aréflexie achilléenne et dans certains cas généralisés, amyotrophie, et scoliose. L'électrophysiologie montre une augmentation des latences distales avec une perte d'amplitude et des blocs de conduction. Les tomacules (saucisses) sont des signes retrouvés lors de la biopsie du nerf révélant des zones épaissies 


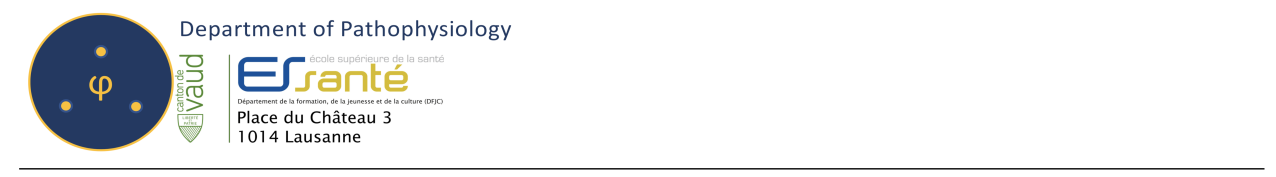

due à la dégénérescence axonale. Il n'existe pas de traitement pour cette pathologie, éviter les compressions pour prévenir l'aggravation des symptômes.

Canal carpien Compression du nerf médian au niveau du poignet sous le ligament antérieur du carpe. Troubles sensitifs et moteurs dans le territoire d'innervation du nerf médian. Troubles moteurs : problème de flexion des phalanges des 2ème et 3ème doigts et du pouce (main du prédicateur). Troubles sensitifs : paresthésie (fourmillements) apparaissant la nuit (réveil nocturne), au volant ou à la lecture. Paresthésie souvent diminuée en secouant la main. Signes : atrophie thénarienne (court adducteur du pouce), faiblesse de la main et paresthésies.

Maladie de Fabry La maladie de Fabry est une maladie héréditaire dominante liée à l'X. Elle se présente par des angiokératomes diffus (lésions maculopapulaires) avec des complications plus graves (comme l'athérosclérose, causant des complications entrainant le décès du patient dans la 5ème décade, ou des cardiomyopathies dilatées). Des douleurs lancinantes des mains et des pieds sont parfois présentes dès la fin de l'enfance. La maladie est causée par une altération de l'alpha-galactosidase qui cause une accumulation de céramide dans les vaisseaux et nerfs. Une thérapie de substitution enzymatique peut être entamée si la maladie est découverte précocement. Pour le traitement des douleurs neuropathique isolées, une prise de carbamazépine est conseillée.

\subsection{Myasthénie}

Les anomalies neuromusculaires de la myasthénie sont déclenchées par une réponse auto-immune via des anticorps anti-AChR. Ces anticorps agissent via différents mécanismes pour réduire in fine le nombre total d'AChR : 1) 


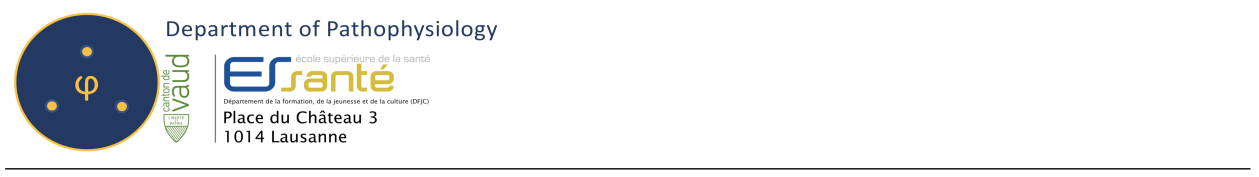

accélération du turnover des récepteurs AChR via des mécanismes d'endocytose, 2) dégâts de la membrane post-synaptique musculaire via anticorps en collaboration avec le complément, 3) blocage du site actif de l'AChR. Un thymus hyperplasique (ou tumoral chez 10\% des patients) semble être à l'origine de la réponse immunitaire exagéré et auto-entretenue. Les anticorps peuvent aussi cibler une kinase musculaire (MuSK) qui s'occupe de regrouper les AChR.

La myasthénie est un syndrome moteur pur, se manifestant via des atteintes des muscles proximaux et extra oculaires (atteinte bulbaire). La cause peut être immunologique (comme énoncé ci-dessus), ou congénitale, avec variation de canaux lents ou rapides et déficits sévères en AChR ou AChE. Elle peut être aussi déclenchés par des troubles métaboliques ou toxiques comme l'hypermagnésémie ou le botulisme. Le froid diminue le décrément par diminution de l'activité de cholinestérase sur ACh.

L'atteinte oculaire se manifeste par une ptose et une atteinte des muscles extra oculaires et des nerfs oculomoteurs, principalement au cours de la maladie $(90 \%, 50 \%$ au début) générant une diplopie. L'atteinte bulbaire se manifeste par une difficulté à la mastication, la parole (dysarthrie), à la déglutition (dysphagie) et de la fatigabilité.

Le diagnostic de la myasthénie se fait via différentes méthodes : essentiellement, une mesure par radioimmunoassay (mais pas uniquement, puisque les résultats définitifs prennent longtemps à être déterminés), sensible chez $85 \%$ des patients avec myasthénie et chez $50 \%$ des patients avec atteinte limitée au niveau extra oculaire (une mesure négative n'exclut pas une myasthénie), et une stimulation répétée du nerf (qui est dépassée en clinique par le EMG à fibre unique) qui met en évidence une diminution de plus de $25 \%$ de la réponse à $3 \mathrm{~Hz}$. Des tests plus simples pour mettre en évidence la maladie 


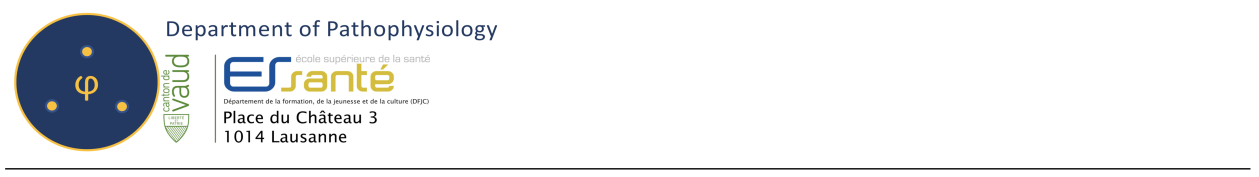

sont fréquemment utilisés, comme le test du comptage (on conte jusqu'à l'apparition de la dysarthrie), et le test du glaçon (agissant sur l'AChE). Le jitter (délai entre stimulation nerveuse et contraction musculaire) est augmenté : il est mesuré via un EMG à fibre unique.

Le traitement de la myasthénie se fait par inhibiteur de cholinestérase (pyridostigmine), immunosuppression par corticostéroïdes ou azathioprine, échanges plasmatiques et IVIg.

\subsection{Botulisme}

Le botulisme dû à l'ingestion une des 7 toxines potentielles produites par Clostridium Botulinum via de la nourriture contaminée est un désordre présynaptique de la jonction neuromusculaire interférant avec les enzymes de la fusion vésiculaire. Les toxines sont composées d'une chaine légère et d'une chaine lourde, cette dernière va rentrer dans le neurone en périphérie en interférant avec les protéines SNARES (Q-SNARE - syntaxine, SNAP25, et R-SNARE - synaptobrevine et synaptotagmine) : l'acétylcholine n'est donc plus libérée, causant une absence de contraction musculaire.

Les symptômes, dans leur ordre respectif d'apparition, sont : sécheresse de la bouche (24h après l'ingestion), diplopie, dysphonie, dysphagie, tetraparésie des membres supérieurs et inférieurs, et propagation aux muscles respiratoires pouvant induire l'arrêt respiratoire et la mort.

Au niveau des potentiels musculaires (CMAP) on peut observer une diminution d'amplitude, la présence d'une facilitation post-exercice dans la phase précoce, une dénervation chimique par présence de positive sharp waves et de fibrillations. Les PUMs sont normaux à aspect myopathique.

Le traitement antitoxine devrait être débuté le plus tôt possible, accompagné d'une assistance ventilatoire et un traitement de support agressif. Un vaccin 


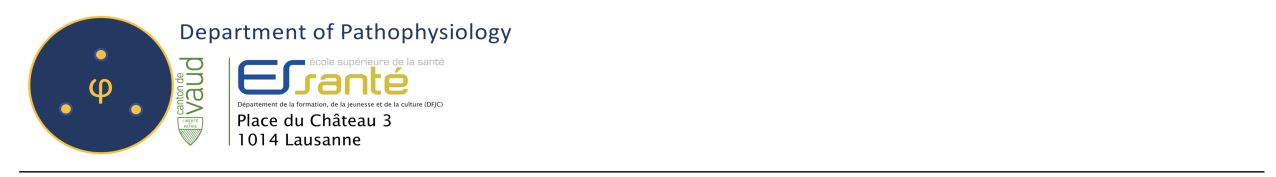

est disponible pour les travailleurs de laboratoires et les personnes à risque.

\subsection{Dystrophie musculaire de Duchenne}

La dystrophie de Duchenne est une dystrophie musculaire héréditaire gonosomique récessive liée à l'X et touchant donc surtout les hommes. Elle est causée par la délétion de $70 \%$ du gène de la dystrophine, protéine permettant l'ancrage de l'actine au sarcolemme (bout $\mathrm{COOH}$ lié au sarcolemme et $\mathrm{NH}$ terminale lié à l'actine). La dystrophine est une protéine présente dans des nombreux tissus, comme le cortex cérébral, la rétine, les cellules de Schwann, foie, et les muscles squelettiques. Les patients synthétisent moins de $5 \%$ de dystrophine normales ce qui cause la pathologie.

La maladie débute le plus souvent entre l'âge de 3 et 5 ans ou l'enfant présente des difficultés à tenir le rythme de jeu avec d'autres enfants, tombe souvent, la course et les sauts sont anormaux. L'enfant doit s'aider de ses mains mettre ses jambes en position debout lorsqu'il se relève d'une position couchée. A partir de 5 ans la maladie est objectivée par une étude électromyographique. La faiblesse commence dans le membre inférieur au niveau proximal et remonte jusqu'au niveau respiratoire. Le patient se retrouve en chaise roulante environ à 12 ans.

L'administration d'un oligonucléotide antisens PRO051 produit une omission de l'exon 51 durant l'épissage de l'ARN messager du gène de la dystrophine, facilitant l'expression d'une nouvelle dystrophine dans les fibres musculaires.

\subsection{Accidents vasculaires cérébraux}

Les accidents vasculaires cérébraux (AVC) sont des pathologies fréquentes (130/100 000 habitants). Ce sont des pathologies graves (25\% des décès dans 


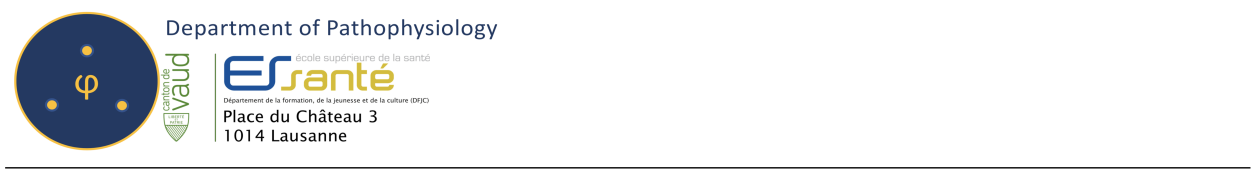

les jours ou semaines suivantes, 50\% handicapés, 25\% sans séquelles, $50 \%$ dépression dans l'année, $25 \%$ de démence dans les 5 ans) et complexes. Il s'agit d'un groupe de maladies dont les manifestations cliniques sont liées à une interruption du flux sanguin suite à une occlusion ou une rupture des vaisseaux. La taille de l'infarctus est en fonction de l'étendue de l'ischémie, de la durée et de la sévérité de l'accident. L'AVC peut être ischémique (occlusion par caillot) ou hémorragique.

Un accident vasculaire cérébral est défini par un déficit neurologique d'apparition brutale et de durée de plus de 24 heures causé par une cause vasculaire focale, contrairement à un accident ischémique transitoire, qui lui dure moins de 24 heures, les symptômes moins d'une heure et souvent ne montre pas de lésion à l'imagerie.

Les causes principales d'AVC sont l'athéromatose des gros vaisseaux, les maladies des petits vaisseaux, les embolies cardiaques ou artério-artérielles, les vasculopathies non athérosclerotiques (dissections, dysplasie fibromusculaire, anomalies héréditaires du tissu conjonctif, vasculites) et l'hypercoagulabilité.

La maladie thromboembolique se divise en embolie (chute brutale du flux sanguin) et thrombose in situ collatérale. Un caillot composé de fibrine, graisse, ou autre obstrue le flux vasculaire normal. La décompensation d'une maladie thromboembolique comprend une diminution de la perfusion proximale (chute de TA et du débit cardiaque), une augmentation des besoins métaboliques (fièvre, acidose, une dérivation du flux sanguin, un infarctus borderzone ou watershed (infarctus caractéristique situé à la jonction de deux territoires artériels différents.

La thrombose, obstruction du flux sanguin par un thrombus débutant du vaisseau, dont les causes peuvent être l'athéromatose, la dissection artérielle, 


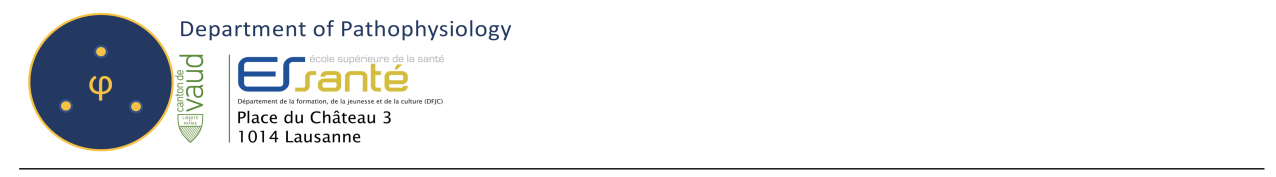

la dysplasie fibromusculaire, le vasospasme (médicamenteux ou inflammatoire), les vasculopathies et les compressions tumorales. Les emboles sont générés par la paroi du vaisseau, peuvent provenir du cœur (fibrillation atriale), du système vasculaire, et peuvent être constitués d'air (embolie gazeuse), de cholestérol et de graisse (graisseuse), de cellules tumorales ou de matériel d'injection. La formation d'un thrombus est un modèle physiopathologique compliqué qui fait intervenir plusieurs agents : tout d'abord, une lésion de la paroi vasculaire (qui peut être induite, par exemple, par un dépôt de graisse dans la paroi) fait appel à la formation d'un dépôt de plaquettes, facteur tissulaire et fibrine. La dysfonction de l'endothélium, élément principale dans la régulation du flux sanguin (via des propriétés anti-athéromateuses et vasodilatatrices du monoxyde d'azote NO) induit un mécanisme pro-inflammatoire qui est prolifératif et procoagulant. Les symptômes sont différents selon le tableau clinique et l'artère en cause.

Le délai essentiel de la prise en charge d'un AVC chez un patient est de $3 \mathrm{~h}$ : il est expliqué par le fait que $30 \%$ (seuil critique) des AVC se compliquent au-delà de ce délai. La réperfusion de la zone atteinte se fait en effectuant une thrombolyse du caillot obstruant la zone. La thrombolyse s'effectue via Alteplase (Actilyse $囚)$, une molécule recombinante identique à l'activateur du plasminogène (rt-PA). L'agoniste de l'activateur du plasminogène active le système fibrinolytique qui cause la lyse du caillot, mais ne peut être utilisé que dans un délai de $3 \mathrm{~h}$ après l'obstruction, sauf si lésion très étendue (contre-indication). Une surveillance est nécessaire puisqu'un switch peut s'observer entre un AVC ischémique et hémorragique. Le NNT de ce traitement (nombre de patient à traiter pour en guérir 1) est de 8. L'aspirine, inhibiteur de la cycloxygénase (en inhibant l'agrégation plaquettaire via une diminution du thromboxane A2) peut être donnée en prévention d'un AVC 


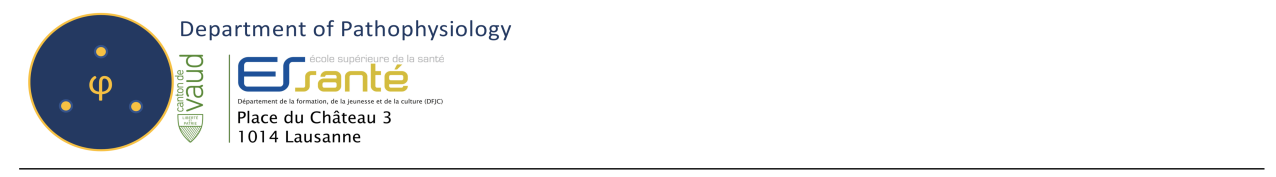

chez un patient à risque.

Une chirurgie de décompression sert à ouvrir un volet crânien pour que la partie sous-jacente de cerveau qui est en train d'enfler puisse avoir de la place pour le faire sans pour autant causer un engagement. Une fois la phase aiguë passée, le crâne peut être fermé.

\subsection{Maladie de Parkinson}

La maladie de Parkinson est la deuxième pathologie dégénérative la plus fréquente après l'AD. L'incidence est de 13,4/100.000/an. Elle touche 2 hommes pour 1 femme. L'âge moyen d'apparition de la maladie est de 55 ans. La maladie de Parkinson est une maladie neurodégénérative qui se manifeste principalement par des troubles du mouvement. Elle peut débuter précocement avant l'âge de 45 ans. En général, la maladie de Parkinson n'est pas mortelle mais évolue peu à peu pour affecter plusieurs aspects de la vie de la personne atteinte.

La maladie de Parkinson s'explique par la destruction de neurones riches en dopamine au niveau de la substance noire compacta (qui fait partie des ganglions de la base : cf. ci-dessous). Au moment du diagnostic de la maladie de Parkinson, environs $70 \%$ des neurones de la substance noire compacta ont déjà été perdu. Cela veut dire que le corps a pu compenser pendant un moment mais lorsque les premiers symptômes apparaissent, le corps n'arrive plus à compenser et il y a décompensation. Cette perte neuronale (perte de neurones à dopamine de la SNc) est généralement associée à l'apparition de corps de Lewy au niveau de la substance noire.

Donc pour résumer dans une maladie de Parkinson, il y a 2 phénomènes qui se produisent au niveau de la substance noire compacta : une perte des neurones à dopamine; une formation de corps de Lewy au niveau de la substance 


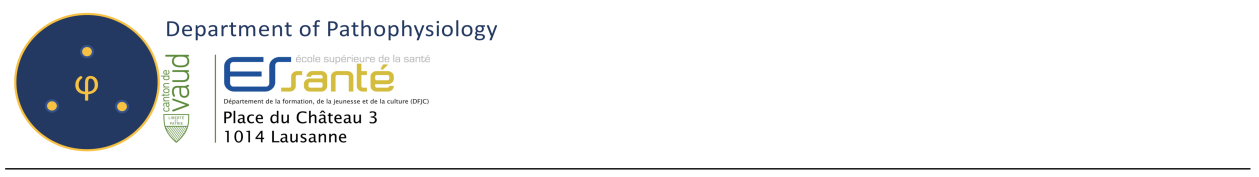

noire. La maladie de Parkinson, du fait de la formation de corps de Lewy est classée dans les alpha-synucléinopathies au même titre que la démence à corps de Lewy. Remarquons néanmoins que dans certaines maladies de Parkinson familiales comme celle liée à la mutation de la parkine, il n’y a pas formation de corps de Lewy. Donc retenons qu'il y a souvent apparition de corps de Lewy dans la maladie de Parkinson mais que dans certaines formes familiales font exception à cette règle. La formation de corps de Lewy n'est donc pas indispensable à la survenue d'une maladie de Parkinson.

Pour comprendre les mécanismes de la maladie de Parkinson, il faut présenter les différents acteurs qui interviennent à savoir les ganglions de la base qui sont : le Striatum (putamen, noyau caudé et noyau accumbens) ; Noyau sousthalamique; Substance noire (pars compacta qui est touchée dans la maladie de Parkinson et pars reticulata); Globus pallidus (interne et externe).

Il existe 3 voies qui permettent au niveau des ganglions de la base qui permettent un mouvement correct.

Voie directe qui favorise le mouvement : le cortex moteur (par le glutamate) et la substance noire pars compacta (par la dopamine) viennent exciter le striatum (via les récepteurs à dopamine D1). Le striatum envoie alors un influx inhibiteur (GABA et substance P) sur le globus pallidus interne et la substance noire pars reticulata (forment le point de sortie des ganglions de la base). Or, le globus pallidus interne et la substance noire envoient des influx inhibiteurs (GABA) vers le thalamus ventro-latéral et les noyaux pédonculo-pontins (voie motrice).

En activant la voie directe, on favorise/facilite le mouvement.

Voie indirecte qui inhibe le mouvement : le cortex moteur (par le glutamate) et la substance noire pars compacta (par la dopamine) viennent activer le striatum (via les récepteurs à dopamine D2). Le striatum (par le GABA et 


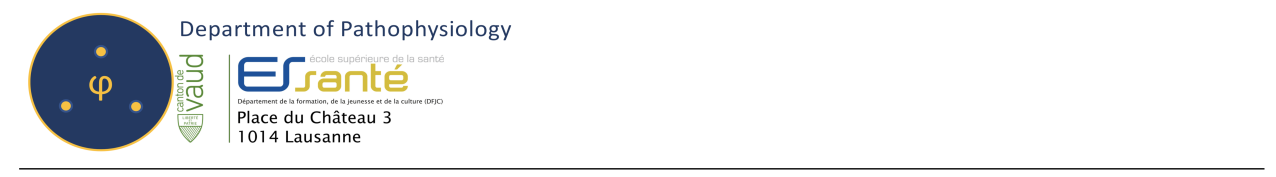

l'enképhaline) inhibe le globus pallidus externe.

Le globus pallidus externe (par le GABA) inhibe le noyau sous-thalamique.

Le noyau sous-thalamique (par le glutamate) stimule le globus pallidus interne et la substance noire pars reticulata, qui inhibent (par le GABA) le thalamus ventro- latéral et la voie motrice, et qui fait un feedback excitateur sur le globus pallidus externe (par le glutamate). En activant la voie indirecte, on inhibe le mouvement.

Voie hyperdirecte qui inhibe le mouvement : Le cortex moteur (par le glutamate) excite le noyau sous-thalamique.

Le noyau sous-thalamique (par le glutamate) excite le globus pallidus interne et la substance noire.

Le GPI et la substance noire (par le GABA) inhibent le thalamus ventrolatéral et la voie motrice.

La voie hyperdirecte diminue l'activité motrice, elle inhibe le mouvement. Les mécanismes de mort neuronale sont les mêmes que dans la plupart des autres maladies neurodégénératives et sont les suivants : dysfonction de la voie ubiquitine-protéasome; anomalies de la conformation des protéines; dysfonction mitochondriale; stress oxydatif; inflammation; lésions des neurones dopaminergiques qui est plus spécifique à la maladie de Parkinson. Les principaux signes de la maladie de Parkinson sont : tremblement de repos (c'est la première chose qui apparait); rigidité (on parle d'hypertonie : résistance accrue à l'étirement passif); akinésie (déficit dans l'initiation du mouvement); bradykinésie (ralentissement des mouvements); instabilité posturale.

De plus, on va aussi observer d'autres signes mineurs qui ne sont que la conséquence des 5 signes principaux ci-dessus : perte du ballant du bras d'un côté; freezing (geler sur place car demi-tour difficile); micrographie (écrit 


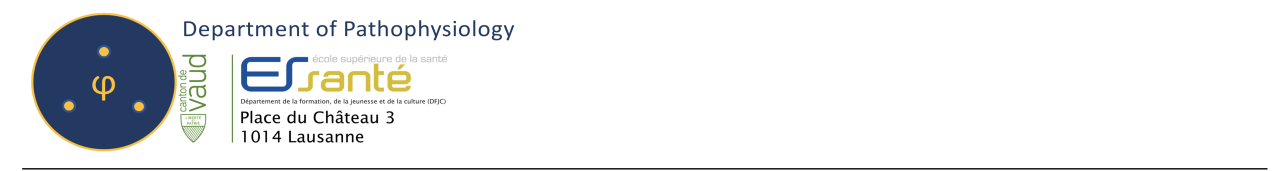

de moins en moins bien et de plus en plus petit); vouté (la tête penchée vers le bas).

Pour le traitement, on administre la L-Dopa avec l'inhibiteur de la décarboxylase (qui est l'enzyme qui explique les effets secondaires donc il faut l'inhiber). L'ensemble donne ce que l'on appelle le Prolopa.

Au début du traitement, le Prolopa va donner une récupération importante. Mais au fur et à mesure, le Prolopa agit moins car les neurones continuent à disparaître. A un moment, on va arriver à un stade de la maladie qu'on qualifie de on-off (ou go-non go). A ce moment-là, le patient est dyskinétique lors de la prise du Prolopa (pleins de mouvements) puis rapidement il est bloqué. A ce moment, la dose doit être réduite et les prises doivent être rapprochées pour éviter ces suites de blocage-dyskinésie.

Quand le patient ne répond plus du tout au traitement, la seule alternative est de venir placer une électrode au niveau du noyau sous-thalamique (NST).

\subsection{Maladie d'Alzheimer}

Le facteur de risque principal est l'âge. L'incidence double tous les 5 ans à partir de 65 ans. La probabilité de recevoir un diagnostic de maladie d'Alzheimer (AD, Alzheimer's Disease) après 85 ans est supérieur à 1 sur 3. Le décès survient dans les 3 à 9 ans après le diagnostic.

La $\mathrm{AD}$ est une maladie neurodégénérative appartenant aux démences primaires. Son évolution est progressive sur 8 à 10 ans et le malade présente : une atteinte mnésique (mémoire à court terme), une désorientation spatiotemporelle, un problème de langage et un problème de calcul (acalculie).

Ce sera dans un premier temps une atteinte mnésique puis une désorientation spatio-temporelle, le reste arrivant encore après. Cela s'explique par le fait 


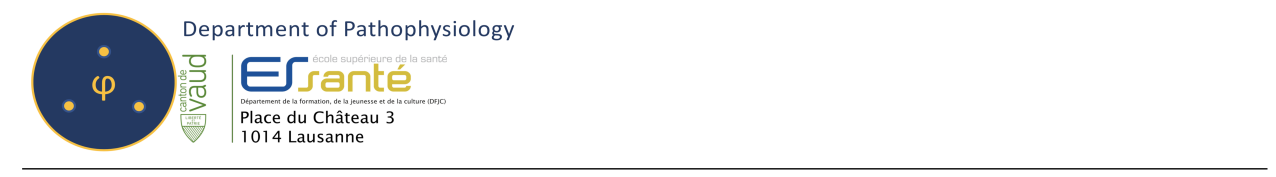

que les dépôts d'amyloïde beta qui explique en partie la maladie se forment d'abord dans la région mésiale des lobes temporaux. Ces régions mésiales (dont l'hippocampe) sont indispensables pour la mémoire. Le patient peut présenter d'autres signes comme : passivité (pas intéressé), agressivité, suspicieux, pauvreté émotionnelle, hallucinations, délire paranoïde et dépression (très souvent).

Il existe peu de formes familiales dans la maladie d'Alzheimer contrairement aux autres maladies neurodégénératives où les formes familiales sont courantes. Ici, dans l'AD, le plus souvent on a à faire à des formes sporadiques. Cependant ce sont les formes familiales qui nous ont permis de comprendre les mécanismes intervenant dans la maladie. Les sujets atteints de trisomie 21 développent de manière précoce des démences et on a constaté lors de l'autopsie de leur cerveau qu'il présentait des lésions histologiques à celle d'un patient atteint de l'AD. C'est ainsi qu'on a identifié chez les sujets trisomiques, une anomalie du gène qui code pour l'APP (gène précurseur de la protéine amyloïde).

D'autres entités ont pu être mises en évidence comme la préséniline qui est une protéine qui forme un complexe avec le beta et la gamma sécrétase. Le gène qui code pour le préséniline est sur le chromosome 14. La pathogénie de l'AD dépend donc probablement de l'interaction de plusieurs gènes.

La AD est une amylopathie et NON une tauopathie car il semble que le processus de départ soit une accumulation d'amyloïde beta. Cette accumulation d'amyloïde beta précède celle des Tau. C'est d'ailleurs l'accumulation d'amyloïde beta qui favoriserait l'accumulation des TAU.

Via les modèles de souris on a découvert la nécessité d'une combinaison d'amyloïde et de la protéine tau pour aboutir à un processus qui entraîne une démence. 


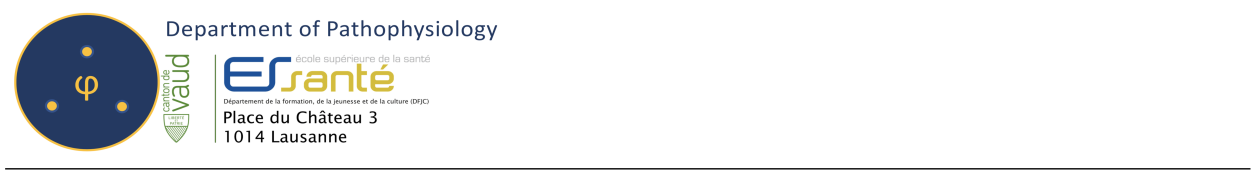

Les anomalies principales rencontrées dans $\mathrm{AD}$ sont : anomalies protéiques (amyloïde beta et tau), altération des fonctions des synapses à cause de amyloïde beta qui est toxique, anomalies mitochondriales (amyloïde beta est toxique pour les mitochondries, qui se rompent : il y a une libération de caspases ou cytochrome qui induit l'apoptose), stress oxydatif, effet vasculaire (angiopathie amyloïde dans $90 \%$ des $\mathrm{AD}$ donc souvent la démence est mixte (primaire et secondaire (vasculaire)), inflammation (processus inflammatoire au niveau des plaques qui perturbent le fonctionnement des neurones), calcium (pores à calcium grâce à amyloïde beta qui entraîne l'apoptose), déficit de transport axonal (surtout à cause de tau), anomalie du métabolisme du cholestérol (souvent associé à hyper cholestérolémie : apoE).

Donc les amyloïde beta vont se déposer au cours du temps. C'est un processus qui est lié à la sénescence. En fonction de la chance que l'on a, on va avoir des protéasomes suffisamment performants pour détruire les plaques ou alors la chance de ne pas trop produire d'amyloïde beta.

Pour expliquer le traitement actuel de la maladie d'Alzheimer, il est important de comprendre l'hypothèse cholinergique. Chez les patients atteints de la maladie d'Alzheimer, on a remarqué un parallélisme entre la perte des neurones cholinergiques et le degré de démence. En effet au cours du temps, on s'est rendu compte de l'importance du noyau basal de Meynert qui contient des neurones à acétylcholine. Ce noyau à acétylcholine projette sur le cortex cérébral. L'utilisation de physostigmine (inhibiteur cholinestérase) associée à la lécithine (précurseur de l'ACh) a permis d'améliorer de manière transitoire les fonctions mnésiques des patients atteints de la maladie d'Alzheimer dans un stade précoce de la maladie.

En effet après un certain temps, ce type de traitement n'a plus d'effet car 


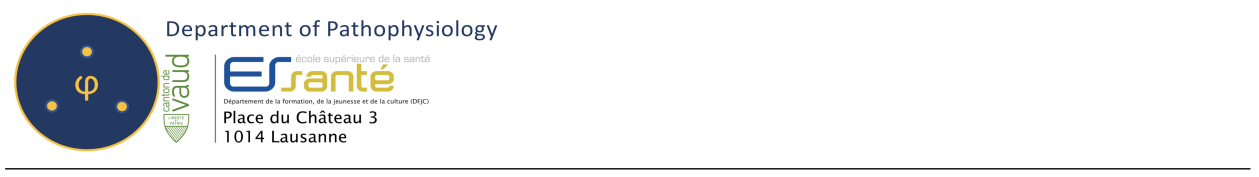

le neurone sont de plus en plus détruits ce qui ne permet plus un largage endogène d'acétylcholine. Ce médicament a été remplacé à cause de sa forte toxicité hépatique et a été remplacé par d'autres inhibiteurs de cholinestérase (aricept, exelon, reminyl).

Ces derniers ont aussi des effets secondaires comme des nausées et des vomissements. Il est important de noter que dans le cadre de nombreuses pathologies, le médecin est amené à prescrire des anticholinergiques.

Si le patient est jeune aucun problème est relevé mais si le patient est âgé, attention avant de prescrire un anticholinergique car si patient MCI (mild cognitive impairment), le traitement anticholinergique pourrait causer une démence. Une chose intéressante à observer dans ce cas sont les biomarqueurs dans la ponction lombaire : si les résultats montrent un dépôt d'amyloïde beta 42 (la forme la moins soluble) bas et une tau hyper phosphorylée haute, la prescription d'anticholinergiques empirerait la situation du patient.

\section{$5.9 \quad$ Epilepsie}

Généralités Les convulsions sont des évènements paroxystiques dus à un excès de synergie neuronale anormale dans le cerveau dont les manifestations cliniques peuvent être variables. Les convulsions, de par leur définition, sont des évènements isolées et ne devraient pas se reproduire chez un sujet : elles sont donc à ne pas confondre avec les épilepsies, définis par des convulsions récurrents causées par un processus neurologique sous-jacent. L'épilepsie est un des problèmes neurologiques les plus courant au monde : environ $3 \%$ de la population mondiale présentera de l'épilepsie à un moment donné de son existence. Les crises spécifiques peuvent être différenciées selon leurs caractéristiques cliniques (partielles complexes, tonico-cloniques). Les syndromes épileptiques sont des entités différenciées selon le type de crise, la 


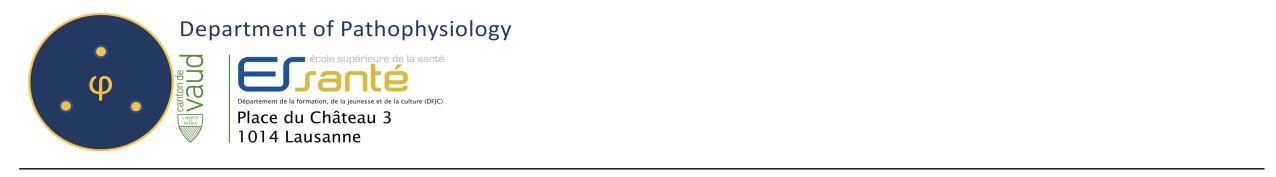

présence ou absence d'anomalies neurologiques ou développementales et les caractéristiques électroencéphalographiques.

Classification Il existe 2 grandes catégories de syndromes épileptiques : les syndromes généralisés et les syndromes partiels. Les épilepsies généralisées débutent le plus souvent simultanément dans les deux hémisphères cérébraux, des nombreuses formes ont une forte composante génétique et pour la plupart des patients la fonction neurologique est normale. Les épilepsies généralisées peuvent être cloniques (, toniques, tonico-cloniques, absences, myocloniques, ou atoniques. Les épilepsies partielles ont une origine focale mais peuvent envahir l'ensemble du cerveau; la plupart sont supposées résulter de lésions du SNC mais souvent ces altérations ne sont pas identifiées. Elles peuvent être simples ou complexes. Les manifestations des épilepsies partielles peuvent être motrices ou vocales, sensorielles (hallucinations simples visuelles, somesthésiques, auditives, gustatives, olfactives, vertigineuses), autonomes (pâleur, rougeur, transpiration, chaleur, froid, piloérection, mydriase, tachycardie/bradycardie, nausées, vomissements), cognitives (dysphasie, dysmnésie, illusions ou hallucinations complexes), psycho-affectives (frayeur, rire, larmes).

Crise généralisée tonico-clonique La crise tonico-clonique présente des éléments des crises cloniques et des crises toniques. La crise débute sans prodrome, même si parfois certaines personnes en aperçoivent 1. La contraction tonique survient en premier, il s'agit d'une contraction de tous les muscles du corps. La contraction du larynx et de l'expiration génère le cri ictal. La contraction de la mâchoire pourrait mordre la langue. La respiration est irrégulière, tandis que le rythme cardiaque, pression artérielle et diamètre pupillaire augmentent. Après 10-20s, la phase tonique évolue vers la phase clonique, c'est à dire la superposition des phases de relaxation des muscles. 


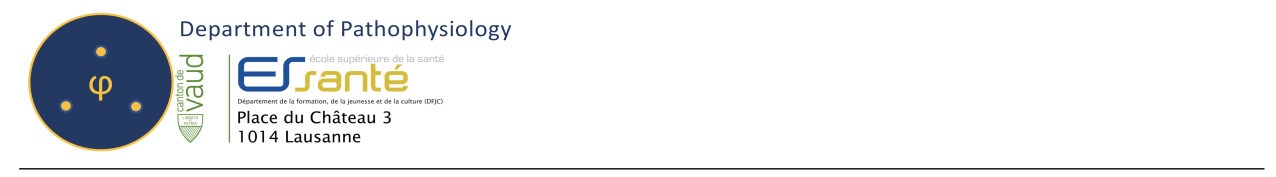

Cette relaxation augmente jusque la fin de la crise. L'incontinence urinaire peut être présente. La confusion post-ictal peut parfois durer des heures. La phase tonique de l'EEG est représente une augmentation progressive d'une activité générale à voltage bas. La phase clonique de l'EEG est représentée par des grandes ondes interrompues par des spike (spike and wave pattern ou pointe-onde).

Crise généralisée de type absence Les épilepsies absences débutent souvent dans l'enfance, caractérisée par des pertes soudaines de conscience sans perte de contrôle postural. La conscience revient après quelques secondes sans confusion post-ictal. La manifestation clinique, habituellement très pauvre et représentée par une rupture de contact et un regard fixe peut parfois aussi inclure des automatismes moteurs bilatéraux comme cligner des yeux, mouvement de mastication, ou mouvements cloniques de la main à petite amplitude. L'EEG montre un caractéristique pointe-onde de $3 \mathrm{~Hz}$ de quelques secondes de durée superposé à un EEG normal. L'origine des crises se situe dans le thalamus et aussi le cortex. Il existe des crises absences atypiques ou l'activité EEG est de plus petite amplitude et de morphologie atypique; ces crises sont moins sensibles aux anticonvulsivants et sont le symptômes de défauts neurologiques et retard mental sous-jacents. Pour une minorité, la crise d'absence sera accompagnée d'une crise généralisée tonico-clonique. Cette généralisation peut s'expliquer par un des circuits thalamocortical composé de 3 populations neuronales à savoir :

Les neurones thalamiques réticulaires

Les neurones thalamiques relais

Les neurones corticaux pyramidaux

En cas de généralisation de la crise, ce circuit va mettre l'ensemble du cer- 


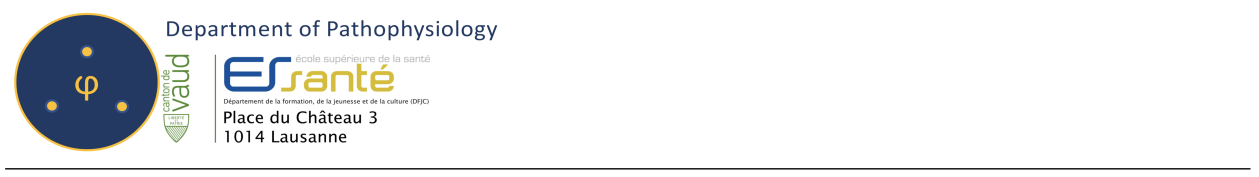

veau dans un état de synchronisation nécessaire à la généralisation de la crise épileptique (pour rappel les cellules d'un foyer épileptique ont 2 caractéristique : hyperexcitabilité et hypersynchronisme). Pour synchroniser le cerveau, les neurones thalamiques réticulaires vont hyperpolariser les neurones thalamiques relais. Quand ces derniers sont hyperpolarisés, ils fonctionnent en mode bouffée et permettent la synchronisation des neurones corticaux pyramidaux; il y a alors généralisation de la crise. Le mode bouffée est permis grâce à des canaux $\mathrm{Ca} 2+$ de type $\mathrm{T}$ dont le seuil de dépolarisation est bas. Une fois, le seuil bas de dépolarisation atteint, les canaux $\mathrm{Na}+$ voltage dépendant vont prendre le relais et générer beaucoup de potentiels d'action : c'est le mode bouffée. En sommeil NON REM, les neurones thalamiques relais fonctionnent en mode bouffée ce qui permet de mettre le cerveau dans un état synchrone.

En sommeil REM, les neurones thalamiques relais fonctionnent en mode tonique ce qui ne permet plus la synchronisation et on a le cerveau qui est dans un état désynchronisé. Dans l'épilepsie d'absence, on a donc une situation similaire au sommeil NON REM, qui produit une activité rythmique du cortex pendant l'éveil (en effet le patient est réveillé quand subit la crise d'absence), ce qui produit les décharges pointes ondes à l'EEG et les manifestations cliniques caractéristiques de l'épilepsie d'absence.

Donc le concept principal est le suivant : il y a une dysfonction d'un circuit neuronale qui produit un état physiologique d'activation rythmique corticale (comme dans le sommeil NON REM) qui peut aboutir au déclenchement d'épisodes anormaux d'activités paroxystiques caractérisées par une activation rythmique corticale (crise d'absence).

A l'heure actuelle, des hypothèses existent pour expliquer les crises d'absence comme des anomalies des canaux calcium de type T. Il y aurait aussi 
probablement une altération des récepteurs GABA favorisant l'excitation par rapport à l'inhibition (PPSE ¿¿PPSI). Ces crises disparaissent à la puberté.

Le traitement est l'acide valproïque (large spectre d'activité donc fonction aussi pour autres types d'épilepsie) ou l'ethosuximide (spécifique aux crises d'épilepsie d'absence donc ne fonctionne pas pour les autres crises d'épilepsie). Faire attention au baclofen, agoniste des récepteurs GABA qui en général est un bon traitement des crises d'épilepsie mais dans le contexte des crises d'épilepsie d'absence, il favorise l'apparition de crise d'absence accompagnée de crise généralisée tonico-clonique. Pour les mêmes raisons, il faut aussi se méfier des benzodiazépines.

Crises généralisées myocloniques Un myoclonus est une contraction brève et soudaine du muscle qui peut inclure un seul muscle ou tous les muscles du corps. Un exemple de myoclonus est le mouvement saccadé soudain que l'on fait lorsque on s'endort. Un myoclonus pathologique est le plus souvent observé lors de désordres métaboliques ou des maladies dégénératives du SNC ou encore des dégâts anoxiques cérébraux. L'EEG peut présenter une décharge pointe-onde synchrone mais cette dernière peut être cachée par des artefacts dus au mouvement.

Crises généralisées atoniques La crise atonique est caractérisée par la perte du tonus musculaire postural pendant 1-2 secondes sans confusion post-ictale (le plus souvent). Au niveau de l'EEG, des pointes ondes soudaines et de brève durée sont observés. Ces crises sont le plus souvent associées à des syndromes épileptiques. 


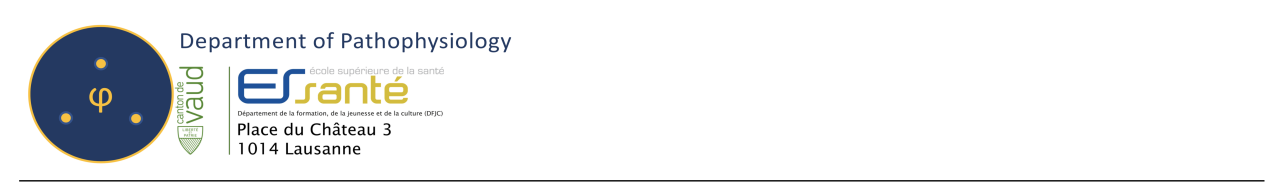

Crises généralisées associées à des mutations des gènes des canaux ioniques Alors que la plupart des épilepsies généralisées ont une hérédité complexe, quelques-unes ont une hérédité de type simple et sont liées à la mutation d'un seul gène. Dans ces cas les mutations concernent les gènes qui encodent les protéines des canaux ioniques.

Epilepsie généralisée avec convulsions fébriles : convulsions fébriles associées à des crises d'épilepsies de type absence ou myoclonique ou atonique ou tonico-clonique, de transmission $\mathrm{AD}$ (chromosome 19q), mutation dans le gène du canal sodium voltage dépendant (sous unité $\beta$ 1) Gène SCN1B modifie les propriétés d'inactivation du canal.

Convulsions néonatales familiales bénignes : crises d'épilepsies généralisées dans les premiers jours, disparaissent spontanément après quelques mois. Transmission AD, mutations dans les gènes KCNQ2 et KCNQ3 des canaux potassium. La réduction des courants potassiques des canaux mutés est probablement à l'origine de l'hyperexcitabilité constatée. Dans ces syndromes épileptiques des mutations dans des gènes codant pour des protéines des canaux ioniques causent une hyperexcitabilité de neurones corticaux en changeant la fonction des canaux ioniques concernés.

Epilepsie partielle bénigne à pointes centro-temporales Début entre 3 et 14 ans, épilepsie focale fréquente de l'enfant. Il s'agit de myoclonies et paresthésies de la joue sans perte de conscience le jour et de crises d'épilepsie généralisée la nuit. L'EEG intercritique est caractérisé par des pointes centrales et temporales uni ou bilatérales, et dans $30 \%$ des cas aussi de l'activité pointe-onde généralisée. Le pronostic est bon. 


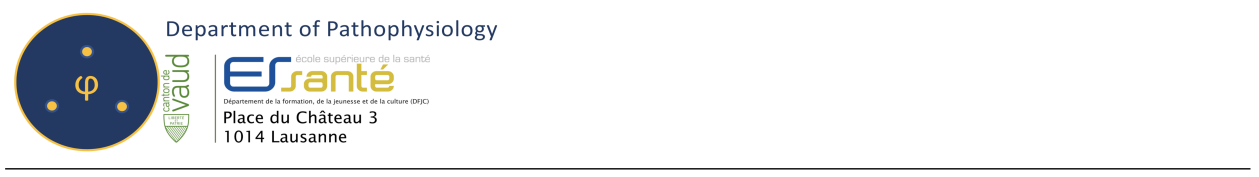

Manifestations cliniques selon lobe atteint Une crise occipitale se présentera par hallucinations visuelles, illusions visuelles, hémianopsie/cécité, déviation oculogyre, nystagmus, flutter palpébral.

Une crise pariétale se présentera par, hallucinations sensitives, illusion somatique, somatognosie, illusions de mouvement, illusions visuelles, dysphasie, dyspraxie, dyslexie, dyscalculie, expérience extracorporelle.

Une crise frontale se présentera par une crise motrice simple clonique ou tonique, oculocéphalogyrie (mouvements de la tête liés à la vision), postures toniques, crises hypermotrices (hyperactivités ou vocalisations), absences frontales.

Une crise temporale se présentera par des manifestations autonomes telles la peur, panique, automatismes oraux, posture dystonique (anormale), automatismes manuels, hallucinations olfactives (cacosmie), déjà vu, hallucinations auditives, illusions auditives.

Déclenchement d'une crise d'épilepsie L'activité synchrone d'un petit nombre de neurones dans un foyer épileptique peut être détectée par l'EEG comme une pointe. Les neurones au sein d'un foyer épileptique sont le siège de dépolarisations paroxystiques synchrones (PDS), signe d'une excitabilité anormale dérivée d'anomalies de l'excitabilité des canaux sodium, potassium et calcium et d'un déséquilibre entre GABA et glutamate. L'excitation est donc bien plus importante que l'inhibition, ce qui sera la cible des traitements pharmacologiques qui augmenteront l'influence GABA (diazepam) ou diminueront l'excitabilité des canaux $\mathrm{Na}+$ voltage dépendants (diphantoine, carbamazépine, lamotrigine). Le foyer épileptique est la zone où va débuter l'épilepsie. Il est dû à un groupe de neurones anormaux qui ont comme caractéristiques : Réponse électrique/dépolarisation stéréotypée 


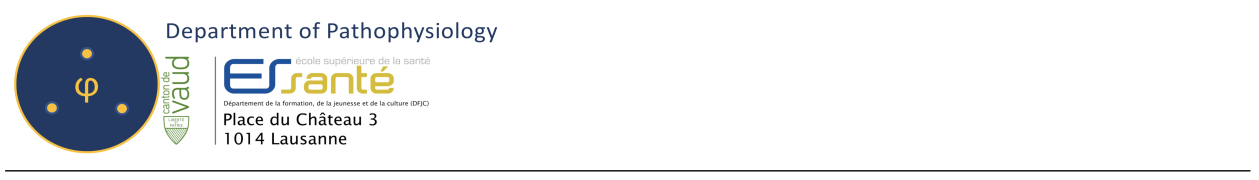

et synchronisée (= PDS pour paroxysmal dépolarisation shift) :

Brusque, ample (20-4mV), longue durée (50-200ms), train de potentiels d'action après le PA normal, suivie d'une hyperpolarisation.

Déroulement d'une crise classique : aura, peur et cacosmie annoncent l'origine de la crise. Augmentation de l'activité du foyer épileptique avec apparition de clonies, généralisation avec perte de conscience, extension de la rigidité (phase tonique - $30 \mathrm{sec}$ ), cris (diaphragme, thorax), perte d'urine, cyanose (tellement contractés qu'ils ne respirent plus), fermeture de la mâchoire, clonies généralisées (phase clonique - $2 \mathrm{~min}$ ), période post-ictale (somnolence, céphalées), coma post épileptique. Normalement, la crise s'arrête toute seule.

\section{Physiopathologie endocrinienne}

Note : certaines pathologies endocriniennes, comme le diabète, ont été abordées au préalable. Ce chapitre se focalise sur les troubles hypophysaires, thyroïdiens et surrénaliens.

\subsection{Définitions}

Les hormones sont des messagers produits par une glande endocrine (versant son contenu directement dans le sang) en réponse à une stimulation et capable d'agir à distance sur les cellules cibles.

Les hormones se divisent en plusieurs catégories selon leur mode de transmission et réception : les hormones paracrines sont des hormones agissant sur les cellules proches de la cellule productrice; les hormones autocrines agissent sur la cellule productrice; les hormones endocrines atteignent des cibles anatomiquement lointaines via le transport sanguin, et les neurohormones sont produits par des neurones. Les hormones ont une fonction de 


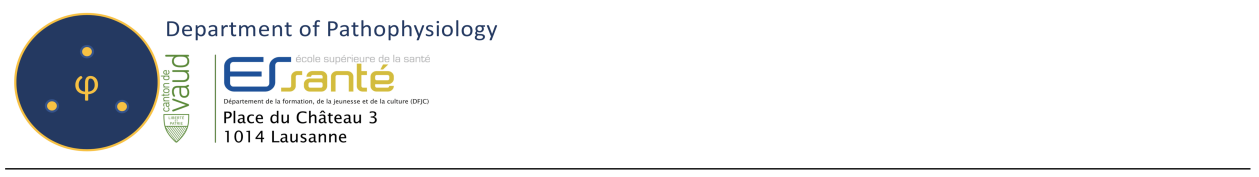

communication, intégrant la réponse de différents organes pour maintenir l'homéostasie d'un ou plusieurs paramètres.

Les catécholamines, les hormones thyroïdiennes et la mélatonine dérivent d'acides aminés. L'hormone antidiurétique (ADH), l'insuline et l'hormone de croissance (growth hormone, GH) dérivent de peptides.

Les hormones stéroïdes de la corticosurrénale et des gonades, tels que le cortisol, les œestrogènes et la testostérone dérivent du cholestérol.

Les prostaglandines dérivent de l'acide linoléique et de l'acide arachidonique.

\subsection{Physiopathologie de l'axe hypothalamo-hypophysaire}

Anatomie et physiologie de l'axe hypothalamo-hypophysaire L'hypothalamus est une région cérébrale située dans la base du crâne antérieur. Il est relié par voie sanguine à l'hypophyse antérieure et communique avec l'hypophyse postérieure via la tige pituitaire. L'hypothalamus co-contrôle avec l'hypophyse les processus de métabolisme, température, faim, soif, comportements sexuels et stress. L'hypothalamuys produit les hormones TRH (thyrotropin releasing hormone), GnRH (gonadotropin-releasing hormone) et $\mathrm{CRH}$ (corticotropin releasing hormone). L'hypophyse (pituitary gland, glande pituitaire) se trouve dans la fosse hypophysaire (située dans l'os sphénoïde dans la fosse moyenne de la base du crâne).

L'hypophyse antérieure produit l'hormone de croissance, la TSH (thyroid stimulating hormone), l'ACTH (adrenocorticotropic hormone, destinée aux glandes surrénales), la FSH (follicule stimulating hormone, destinée aux gonades), la LH (luteinic hormone, destinée aux gonades) et la prolactine (pour les glandes mammaires). L'hypophyse postérieure est une extension inférieure de l'hypothalamus, avec lequel elle communique via la tige pituitaire. Elle s'occupe de la libération de l'hormone antidiurétique (ADH) et 
de l'ocytocine.

L'hormone CRH induira la production de ACTH et donc de cortisol.

L'hormone TRH induira la production de TSH et donc d'hormones thyroïdiennes.

L'hormone GnRH induira la production de FSH/LH et d'œstrogènes notamment.

Panhypopituitarisme Le panhypopituitarisme est une interruption fonctionnelle de l'hypophyse, qui peut être une conséquence d'une hypophysite, ou un processus obstructif de la tige pituitaire (tel un processus tumoral).

La déconnexion cause un hypocorticisme (taux bas de cortisol) qui seront corrigés via dexaméthasone, une hypothyroïdie qui doit être substituée, un diabète insipide (manque de ADH) qui sera corrigée avec une hormone artificielle, un hypogonadisme (surtout problématique si femme en âge de procréer et désir de grossesse) et une hyperprolactinémie de déconnexion.

L'hyperprolactinémie est causée par le manque de feedback négatif physiologique de l'hypothalamus à l'hypophyse du à la déconnexion.

Adénome hypophysaire L'adénome hypophysaire est une tumeur généralement bénigne de l'hypophyse antérieure. L'adénome peut être lactotrope (causant une hyperprolactinémie de déconnexion par absence de feedback négatif physiologique hypothalamique), thyrotrope (causent hyperthyroïdie par hypersécrétion de TSH), somatrotrope (causent l'acromégalie, agrandissement des extremités, par excès de GH) et corticotrope (causant la maladie de Cushing). 


\subsection{Physiopathologie thyroïdienne}

Anatomie et physiologie thyroïdienne La glande thyroïde est une glande endocrine sécrétant les hormones thyroïdiennes T3-T4. Elle est constituée de 2 lobes mesurant 6 à 8 centimètres. Les deux lobes sont reliés par un isthme thyroïdien surmonté par le lobe pyramidal (de Lalouette). La thyroïde produit sous stimulation de la TSH les hormones T3 et T4, ayant comme fonction d'accélérer le métabolisme.

Hyperthyroïdie L'hyperthyroïdie a comme étiologies principales la maladie de Graves (thyroïdite auto-immune, sécrétion d'anticorps stimulant les récepteurs thyroïdiens à produire des hormones en excès), un goitre multinodulaire (maladie de Plummer) ou un adénome toxique. Des médicaments (amiodarone, interféron alpha, lithium) peuvent aussi causer l'hyperthyroïdie. Lors d'une maladie de Graves, le goitre diffus toxique est causé par la production d'anticorps stimulant la thyroïde (thyroid stimulating immunoglobulin, TSI) qui stimulent la sécrétion de T3 et T4. Suite à un excès continu d'hormones thyroïdiennes, le patient présentera des symptômes cardiovasculaires (accélération du rythme cardiaque, fibrillation atriale), neuropsychiatriques (hyperactivité, troubles du sommeil, fragilité émotionnelle), digestifs (diarrhée, perte de poids) ainsi que de la transpiration exagérée, et une exophtalmie (yeux du patient extériorisés avec rétraction des paupières. Le diagnostic se pose par dosage de TSH (qui sera diminué, sauf dans le cas d'hyperthyroïdie secondaire). Le traitement se fait par voie médicamenteuse avec des médicaments antithyroïdiens (comme le propylthiouracile ou PTU).

Hypothyroïdie L'hypothyroïdie est une pathologie dont les étiologies sont variées : une thyroïdite auto-immune prolongée, une chirurgie de la thyroïde, 


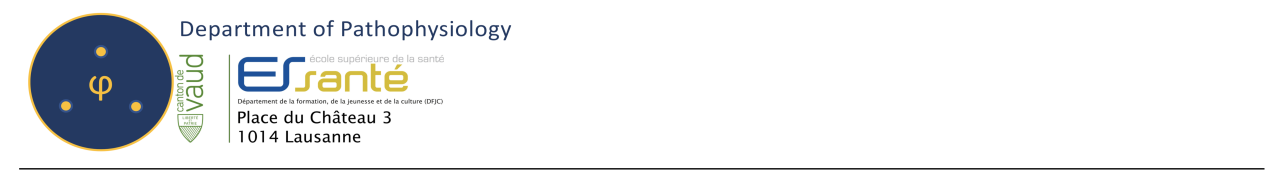

le lithium peuvent en être les causes. L'hypothyroïdie peut être secondaire à un dysfonctionnement de l'hypophyse (hypothyrö̈die induite secondaire) ou de l'hypothalamus (hypothyroïdie induite tertiaire). Lors de l'hypothyrö̈die, les niveaux sanguins des hormones thyrö̈diennes seront bas. Les signes et symptômes de l'hypothyroïdie chez les adultes comprennent léthargie, constipation, intolérance au froid, crampes, et ménorragie (abondance anormalement excessive des règles). L'hypothyroïdie se diagnostique par le dosage de TSH sanguine (qui sera élevée dans l'hypothyroïdie primaire) et des hormones thyroïdiennes (qui seront diminuées). Le traitement se fait par voie médicamenteuse via substitution des hormones thyroïdiennes (L-thyroxine).

\subsection{Physiopathologie surrénalienne}

Anatomie et physiologie surrénalienne La glande surrénale est située sur le bord supérieur du rein et est subdivisée en deux parties. La partie corticale sécrète les corticostéroïdes et androgènes. La partie médullaire sécrète l'adrénaline et la noradrénaline.

Maladie de Cushing La maladie de Cushing est un ensemble d'anomalies cliniques causées par une exposition prolongée à des niveaux élevés de cortisol. L'étiologie peut être iatrogène (causés par utilisation prolongée de corticoïdes), relative à un adénome hypophysaire secrétant de l'ACTH, ou relative à une néoplasie des surrénales. Les signes cliniques associés avec un tel tableau physiopathologique sont : faciès semi-lunaire, obésité tronculaire, ostéoporose (catabolisme osseux accéléré). Chez les femmes, il est fréquent de rencontrer de l'hirsutisme, acné et oligoménorrhée (règles moins fréquentes) ou aménorrhée (absence de règles). L'hypokaliémie est souvent présente est associée à l'excès de production de minéralocorticoïdes par les 
stéroïdes. Le diagnostic s'obtient en mesurant les anomalies sanguines, salivaires ou urinaires de cortisol. Les tests disponibles sont le test de suppression à la dexaméthasone (cherchant à inhiber chez l'individu normal l'axe ACTH-production de cortisol), la mesure du cortisol salivaire de 23h (cortisol généralement bas à cette heure) et les urines de $24 \mathrm{~h}$. Le traitement dépend de l'étiologie de la pathologie. 


\section{Index}

Électrophysiologie de la

contraction myocardique,

12

Épidémiologie cardiovasculaire, 8

Équilibre acido-basique

pulmonaire, 37

Accidents vasculaires cérébraux,

88

Adénome hypophysaire, 106

Amyloïdose familiale et acquise, 81

Anatomie cardiovasculaire, 3

Anatomie et histologie

respiratoire, 22

Anatomie et physiologie de l'axe

hypothalamo-

hypophysaire,

105

Anatomie et physiologie

pancréatique, 58

Anatomie et physiologie

surrénalienne, 108

Anatomie et physiologie

thyroïdienne, 107

Angina pectoris (angor), 8
Appendicite aigue, 51

Asthme, 33

Battement prématuré, 14

Biophysique de la pression

artérielle, 16

Bloc atrioventriculaire, 14

Bloc sino-atrial, 14

Botulisme, 87

Bradycardie, 13

Bronchopneumopathie chronique obstructive, 33

Canal carpien, 85

Caractéristiques

électrophysiologiques de

l'atteinte axonale et

démyélinisante, 80

Cavité orale, pharynx et

oesophage, 40

Cholélithiase et cholécystite, 58

Cirrhose, 57

Classification, 98

Colon irritable, 48

Compliance vasculaire, 18

Compression dynamique des voies 


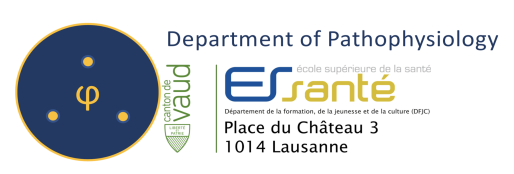

aériennes, 32

Conditionnement de l'air dans les

voies aériennes

supérieures, escalator

mucociliaire, filtration et

taux de déposition, 27

Constipation, 48

Crise généralisée de type absence,

99

Crise généralisée tonico-clonique, 98

Crises généralisées associées à des mutations des gènes des canaux ioniques, 101

Crises généralisées atoniques, 101

Crises généralisées myocloniques, 101

Cycle respiratoire et volumes respiratoires, 31

Déclenchement d'une crise

d'épilepsie, 103

Définitions, 104

Diabète de type II, 60

Diagramme de Davenport et désordres acidobasiques, 37

Diarrhées, 47
Diverticulose et diverticulite colique, 50

Dystrophie musculaire de Duchenne, 88

Effet du tabac sur les voies aériennes, 27

Effet Windkessel, 18

Embolie pulmonaire, 35

Emphysème pulmonaire, 31

Endocardite, 11

Entérocolites d'étiologies connues, 50

Epilepsie, 97

Epilepsie partielle bénigne à pointes centro-temporales, 102

Estomac, 42

Exploration fonctionnelle de l'activité cardiaque, 6

Fibrillation atriale, 15

Fibrillation ventriculaire, 15

Fibrose pulmonaire, 26

Flutter atrial, 15

Foie et vésicule biliaire, 51

Généralités, 97

Ganglions de la base, 73 
Gastrite, 43

Gastrite chronique à Helicobacter Pylori, 43

Gastrite secondaire aux AINS, 43

Hémisphères cérébraux, 70

Hépatite A, 54

Hépatite B, 55

Hépatite C, 55

Hépatite D, 56

Hépatite E, 56

Hépatites, 54

Hépatites virales, 54

hernie hiatale, 41

Histologie cardiovasculaire, 7

Hyperbilirubinémie, 53

Hypertension artérielle, 20

Hyperthyroïdie, 107

Hypothalamus, 73

Hypothyroïdie, 107

Insuffisance cardiaque gauche, 21

Insuffisance rénale aigue, 67

Insuffisance rénale chronique, 68

Intestin grêle et côlon, 46

Introduction et histologie

digestive générale, 38
Loi de Starling, 19

Mécanique respiratoire, 29

Méninges, 77

Maladie cardiaque ischémique, 7

Maladie coeliaque, 48

Maladie d'Alzheimer, 94

Maladie de Charcot Marie Tooth, 83

Maladie de Crohn, 49

Maladie de Cushing, 108

Maladie de Fabry, 85

Maladie de Hirschprung, 39

Maladie de Parkinson, 91

Maladie valvulaire, 6

Manifestation clinique de l'hépatite, 56

Manifestations cliniques selon lobe atteint, 102

Mesure de la tension artérielle en pratique courante, 17

Moelle épinière, 76

Muscle lisse intestinal, 38

Myasthénie, 85

Néphrosclérose, 67

Nerfs crâniens, 75

Neuroanatomie et 


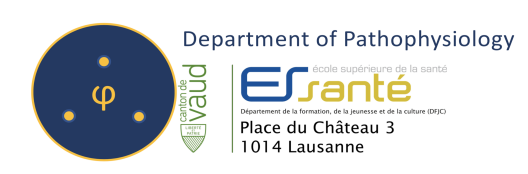

neurophysiologie, 69

Neuropathie diabétique, 82

Neuropathie tomaculaire (HNPP

Hereditary Neuropathy

with liability to Pressure

Palsies), 84

Neuropathies, 80

Neurophysiologie, 77

Obésité morbide, 44

Péricardite, 10

Pancréas, 58

Pancréatite, 60

Panhypopituitarisme, 106

Physiologie cardiovasculaire, 4

Physiologie de la pression artérielle, 16

Physiologie respiratoire, 25

Physiopathologie de l'axe

hypothalamo-

hypophysaire,

105

Physiopathologie surrénalienne, 108

Physiopathologie thyroïdienne, 107

Pneumonie, 28
Pneumothorax, 31

Postcharge, 20

Précharge, 20

Principes physico-chimiques, 25

Régions de la paroi abdominale, 39

Rectocolite ulcéro-hémorragique

$$
\text { (RCUH), } 49
$$

Reflux gastro-oesophagien, 41

Sténose carotidienne, 17

Syndrome coronarien aigu (SCA), 9

Syndrome de Guillain-Barré, 82

Tachycardie, 14

Tampon bicarbonate, 37

Thalamus, 72

Tronc cérébral, 74

Troubles du rythme cardiaque, 13

Tuberculose, 28

Ulcère gastroduodénal, 43

Ventilation et perfusion

pulmonaire, 34

Volumes statiques, 32

Vomissements, 45 